Aus dem Institut für Neuro- und Sinnesphysiologie

(Prof. Dr. rer. nat. S. O. Rizzoli)

im Zentrum Physiologie und Pathophysiologie

der Medizinischen Fakultät der Universität Göttingen

\title{
Kombinatorische Analyse von Nanobody-markierten Epitopen zur Proteinbestimmung
}

\author{
INAUGURAL-DISSERTATION \\ zur Erlangung des Doktorgrades \\ für Zahnheilkunde \\ der Medizinischen Fakultät der \\ Georg-August-Universität zu Göttingen
}

vorgelegt von

Merle Hoff, geb. Wassmann

aus

Bielefeld

Göttingen 2020 
Dekan:

\section{Betreuungsausschuss}

Betreuer/in

Ko-Betreuer/in:

\section{Prüfungskommission}

Referent/in

Ko-Referent/in:

Drittreferent/in:

Datum der mündlichen Prüfung:
Prof. Dr. med. W. Brück

Prof. Dr. rer. nat. S. O. Rizzoli

Prof. Dr. rer. nat. B. Schwappach-Pignataro

Prof. Dr. rer. nat. R. Kehlenbach

Prof. Dr. med. dent. R. Mausberg

22.02.2021 
Hiermit erkläre ich, die Dissertation mit dem Titel "Kombinatorische Analyse von Nanobody-markierten Epitopen zur Proteinbestimmung" eigenständig angefertigt und keine anderen als die von mir angegebenen Quellen und Hilfsmittel verwendet zu haben.

Göttingen, den 


\section{Inhaltsverzeichnis}

Abbildungsverzeichnis .......................................................................................... III

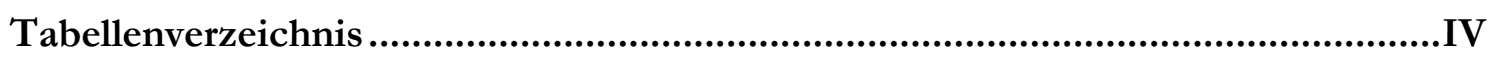

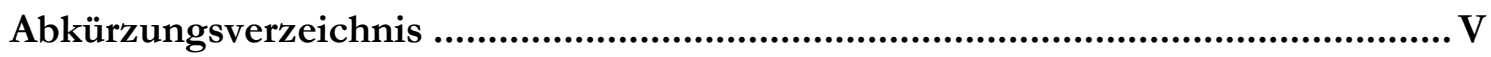

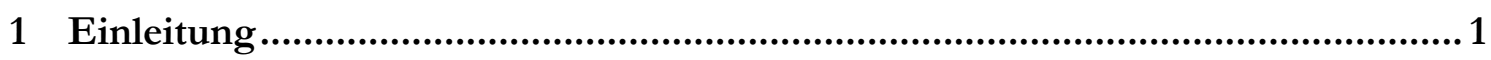

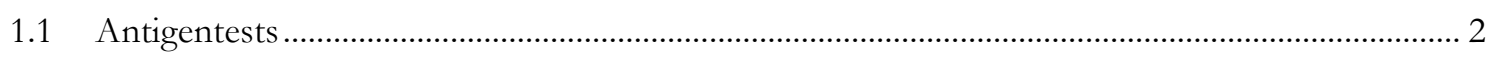

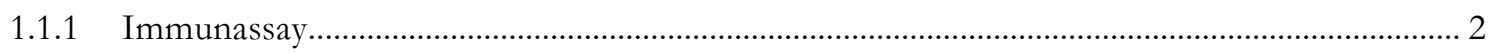

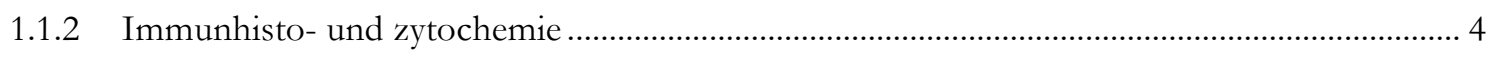

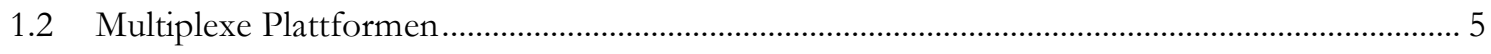

1.2.1 Protein-Arrays: Multiplexe Immunassays zur Quantifizierung von Proteinen........................... 6

1.2.2 Multiplexe Immunzytochemie und -histochemie zur Visualisierung von Proteinen ............... 9

1.3 Antikörper als Grundbestandteil immunbiologischer Verfahren ............................................... 12

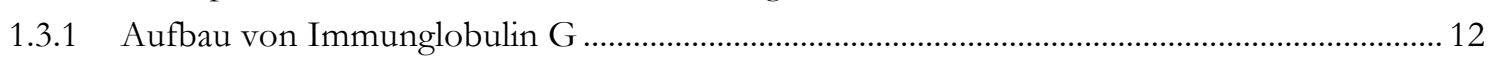

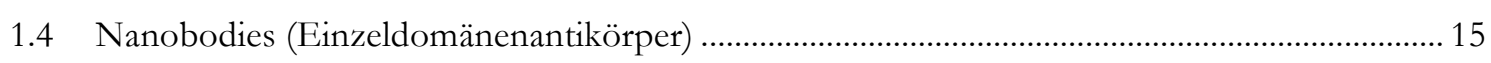

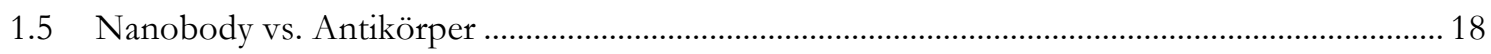

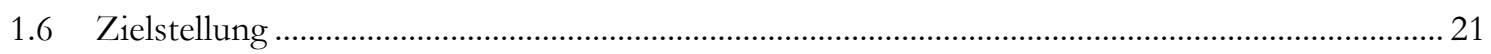

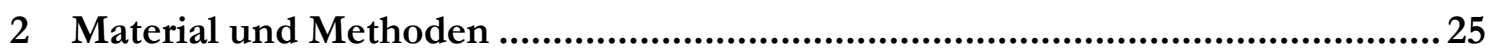

2.1 Zellkultur: human embryonic kidney (HEK)-293-Zellen................................................................ 25

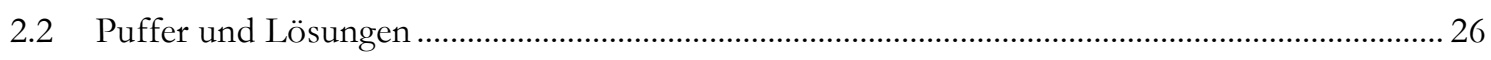

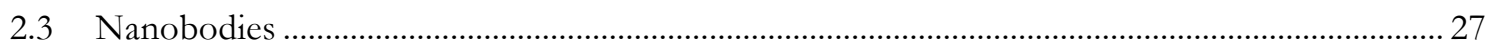

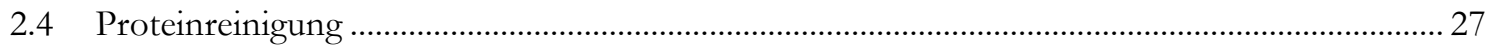

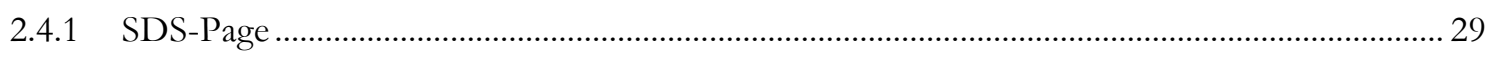

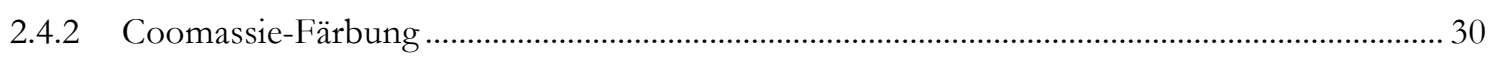

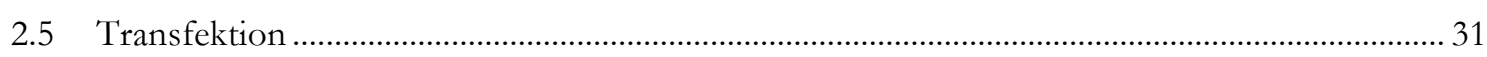

2.5.1 Plasmide für die Vorexperimente bzw. für den Funktionstest .................................................. 32

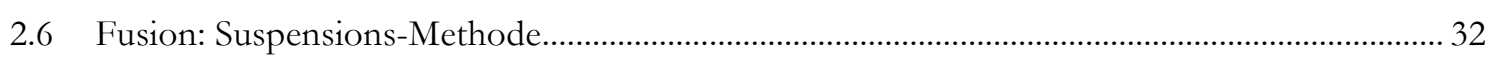

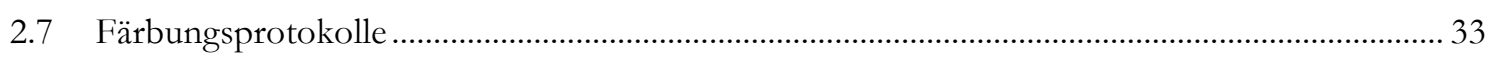

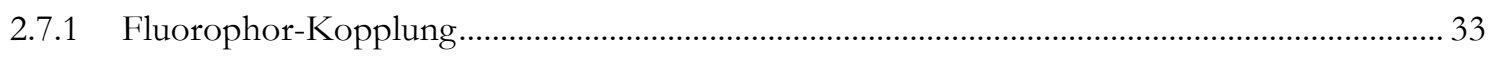

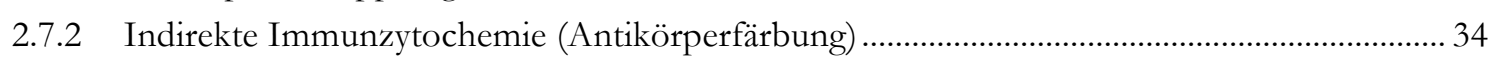

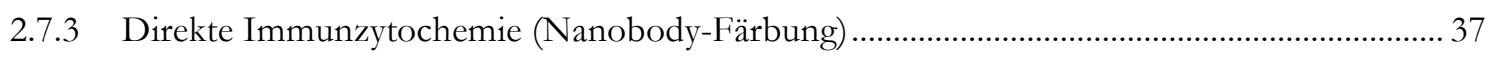

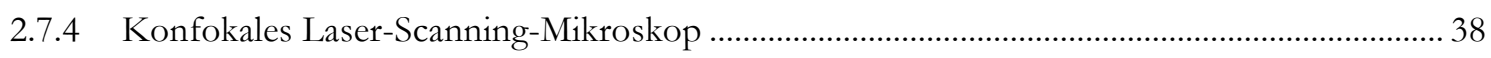

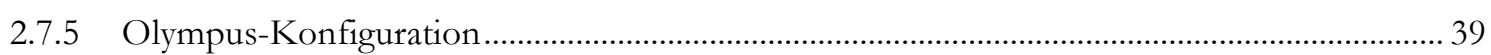

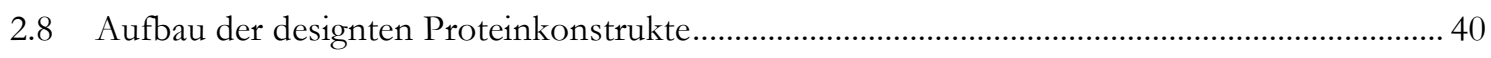

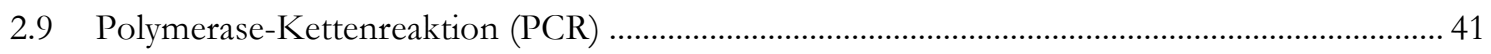

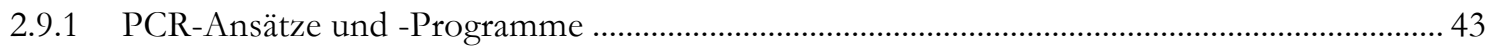

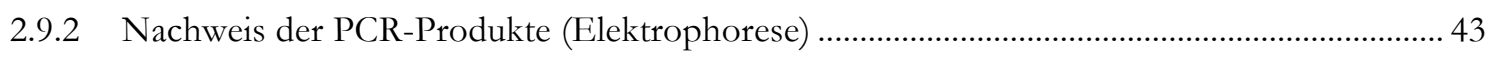

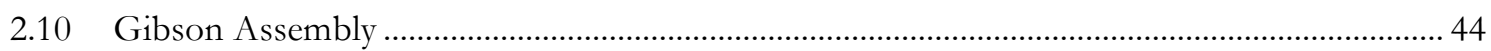




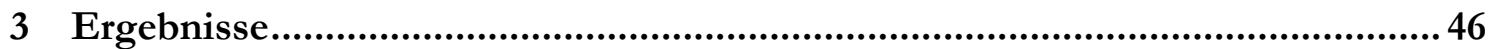

3.1 Transfektion von Plasmiden: Ein-Plasmid-Transfektion.............................................................. 46

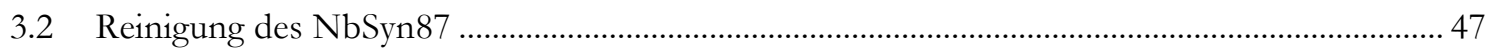

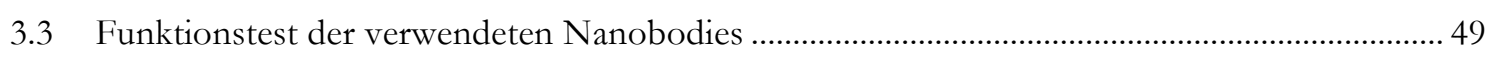

3.4 Singleplexe Epitop-Analyse zur Einzeltestung der Genkonstrukte ............................................. 51

3.5 Methoden zur Kreierung einer Multitransfekt-Zelle ...................................................................... 56

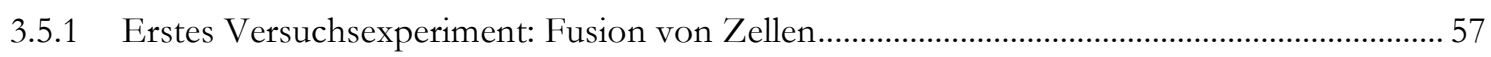

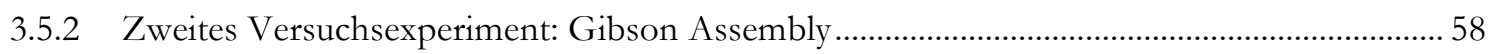

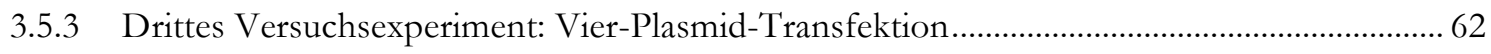

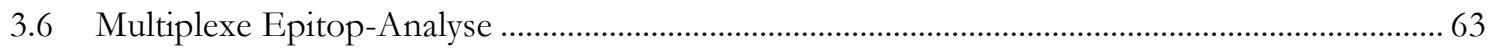

3.6.1 Anwendung der multiplexen Epitop-Analyse nach einer direkten Immunfärbung der

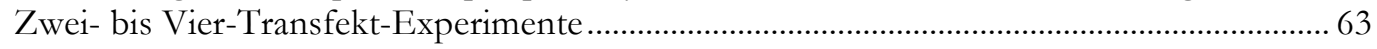

3.6.2 Anwendung der multiplexen Epitop-Analyse bei einer sequenziellen direkten

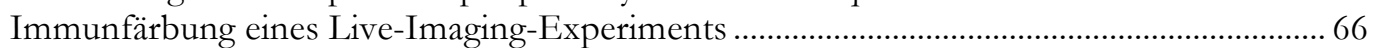

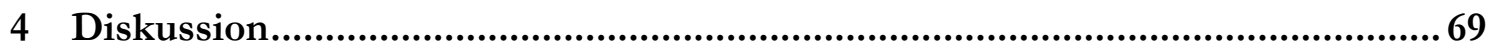

4.1 Gewinnung und Funktionalität der Nanobodies.......................................................................... 70

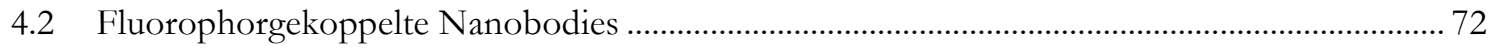

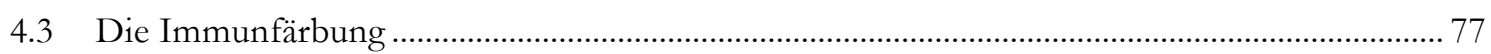

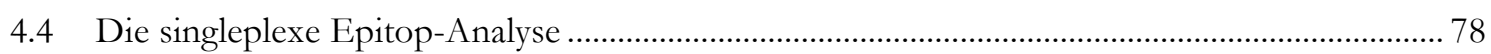

4.5 Die Kreierung einer Multitransfekt-Zelle ................................................................................... 79

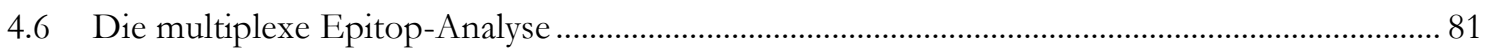

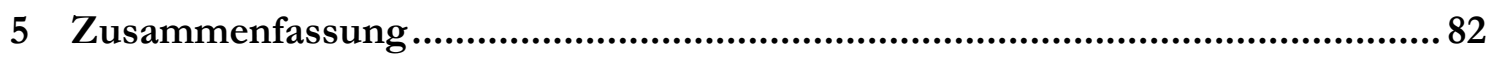

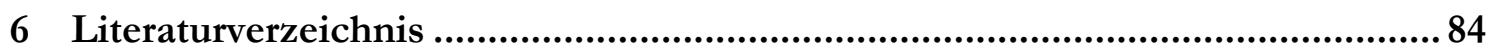




\section{Abbildungsverzeichnis}

Abbildung 1: Absorptions- und Fluoreszenzspektren....................................................................... 5

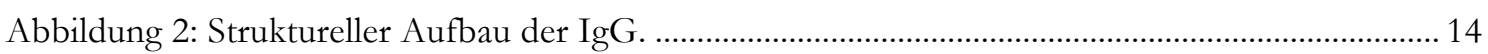

Abbildung 3: Derivate der konventionellen Antikörper.................................................................... 15

Abbildung 4: Schematische Darstellung der im Serum der Camelidae-Familie vorkommenden

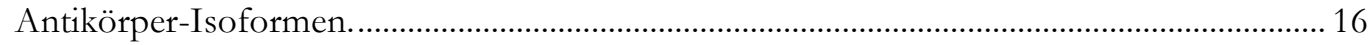

Abbildung 5: Schematische Strukturdarstellung eines Nanobodies. ..................................................... 17

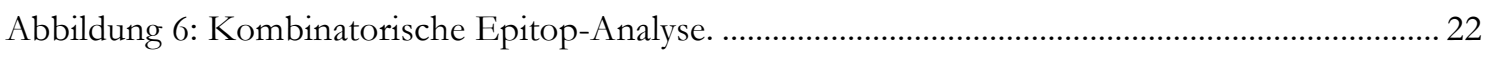

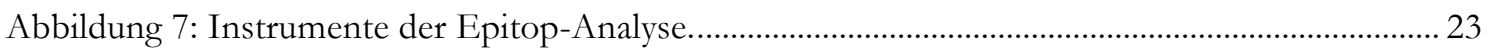

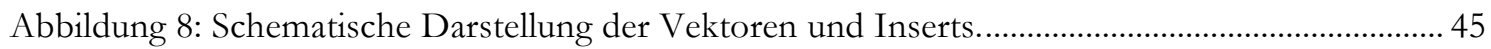

Abbildung 9: Ein-Plasmid-Transfektion von HEK-293-Zellen................................................................ 47

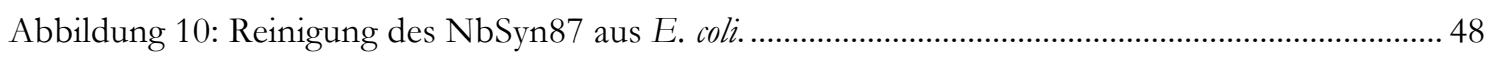

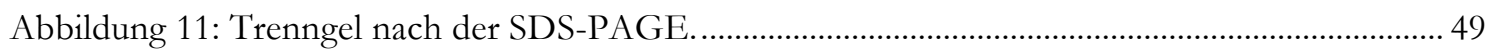

Abbildung 12: Spezifische Bindung der Nanobodies an ihre Epitope................................................. 51

Abbildung 13: Proteinidentifizierung mittels kombinatorischer Epitop-Analyse durch (in)-

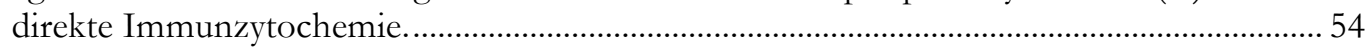

Abbildung 14: Fusion von mindestens vier transfizierten HEK-293-Zellen......................................... 58

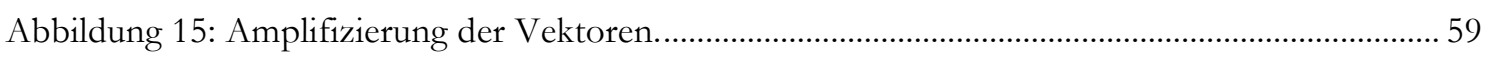

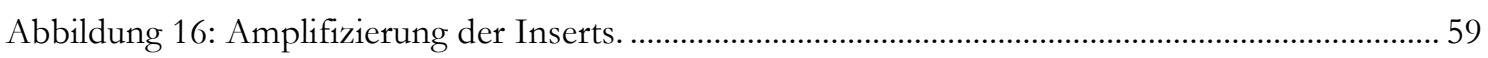

Abbildung 17: Plasmidkarte für das GFP_NLS_mCherry_GFP_syn2-Gibsonkonstrukt. ....................60

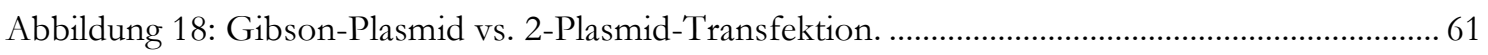

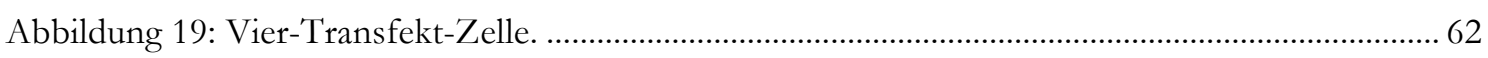

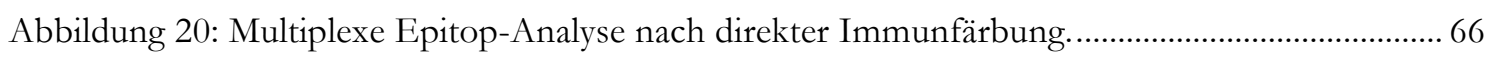

Abbildung 21: Multiplexe Epitop-Analyse während eines Live-Imaging-Experiments........................ 68 


\section{Tabellenverzeichnis}

Tabelle 1: Puffer und Lösungen sowie ihre Zusammensetzungen ........................................................ 26

Tabelle 2: Verwendete Nanobodies als Instrumente der auf Nanobodies basierenden EpitopAnalyse.... 27

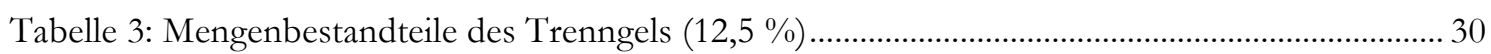

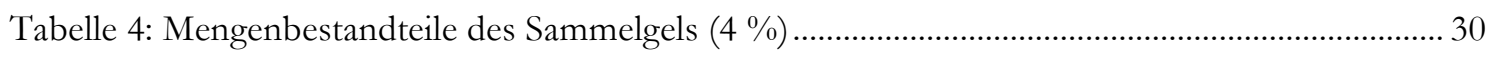

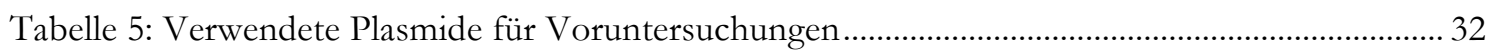

Tabelle 6: Fluorophore für die Markierung von Nanobodies ............................................................ 34

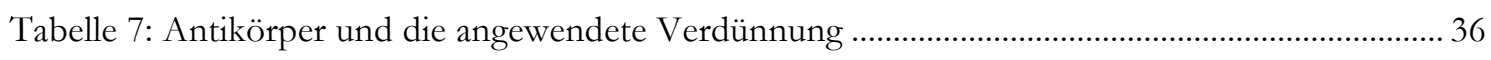

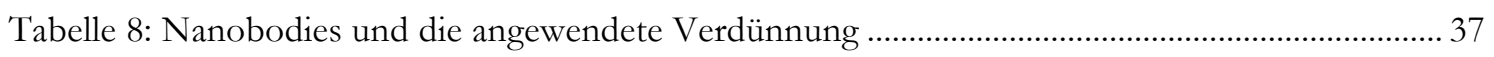

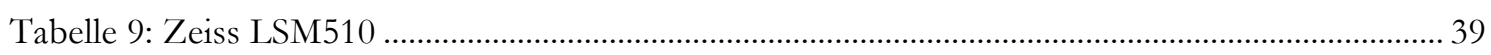

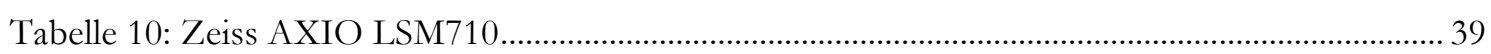

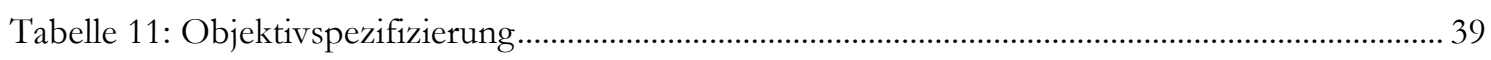

Tabelle 12: Proteine mit verschiedenen Epitop-Kombinationen ....................................................... 41

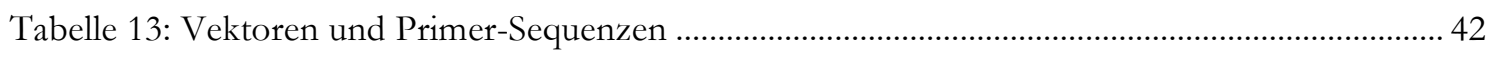

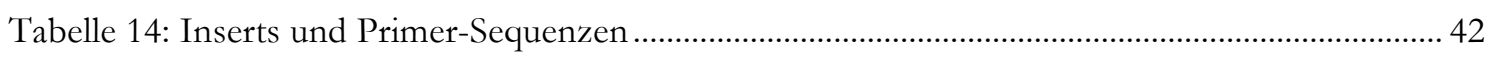

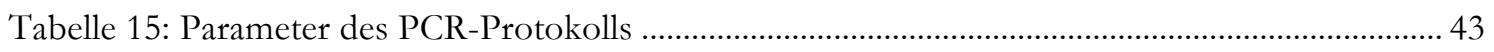

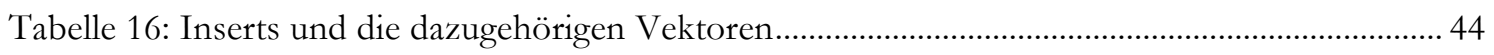




\section{Abkürzungsverzeichnis}

\begin{tabular}{|c|c|}
\hline AP & alkalische Phosphatase \\
\hline APS & Ammoniumperoxidsulfat \\
\hline bp & Basenpaare \\
\hline BSA & bovines Serumalbumin \\
\hline CDR & komplementär-determinierende Region \\
\hline $\mathrm{C}_{\mathrm{H}}$ & konstante Domäne der schweren Kette \\
\hline $\mathrm{C}_{\mathrm{L}}$ & konstante Domäne der leichten Kette \\
\hline CLIA & Clinicial Laboratory Improvement Amendments \\
\hline $\mathrm{COO}^{-}$ & C-Terminus \\
\hline $\mathrm{ddH}_{2} \mathrm{O}$ & doppelt destilliertes Wasser \\
\hline ddNTP & Didesoxynukleosidtriphosphat \\
\hline DMAA & N,N-dimethylacrylamide \\
\hline DMEM & Dulbecco's Modified Eagle Medium \\
\hline DMSO & Dimethylsulfoxid \\
\hline DNA & Desoxyribonukleinsäure \\
\hline DTT & Dithiothreitol \\
\hline ECL & enhanced chemoluminescence \\
\hline E. coli & Escherichia coli \\
\hline EDTA & Ethylendiamintetraacetat \\
\hline ELISA & ensyme-linked immunosorbent assays \\
\hline Fab & Antigenbindungs-Fragment \\
\hline $\mathrm{Fc}$ & fragment crystallizable region \\
\hline FCS & fetal calf serum \\
\hline FR & Rahmenregionen \\
\hline GFP & green fluorescent protein \\
\hline $\mathrm{HCAb}$ & Schwere-Ketten-Antikörper \\
\hline HEK-293 & buman embryonic kidney-293 \\
\hline HEPES & $\mathrm{N}$-(2-Hydroxyethyl-)piperazin-N'-2-Ethansulfonsäure \\
\hline His $_{14-t a g}$ & 14x-Polyhistidine-tag \\
\hline HRP & Meerrettichphosphatase \\
\hline ICC & Immunzytochemie \\
\hline $\operatorname{Ig}$ & Immunglobulin \\
\hline $\operatorname{IgA}$ & Immunglobulin A \\
\hline $\mathrm{IgD}$ & Immunglobulin D \\
\hline $\operatorname{IgG}$ & Immunglobulin $G$ \\
\hline $\operatorname{IgM}$ & Immunglobulin $\mathrm{M}$ \\
\hline
\end{tabular}



Immunhistochemie

IMAC Metallaffinitätschromatographie

IPTG Isopropyl- $\beta$-D-thiogalactopyranosid

$\mathrm{K}_{\mathrm{D}}$ Dissoziationskonstante

$\mathrm{kDa}$ Kilodalton

KPS

Kaliumperoxodisulfat

$\mathrm{L}$ Linker

LOD limit of detection (Nachweisgrenze)

MHRA Medicines and Healthcare Products Regulatory Agency

$\mathrm{Nb}$ Nanobody

$\mathrm{NH}_{3}^{+}$ N-Terminus

Ni-NTA Nickel-Nitrilotriessigsäure

PBS phosphatgepufferte Salzlösung

PCR Polymerase-Kettenreaktion

PFA Paraformaldehyd

PMSF Phenylmethylsulfonylfluorid

$\mathrm{scFv}$ single-chain Fus

SNAP synaptosomal associated protein of $25 \mathrm{kDa}$

SOC Super Optimal broth with Catabolite repression

STORM stochastic optical reconstruction microscopy

TB Terrific Broth

TBE TRIS-Borat-EDTA

TCEP Tris(2-chlorethyl)posphat

TEMED N, N, N', N'-Tetramethylethylendiamin $\mathrm{V}_{\mathrm{H}}$ variable Domäne der schweren Kette

$\mathrm{V}_{\mathrm{H}} \mathrm{H}$ Nanobody (Antigenbindungsstelle) $\mathrm{V}_{\mathrm{L}}$ variable Domäne der leichten Kette 


\section{Einleitung}

Die meisten biologischen Prozesse im menschlichen Körper unterliegen vielfältigen ProteinProtein-Interaktionen (Petta et al. 2015). Kenntnisse über das menschliche Proteom sind somit eine Voraussetzung dafür, einen Einblick in die subzellulären Organisationen und Funktionen zu erhalten sowie physiologische Veränderungen im Organismus im Zusammenhang mit Proteinkonzentration zu verstehen (Legrain et al. 2011).

Die zellulären Funktionen beruhen auf der Zusammenarbeit und der Organisation von mehreren tausend Proteinen. Damit die Abläufe optimal stattfinden können, ist die Expression der Proteine durch vielfältige molekulare Mechanismen genau geregelt (Wagner 2005). Eine abnormale Expression von einem Protein kann negative Auswirkungen auf verschiedenste Zellfunktionen haben und in einigen Fällen zu einem vollständigen Funktionsverlust führen (Prelich 2012). Die Überexpression von Proteinen aufgrund von Genamplifikationen ist u. a. die Ursache der Trisomie 21 sowie für verschiedene Arten von Krebserkrankungen verantwortlich (Tang und Amon 2013). Die Überexpression des EGFR-Rezeptors HER2 steht zum Beispiel mit dem Auftreten von Brustkrebs in Zusammenhang. Des Weiteren ist die irreguläre Expression von Proteinen für die Auslösung von Erkrankungen wie Diabetes mellitus, Fibrosen der Lunge, malignen Neoplasien und vielen pathologischen Veränderungen im Bereich der Neurologie verantwortlich (Shastry 1995). Neben Ursachen wie Strukturveränderungen aufgrund von Genmutationen sind für den Großteil der zellulären Disfunktionen die Überbzw. Unterexpression regulär exprimierter Gene verantwortlich.

Die Fähigkeit der Proteinbestimmung und -messung ist somit für die biologische und medizinische Forschung von großer Bedeutung. Das Grundprinzip aller Verfahren zur Bildgebung von Proteinen beruht dabei auf der Markierung der zu untersuchenden Proteine mithilfe von Sonden. Als Sonden werden häufig Antikörper eingesetzt, die jeweils spezifisch Proteine anhand ihrer antigenen Determinanten (Epitop) detektieren. Zu den etablierten Verfahren für die Identifizierung und Messung von Molekülen zählen unter anderem die Immunassays/Mikroarrays (z. B. ELISA) sowie die immunzyto- oder immunhistochemischen Verfahren. Diese Verfahren basieren auf dem gleichen Grundprinzip. Für jedes zu bestimmende Protein (Antigen) wird ein spezifischer Antikörper für die Detektion benötigt. Die Identifizierung von „n“ Proteinen verlangt also ebenfalls „,n“ Antikörper. Diese Modalität stellt neben den Beschränkungen aufgrund von verfügbaren Werkzeugen und Methoden eine der Barrieren dar, die bisher den Durchbruch der Bildgebung als multiplexes Verfahren vereiteln. Um 
Informationen über die räumlichen Beziehungen und Interaktionen zwischen und innerhalb von Zellen und Geweben zu erhalten, ist eine Analyse von multiplen Molekülen in einer Probe unumgänglich (Stack et al. 2014).

Aus diesem Grund befasst sich die vorliegende Dissertation mit der Entwicklung einer auf Nanobodies basierenden Epitop-Analyse von Proteinen. Dieser neue Ansatz soll eine Lösung für die aktuellen Komplikationen der Bildgebung offerieren, sodass dem Bestreben einer multiplexen Entschlüsselung von Proteinen neue Möglichkeiten eröffnet werden können.

Im Folgenden werden zunächst die etablierten Methoden der Proteinmessung und -bildgebung sowie der allgemeine Aufbau von Antikörpern, welche die Basis der beschriebenen Verfahren bilden, erläutert. Anschließend wird Bezug auf die Nanobodies genommen, die in diesem Projekt die Antikörper als Grundbaustein ersetzen sollen. Darauffolgend wird in Kapitel 1.6 auf die genaue Vorgehensweise der Epitop-Analyse und deren Verifizierung als wissenschaftliches Verfahren zur Proteinbestimmung eingegangen.

\subsection{Antigentests}

In diesem Kapitel werden zunächst die singleplexen Verfahren der Proteinmessung und -bildgebung beschrieben, bevor in Kapitel 1.2 auf ihre Weiterentwicklung in Richtung multiplexer Plattformen eingegangen wird.

\subsubsection{Immunassay}

Durch die von J. G. Feinberg 1961 vorgestellte Mikrospot-Technik, wurde die einmalige Funktion der Strukturspezifität von Antikörpern zur Antigen-Detektion aufgrund von Antikörper-Antigen-Interaktionen bewiesen (Feinberg 1961). Die klassischen Immunassays beruhen dabei auf der Eigenschaft von Antikörpern, die Konzentrationsmessung einer für sie jeweils strukturspezifischen Substanz (Analyt) zu ermöglichen. Die Verfahren der Immunassays wurden 1989 von R. Ekins mit der Theorie geprägt, dass eine Miniaturisierung der Immunassays die Nachweisgrenze (LOD) verbessert (Ekin 1989). Dies ermöglichte die Herabsetzung der Mindestkonzentration des zu bestimmenden Analyten, mit der noch ein statistisch signifikanter Wert erzielt werden kann. Die stetige Weiterentwicklung der singleplexen Immunassays zeigt sich gegenwärtig in dem vielfältigen Sortiment verschiedenster Verfahren. Je nach Assayformat werden unterschiedliche Markierungsmaßnahmen zum Nachweis oder zur quantitativen Bestimmung des Analyten vorgenommen. Zu den am weitesten verbreiteten Methoden in der Bioanalytik zählen unter anderem die Marker-basierten ensyme-linked immunosorbent assays (ELISA). Als Alternativen existieren zusätzlich Marker-freie Methoden, wie zum Beispiel die 
Spinnscheiben-Mikrointerferometry (Varma et al. 2004) oder piezoelektrische Akustiksensoren (Luo et al. 2006).

\subsubsection{Enzyme-linked immunosorbent assays (ELISA)}

Die Detektion der enzyme-linked immunosorbent assays (Engvall und Perlmann 1971) erfolgt mittels der substratbasierten Reaktion eines Reporterenzyms, das an einen für ein Antigen/Antikörper spezifischen Antikörper gekoppelt wurde (Avrameas 1969). Die ELISATechnik wird in zwei Hauptvarianten aufgeteilt: die kompetitiven ELISAs und die nicht kompetitiven ELISAs.

Die kompetitiven ELISAs (antigen caputre assays) dienen zur Berechnung der Antigenkonzentration aus einer Probe und können in ein direktes und ein indirektes Verfahren unterteilt werden. Beide Verfahren gehören zu den heterogenen Immunassays, da ein Element an eine feste Phase gebunden wird. Bei dem direkten Verfahren wird zunächst der Antikörper an eine feste Oberfläche gebunden, während bei dem indirekten kompetitiven ELISA als erstes das Antigen immobilisiert wird. Die zu untersuchende Probe enthält bei dem direkten Verfahren zwei Antigene und bei dem Indirekten einen Antikörper und ein weiteres Antigen. Die Messung der Antigenkonzentration beruht bei der direkten Methode auf der Kompetitivität zwischen dem Probenantigen und einem enzymmarkierten Antigen um die spezifischen Bindungsstellen des immobilisierten Antikörper. Das indirekte Verfahren wiederum nutzt die Rivalität des gebundenen Probenantigens mit dem freien analogen Antigen um die Bindungsstelle des ebenfalls ungebundenen freien Antikörpers. Dieser wird schließlich durch einen enzymmarkierten Sekundärantikörper detektiert. Durch die Zugabe eines jeweils zum Enzym passenden Substrats entsteht bei beiden Verfahren ein Reaktionsprodukt, das als ein detektierbares Signal gemessen werden kann. Das Signal ist bei beiden Techniken antiproportional zu der Menge des Probenantigens (Shah und Maghsoudlou 2016).

Der antibody capture assay ist eine Methode der nicht kompetitiven ELISAs und wird hauptsächlich zur Bestimmung des Immunstatus eines Menschen verwendet. Hierzu wird das Antigen direkt auf der Oberfläche einer Mikrotiterplatte immobilisiert. Anschließend wird die Probe mit dem zu bestimmenden Antikörper aufgetragen, der das Antigen bindet. Die Detektion erfolgt in einem zweiten Schritt durch die Zugabe eines zu dem ersten Antikörper spezifischen Enzym-gekoppelten Sekundärantikörpers sowie eines zum Enzym passenden Substrats. Wenn ein spezielles Protein in einer Probe detektieren werden soll, eignet sich das Sandwich-Assay. Dieses gehört ebenfalls zur der Gruppe der nicht kompetitiven ELISAs. Bei diesem Verfahren wird ein ungekoppelter immobilisierter Antikörper und ein Enzym-gekoppelter Sekundärantikörper verwendet, um in einer Probe ein spezielles Protein detektieren zu können. Da das 
Antigen von zwei Antikörpern gleichzeitig an verschiedenen Stellen gebunden wird, ist der Name Sandwich Assay entstanden. Das gemessene Signal ist bei beiden Verfahren proportional zu der in der Probe enthaltenden Antikörperkonzentration.

\subsubsection{Immunhisto- und zytochemie}

In der Immunhistochemie (IHC) und Immunzytochemie (ICC) wird die Spezifität von Antikörpern genutzt, um die Verteilung von Antigenen unter anderem am histologischen Schnitt, in Zellkulturen, im Blut oder im Liqour sichtbar zu machen. Mit der direkten oder indirekten IHC/ICC existieren zwei Basismethoden, die bezüglich ihrer Anwendung unterschieden werden können. Die direkte IHC/ICC basiert auf bereits an Fluorophore gekoppelten Detektionsantikörpern, während bei der indirekten Methode unmarkierte Antikörper durch einen fluorophorgekoppelten Sekundärantikörper visualisiert werden können.

Den ersten Nachweis, dass mit fluoreszierenden Antikörpern in einer Probe spezifisch Proteine nachgewiesen werden können, lieferten A. Coons et al. 1942. Für die Immunfärbungen von Antigenen benötigen diese Methoden affinitäre fluorophorgekoppelte Antikörper, die als Marker für die darzustellenden Proteine verwendet werden. Nach einer spezifischen Anregung fluoreszieren die Farbstoffe in einem bestimmten Wellenlängenbereich (Stokes shift), wodurch ein messbares Signal entsteht. Jedes Fluorophor emittiert dabei einen individuellen spektralen Peak. 
Fluorophor 488

Fluorophor $350 \quad$ Fluorophor 546 Fluorophor 633

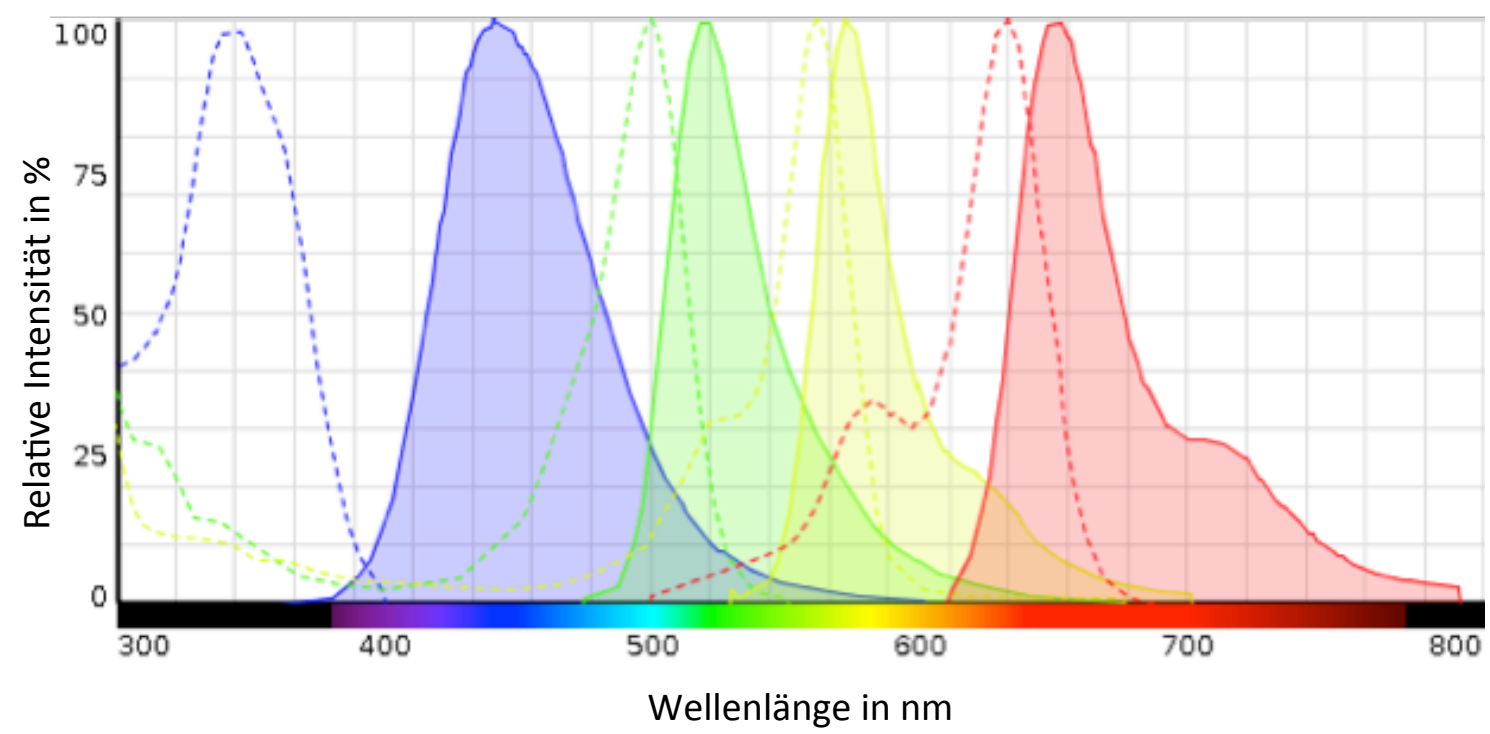

Abbildung 1: Absorptions- und Fluoreszenzspektren. Nach Wedler wird unter Fluoreszenz die spontane Emission von Licht verstanden, die nur solange andauert, wie die fluoreszierenden Moleküle nach Lichtabsorption angeregt werden. Das Fluoreszenzspektrum ist gegenüber dem Absorptionsspektrum zu energetisch kleineren Wellenlängen verschoben (Stokessche Regel). Gezeigt sind die Absorptions- (gestrichelte Linien) und Fluoreszenzspektren (ausgefüllte Linien) der Fluorophore $350\left(\lambda_{\mathrm{ex}} 347 \mathrm{~nm}\right.$ und $\left.\lambda_{\mathrm{em}} 448 \mathrm{~nm}\right),-488\left(\lambda_{\mathrm{ex}} 493 \mathrm{~nm}\right.$ und $\left.\lambda_{\text {em }} 516 \mathrm{~nm}\right),-546\left(\lambda_{\text {ex }} 554 \mathrm{~nm}\right.$ und $\left.\lambda_{\text {em }} 570 \mathrm{~nm}\right)$ und $-633\left(\lambda_{\text {ex }} 630 \mathrm{~nm}\right.$ und $\left.\lambda_{\text {em }} 650 \mathrm{~nm}\right)$ (nach Fluorescene SpectraViewer ThermoFisher Scientific).

In den letzten 20 Jahren hat die Bedeutung der Immunfluoreszenz rapide zugenommen und dazu geführt, dass sich das Verfahren als diagnostische Methode zu einem unverzichtbaren Hilfsmittel in der Zytomorphologie etablieren konnte. Neben der Verbesserung in der Genauigkeit von Diagnosetests, konnten ebenso Fortschritte bei der Identifizierung von Indikatoren für Zieltherapien erreicht werden. Zu den Spezialgebieten der ICC und IHC gehören vor allem die Diagnosen von pathologischen Lymphoproliferationen sowie von Metastasen unbekannter Herkunft (Skoog und Tani 2011).

\subsection{Multiplexe Plattformen}

Aufgrund der vielfältigen Protein-Protein-Interaktionen im menschlichen Körper ist für eine adäquate Diagnose von pathologischen Veränderungen ein umfassender Einblick in das menschliche Proteom unabdingbar (Petta et al. 2015). Die Forschungsansätze bezüglich der regulären Zellphysiologie sowie der Krankheitspathogenese dienen der Entschlüsselung der Komplexität der intrazellulären molekularen Mechanismen und Wege (Zrazhevskiy und Gao 2013). Die Zielvorstellung der multiplexen Plattformen, eine umfassende molekulare Profilie- 
rung einzelner Zellen zu realisieren, beruht dabei nicht auf der Messung einzelner Proteinkonzentrationen. Die Profilierung kann nur durch die Studien über Proteinnetzwerke und Proteininteraktionen erreicht werden. Diese proteomische Studien (Proteomiks) beruhen auf multiplexen Verfahren, bei denen nicht nur die Häufigkeit eines Proteins gemessen wird (zum Beispiel mittels der multiplexen Immunassays). Durch verschiedene Ansätze soll ein Einblick über die Wirkung von interagierenden, antagonistischen oder synergistischen Proteinen gegeben werden (Kingsmore und Patel 2003). Dieser Einblick soll mithilfe der multiplexen IHC/ICC erreicht werden. Angesichts des Einflusses pathologischer Prozesse auf die komplexen Proteinnetzwerke stellen die Proteomiks sowohl einen wichtigen Aspekt für die Weiterentwicklung der Krebsforschung als auch für die allgemeine Diagnose von Krankheiten dar. Dieser Kontext wird durch die synchron steigende Veröffentlichungsrate der Proteomiks + Krebs-Studien bestätigt (Kumar et al. 2015). Der Fokus der allgemeinen Omic-Forschung beruhte dabei zunächst auf den Untersuchungen der Genomiks und Transkriptomiks. Bei diesen Ansätzen standen die Sequenzanalyse und die Annotierung einzelner Gene sowie die Transkriptomanalyse im Mittelpunkt. Da die Menge an mRNA eines Gens jedoch nicht äquivalent mit der Menge bzw. Aktivität des translatierten Proteins ist, konnten viele Fragestellungen nicht beantwortet werden. Im Laufe der Zeit wurde daher ein zunehmender Trend in Richtung Proteomik registriert (Gomez-Cabrero 2014).

Die Weiterentwicklung sowohl der traditionellen Immunassays als auch der immunzytochemischen oder -histochemischen Verfahren in Richtung multiplexer Messung nimmt dabei eine Schlüsselposition auf dem Weg der Entwicklung der Proteomiks sowie der anderen OmicBereiche ein (Kumar et al. 2015). Die gemeinsame Grundkomponente vieler multiplexer Plattformen basiert häufig auf der Entschlüsselung und Quantifizierung der Proteine durch den Einsatz von Antikörpern. Die Omic-Erforschung und -entschlüsselung erfordert zudem geeignete Methoden, damit die Fülle der erhaltenen Daten der Omics-Analysen dargestellt werden kann (Gomez-Cabrero 2014).

\subsubsection{Protein-Arrays: Multiplexe Immunassays zur Quantifizierung von Proteinen}

Die traditionellen Immunassays wie ELISA ermöglichen als singleplexe Tests die Bestimmung von einem Antigen pro well. Pro Testdurchlauf kann so jeweils nur ein Krankheitsmarker bestimmt werden. Um die Entschlüsselung komplexer krankheitsspezifischer Biomarker zu ermöglichen, ist es von großer Bedeutung multiplexe Verfahren zu entwickeln, mit denen mehrere Analyten innerhalb einer Probe gleichzeitig bestimmt werden können. In Anlehnung an den Entwicklungsverlauf der Genomiks, ging der Trend der Proteomiks in Richtung Parallelität, Miniaturisierung und Durchsatzerhöhung. So sollte die Analyse von Proteinen in hohem 
Maßstab vollzogen werden. Dabei wurden die traditionellen analytischen Methoden der Proteomiks in Anbetracht der bereits etablierten multiplexen DNA-Mikroarrays der Genomiks modifiziert. Ende der 90er Jahre wurden die ersten Protein-Arrays vorgestellt, deren technische Weiterentwicklung aufgrund der Diversität und Komplexität der Proteine zunächst eine Herausforderung darstellte. Die Verwendung dieser neu entwickelten Protein-Arrays bietet erhebliche Fortschritte in Bezug auf ihre Schnelligkeit, Effizienz und Leistungsfähigkeit. Des Weiteren ermöglichen diese multiplexen Immunassays neben einer allgemeinen Kostenreduzierung eine Minimierung des Arbeitsaufwandes (Krick 1992). Die Protein-Arrays sind jedoch auf eine Quantifizierung der in der Probe gemessenen Proteine beschränkt. So besteht weiterhin das Bedürfnis zur Entwicklung eines Verfahrens zur quanti- und qualitativen Bestimmung von Proteinen.

Ähnlich den singlexen Immunassays existiert bei den multiplexen Immunassays eine endlose Reihe verschiedenster Verfahren, die sich jedoch in zwei Kategorien unterteilen lassen. Die Verfahren der räumlich getrennten Assays (z. B. planare Assys) basieren auf Antikörpern, die auf festen Oberflächen immobilisiert worden sind. Die Tests werden dabei für jeden Analyten räumlich voneinander getrennt durchgeführt. Die übrigen Methoden beruhen auf der Immobilisierung von Antikörpern auf Beads (Perlen) oder anderen Partikeln, die für jeden Analyten das jeweilige Assay darstellen ( z. B. Beads-basierte Suspensionsassays).

Da ein Einblick in die Eigenschaften der derzeitigen Protein-Arrays gegeben werden soll, werden im Folgenden die derzeitig etablierten Methoden zur quantitativen Messung von Proteinen vorgestellt. Dieser Kenntnisstand ist wichtig, um die Vor- und Nachteile der aktuellen multiplexen Technologien abzuwägen sowie die Notwendigkeit und Eignung des in dieser Arbeit neu entwickelten Verfahrens zu erkennen.

\subsubsection{Planare Assays}

Die auf der Ekins-Theorie basierenden planaren Mikroassays können als Slide- oder Mikrotiterplatten-Verfahren angewendet werden. Beide Formate beruhen auf Mikrospots von hochaffinitären, auf einer starren Oberfläche immobilisierten Liganden. Als affinitäre Liganden werden Antikörper, Aptamere, Kohlenhydrate usw. eingesetzt. Der überwiegend verwendete Typ ist dabei der Antikörper-Array. Die Identifizierung der Proteine erfolgt anhand der x-,yKoordinaten (Tighe et al. 2015).

Die häufigste Anwendung erfahren die Mikrotiterplatten-basierten Arrays bei der Immunabscheidung von Analyten aus einem flüssigen Medium. Die Antikörper werden durch einen automatisierten Dispenser in die Vertiefungen der Mikrotiterplatte verteilt, sodass die Anti- 
körper in jedem well als kleine Spots in Form eines Gittermusters organisiert sind. Die nachfolgenden Behandlungen ähneln denen der konventionellen Immunassays mit der letztendlichen Detektion des Analyten durch einen Reporter-Antikörper (Tighe et al. 2015). Zur Visualisierung des Analyten existieren diverse Möglichkeiten. Es können unter anderem Fluoreszenz- und Streptavidin-Farbstoffe oder Chemie- und Elektrolumineszenzen verwendet werden. Ein Nachteil der Antikörper-Arrays besteht darin, dass eine hochauflösende Visualisierung jedes wells notwendig ist, damit die Signale der Antikörper unterschieden werden können (Tighe et al. 2013). Zusätzliche Einschränkungen des Verfahrens ergeben sich aufgrund der Dimension eines wells sowie der begrenzten Genauigkeit der Dispenserspitzen, mit denen die Antikörper in Gitterform angeordnet werden. Bei den auf Mikrotiterplatte basierten Assays ist die maximale Zahl der gleichzeitig zu identifizierenden Proteine auf ca. 20 Proteine beschränkt.

Das Konzept der Immobilisierung von Antikörpern wird auch bei den Slide-basierten Systemen angewendet. Ein großer Vorteil der Slide-basierten Systeme ist, dass die Größe der Slides entsprechend der gewünschten Anzahl an Antikörpern angepasst werden kann. Auf den Slides können so im Gegensatz zu den Mikrotiterplatten Dichten von bis zu 2000 Antibodies pro $\mathrm{cm}^{2}$ erreicht werden.

\subsubsection{Suspensionsassays}

Die nicht-arraybasierten Suspensionsassays beruhen im Vergleich zu den planaren Assays auf farben- oder größenkodierenden Beads, Nanopartiken oder Quantenpunkten, an denen affinitäre Liganden immobilisiert werden können (Horan und Wheeless 1977). Bei der Beadsbasierten Methode werden die individuell gekoppelten Beads durch eine einzigartige fluoreszente Markierung voneinander unterschieden. Die Beads-Sets werden mit der zu untersuchenden Probe gemischt, wodurch der Analyt gebunden werden kann. Der zu identifizierende Analyt ist durch ein eigenes direktes Label markiert oder kann in einem zweiten Schritt durch einen Farbstoff-gekoppelten Reporter-Antikörper detektiert werden (de Jager und Rijkers 2006; Tighe et al. 2015). Die Erkennung und Sortierung der Analyten erfolgt mittels Durchflusszytometrie. Die quantitative Analyse der Analyten wird dabei durch die Messung der Fluoreszenz des Reporter-Antikörpers bzw. des Analyten ermöglicht (LV und Liu 2007).

Die Weiterentwicklung von singleplexen zu multiplexen Immunassays ermöglicht also die Bestimmung und Quantifizierung einer Vielzahl von Proteinen innerhalb einer Probe. Die allgemeine Kompetenz der Immunassays als Diagnose- und Kontrollmittel von Krankheiten oder als Nachweis- und Überwachungsmethode von Arzneistoffen und/oder Giften konnte so rapide gesteigert werden. Trotz dieser Erfolge stellt die erforderliche und derzeit nicht ge- 
gebene Bereitstellung von multiplen Antikörpern für die Anwendung der Antikörper-Arrays eine Limitierung dar. Diese Limitierung hinsichtlich der Herstellung und Bereitstellung von Antikörper sowie die Komplikationen in Bezug auf ihre (strukturellen) Eigenschaften wurden ebenso in anderen Bereichen zur Bildgebung und Identifizierung von Proteinen aufgezeigt. Die auf Antikörpern beruhenden Herausforderungen der Bildgebung und Identifizierung von Proteinen konnten mit der Entwicklung der Protein-Arrays nicht umgangen werden, da diese ihre Basis trotz diverser Entwicklungsprozesse in anderen Bereichen auf Antikörpern begründen. So bleibt das Prinzip „n“ Antikörper für „n“ Proteine weiterhin bestehen.

Eine weitere Problematik der multiplexen Immunassays besteht darin, dass ihre klinische Anwendung eingeschränkt ist. Laut Regulierungsstellen wie der CLIA (Clinicial Laboratory Improvement Amendments) oder der MHRA (Medicines and Healthcare Products Regulatory Agency) erfordert eine klinische Anwendung eine allgemeine Validierung der Technologien hinsichtlich ihrer Reproduzierbarkeit, Spezifität, Sensibilität und Durchführbarkeit. In der klinischen Praxis umfasst diese Validierung zusätzlich eine Bewertung der Mitarbeiterkompetenz, eine Kalibrierung der Instrumente und eine Korrelation bezogen auf klinische Befunde. Für klinische Laboratorien ist es schwierig diese Validierungen in ausreichendem Maße nachzuweisen (Boja et al. 2011).

\subsubsection{Multiplexe Immunzytochemie und -histochemie zur Visualisierung von Proteinen}

Neben den multiplexen Immunassays wurden auch die Verfahren der Immunzytochemie bzw. -histochemie dahingehend entwickelt, dass simultane Visualisierungen von mehreren Proteinen möglich sind. Der Vorteil der IHC oder ICC gegenüber den Immunassays ist, dass multidimensionale Informationen hinsichtlich der räumlichen Verteilung von Zellphänotypen sowie Informationen über die Koexpression von Signal- bzw. Zellzyklusmarkern wiedergegeben werden können (Stack et al. 2014). Damit dieses Potenzial ausgenutzt werden kann, ist eine multiplexe Bildgebung unerlässlich. Da die multiplexen IHC auf der multiplen Anwendung fluoreszierender Farbstoffe beruhen, kann die Interpretation der Probenauswertung jedoch aufgrund von spektralen Emissionsüberlappungen erschwert werden. Wenn Farbstoffe verwendet werden, die in verschiedenen Bereichen des elektromagnetischen Spektrums emittieren, ist es möglich mehrere Proteine gleichzeitig in derselben Probe zu lokalisieren. Dieser Lösungsansatz offeriert jedoch trotzdem eine begrenzte Anzahl an gleichzeitig zu identifizierenden Proteinen (ca. fünf). Die Beschränkung resultiert aus der eingeschränkten Zahl an optisch differenzierbaren Bereichen des elektromagnetischen Spektrums (Stack et al. 2014). 


\subsubsection{Multiplexe Färbungsmethoden}

Bei den Färbungsmethoden der multiplexen ICC/IHC kann grundsätzlich die fluorescent multiplexing-Färbung von der brightfield multiplexing-Färbung unterschieden werden.

Die fluorescent multiplexing-Methode beruht auf der Verfügbarkeit von Fluorophoren, die nach einer spezifischen Anregung eine Fluoreszenz längerer Wellenlänge als die Anregungswellenlänge emittieren. Die fluorescent multiplexing-Methode unterscheidet sich analog zu den singleplexen ICC/IHC in ein direktes und ein indirektes Verfahren. Der multiplexe Ansatz beider Verfahren wird ebenfalls aufgrund der spektralen Emissionsüberlappungen der verwendeten Farbstoffe begrenzt. Eine zusätzliche physikalische Einschränkung der multiplexen Kapazität dieses Verfahrens ergibt sich infolge der Auswahl an möglichen Anregungs- und Emissionsfiltern. Die Filter werden spezifisch für die jeweiligen Fluorophore ausgewählt. Für das Fluorophor Alexa Fluor 488 wird zum Beispiel ein Anregungsfilter für eine $\lambda_{\mathrm{ex}} 493 \mathrm{~nm}$ benötigt, während der Emissionsfilter eine $\lambda_{\text {em }} 516 \mathrm{~nm}$ durchlassen muss. Die Wahl des benutzten Equipments zur multiplexe Bildgebung hat also einen Einfluss darauf, in wieweit die Limitierung der spektralen Überlappung ausschlaggebend ist (Stack et al. 2014). Der Einsatz von konfokalen Lasermikroskopen hat den entscheidenden Vorteil, dass mithilfe spezifischer Emissionsfilter und der Auswahl eines geeigneten Lasers, die Spektren von individuellen Markern einzeln und ohne Überlappung mit anderen Emissionen detektiert werden können (Dickinson et al. 2001). Im Gegensatz zur normalen Fluoreszenzmikroskopie wird das Präparat streifenweisen von einem Lichtpunkt abgetastet, sodass die Fluoreszenz immer nur an einem Punkt angeregt wird. Zusätzlich blendet das pinhole das out of focus-Licht aus und lässt nur das Licht aus der Fokusebene passieren. Durch diese Reduktion von Streulicht kann eine gute Auflösung erreicht werden.

Neue Studien sehen Quantendots im Vergleich zu den herkömmlichen Fluorophoren als eine geeignetere Alternative an (Xing et al. 2007). Durch die Kopplung der Detektionsantikörper an Quantendots kann die Limitierung der multiplexen Bildgebung aufgrund spektraler Überlappungen minimiert werden (Zrazhevskiy und Gao 2013). Trotz der vielversprechenden Eigenschaften der Quantendots sind die Anforderungen der verfügbaren Unterlagen zeit- und kostenintensiv, wodurch ihre Anwendbarkeit erschwert wird (Xing et al. 2007).

Im Gegensatz zur der Fluoreszenz-Methode basiert die brightfield-Methode auf der Verteilung von verschiedenen Chromogenen. Diese können mit der Meerrettichphosphatase (HRP') oder der alkalischen Phosphatase (AP) visualisiert werden (van der Los 2008). Angesichts des Gebrauches von Phosphatasen können bei der Anwendung der brithfield-Färbung Kreuzreaktionen auftreten. Die auf Chromogenen basierenden Verfahren der multiplexen ICC/IHC die- 
nen vor allem zur Unterscheidung verschiedener Zelltypen. Die Differenzierung von Proteinen hinsichtlich ihrer Lokalisationen innerhalb einer Zelle ist aufgrund der spektralen Überlagerung schwierig und ist in der Regel auf drei Zielobjekte begrenzt (van der Loos 2013).

Da diese Arbeit auf der Notwendigkeit beruhte mehrere Ziele innerhalb einer Zelle differenzieren zu können, wurde die Visualisierung der untersuchten Proteine während EpitopAnalyse auf Basis der beschriebenen Fluoreszenz-Methode durchgeführt. Mit der fluorescent multiplexing-Methode ist es möglich Fluorophore mit den entsprechenden Wellenlängenbereichen spezifisch anzuregen und die Signale zu detektieren.

\subsubsection{Multiplexe Bildgebung}

Der Wert der multiplexen ICC/IHC liegt vor allem in ihrem Potenzial, die Erfassung multidimensionaler Daten zu ermöglichen. Des Weiteren beinhaltet ihr Informationsgehalt Angaben über die räumliche Verteilung von multiplen Zellphänotypen und der Signalisierung von Koexpressionen. Die Visualisierung dieser nutzbaren Informationen ist von der Möglichkeit einer multiplexen Bildgebung abhängig (Stack et al. 2014). Diese Bedingung soll unter anderem durch die Strategie einer multiplexe serial sectioning-Methode erfüllt werden, bei der einzelne Bilder von aufeinanderfolgenden Serienabschnitten aufgenommen werden können. Die multiplexe Eigenschaft der Strategie bleibt, wie bei vielen anderen sequenziellen Bildgebungsverfahren, weiterhin eingeschränkt, da Informationen über Koexpressionen und Signalkaskaden innerhalb individueller Zellen mit dieser Vorgehensweise nicht erfasst werden können (Potts et al. 2011). Ein weiterer multiplexer Ansatz beinhaltet die Extraktion von Proteinen aus einzelnen Gewebeschnitten mittels geschichteter Membranen, anhand derer anschließend die IHC zur Untersuchung der Proteinexpression durchgeführt wird. Die Signale der Membranen werden einzeln von einem Microarray-Laser erfasst, und die Bilder können anschließend auf dem ursprünglichen Gewebeabschnitt überlagert werden (Stack et al. 2014).

Die vorgestellten Methoden und Technologien zur multiplexen Analyse von Proteinen sind zum Teil kostspielig und aufwendig in ihrer Durchführung. Trotz der Entwicklung in Richtung multiplexer Plattformen bleibt bei diesen Verfahren das Prinzip bestehen, dass für die

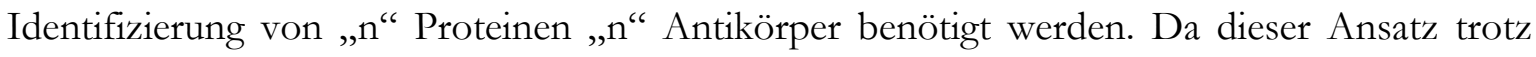
verschiedenster Techniken der multiplexen Technologien bestand hat, soll in dieser Arbeit eine Methode entwickelt werden, die sich von den Antikörpern als Basiskomponente abwendet. Des Weiteren soll diese Methode ermöglichen mit „n“ Sonden „2 $\mathrm{n}^{-1 ، ~ P r o t e i n e ~ z u ~ i d e n t i f i-~}$ zieren. Durch dieses neue Verfahren wird eine einfache und schnelle Methode zur multiplexen Bildgebung präsentiert. 


\subsection{Antikörper als Grundbestandteil immunbiologischer Verfahren}

Das Immunsystem produziert gegen körperfremde Erreger (Antigene) Antikörper. Diese Antikörper, oder auch Immunglobuline (Igs) genannt, dienen der natürlichen molekularen Abwehr, indem sie Antigene mit hoher Spezifität an einer für sie bestimmten Region, dem Epitop, binden (Fagraeus 1948). Aufgrund dieser hohen Spezifität dienen Antikörper in verschiedensten biomedizinischen Anwendungen als Basiswerkzeug für die Erkennung, Bindung und Detektion von Zielstrukturen.

Im Folgenden wird ein detaillierter Einblick in die Struktur und die Eigenschaften der Antikörper gegeben. Diese Kenntnis ermöglicht einen Vergleich mit den in dieser Arbeit eingesetzten Nanobodies. Des Weiteren soll die Entscheidung des Einsatzes der Nanobodies anstelle der Antikörper als Liganden des neu entwickelten Verfahrens nahegelegt werden.

\subsubsection{Aufbau von Immunglobulin G}

Die Antikörper sind Teil des erworbenen humoralen Immunsystems und können durch Erkennung und Bindung von Antigenen eine Immunantwort einleiten. Sie zirkulieren als Produkte von Plasmazellen im Blut oder sind auf der Oberfläche von allen B-Lymphozyten über eine Transmembransequenz fixiert. Lösliche Antikörper sind bei der elektrophoretischen Auftrennung der Plasmaproteine in der $\gamma$-Globulin-Fraktion nachweisbar und werden deshalb als Immunglobuline bezeichnet.

Die Immunglobuline G ( $\operatorname{IgG}$ ) bilden den Großteil (70 \%) der fünf im Serum vorkommenden Isotypen von Antikörpern (IgG, IgA, IgM, IgD). Die IgG weisen eine heterotetramere Struktur auf, die aus zwei identischen leichten (L-Kette, $25 \mathrm{kDa}$ ) und zwei identischen schweren (H-Kette) Ketten besteht. Die L-Kette kann entweder aus dem $\kappa$ - oder $\lambda$-Typ bestehen. Bei der H-Kette existieren acht mögliche Subtypen, die den jeweiligen Typ der Immunglobuline bestimmen. Die H-Ketten bestehen aus 440-450 Aminosäuren (50 kDa) während die LKetten 220 Aminosäuren $(25 \mathrm{kDa})$ umfassen. Wie in Abbildung 2 dargestellt werden die $\mathrm{H}$ Ketten in dem Scharnierbereich (Hinge) durch Disulfidbrücken miteinander verbunden und ergeben eine Y-ähnliche Struktur. Eine weitere Disulfidbrücke stellt ebenfalls eine Verbindung zu den leichten Ketten her (Williams und Barclay 1988). Die vorhandenen intramolekularen Disulfidbrücken dienen der Faltung globulärer Domänen (ca. 110 Aminosäuren) innerhalb der Struktur der Antikörper (Safarnejad et al. 2011).

Die Strukturabschnitte am C-Terminus (COO') der schweren und der leichten Kette sind charakteristisch für ihre geringe Variabilität. Sie werden als konstante Domänen $\left(\mathrm{C}_{\mathrm{H} / \mathrm{L}}\right)$ bezeichnet. 
Die Regionen am N-Terminus $\left(\mathrm{NH}_{3}^{+}\right)$zeichnen sich dagegen als variable Bereiche $\left(\mathrm{V}_{\mathrm{C} / \mathrm{I}}\right)$ aus. Die Struktur der L-Kette umfasst insgesamt eine variable $\left(V_{L}\right)$ und eine konstante $\left(C_{L}\right)$ Domäne, während die schweren Ketten aus einer variablen $\left(\mathrm{V}_{\mathrm{H}}\right)$ und drei konstanten Domänen $\left(\mathrm{C}_{\mathrm{H}}\right.$ 1, $\left.\mathrm{C}_{\mathrm{H}} 2, \mathrm{C}_{\mathrm{H}} 3\right)$ gefaltet sind. Das funktionale Antigen-Bindungsfragment (Fab) dient der Bindung von Antigenen und wird aus den verbundenen $V_{H}, V_{L}, C_{H} 1$ und $C_{L}$ gebildet. Die zwei Fab-Fragmente enthalten jeweils ein identisches Paratop. Dieses tritt spezifisch mit dem entsprechenden Epitop des Antigens in Wechselwirkung. Das eigentliche Paratop wird dabei nur von den variablen Domänen $\left(\mathrm{V}_{\mathrm{H}}, \mathrm{V}_{\mathrm{I}}\right)$ gebildet. Die Anordnung der Ketten bildet neben den zwei Fab-Fragmenten ein Fc-Fragment sowie eine Scharnierregion. Über die Scharnierregion kann die räumliche Beziehung der Fab-Fragmente zueinander variiert werden. Das FcFragment ist für die Aktivierung des Komplementsystems und für die Rezeptor-vermittelte Rekrutierung von zytotoxischen Effektorzellen verantwortlich (Natsume et al. 2009). Des Weiteren ermöglicht das Fc-Fragment eine lange Serumhalbwertszeit von Antikörpern durch die Bindung an den neonatalen Fc-Rezeptor (FcRn) (Roopenian und Akilesh 2007). 


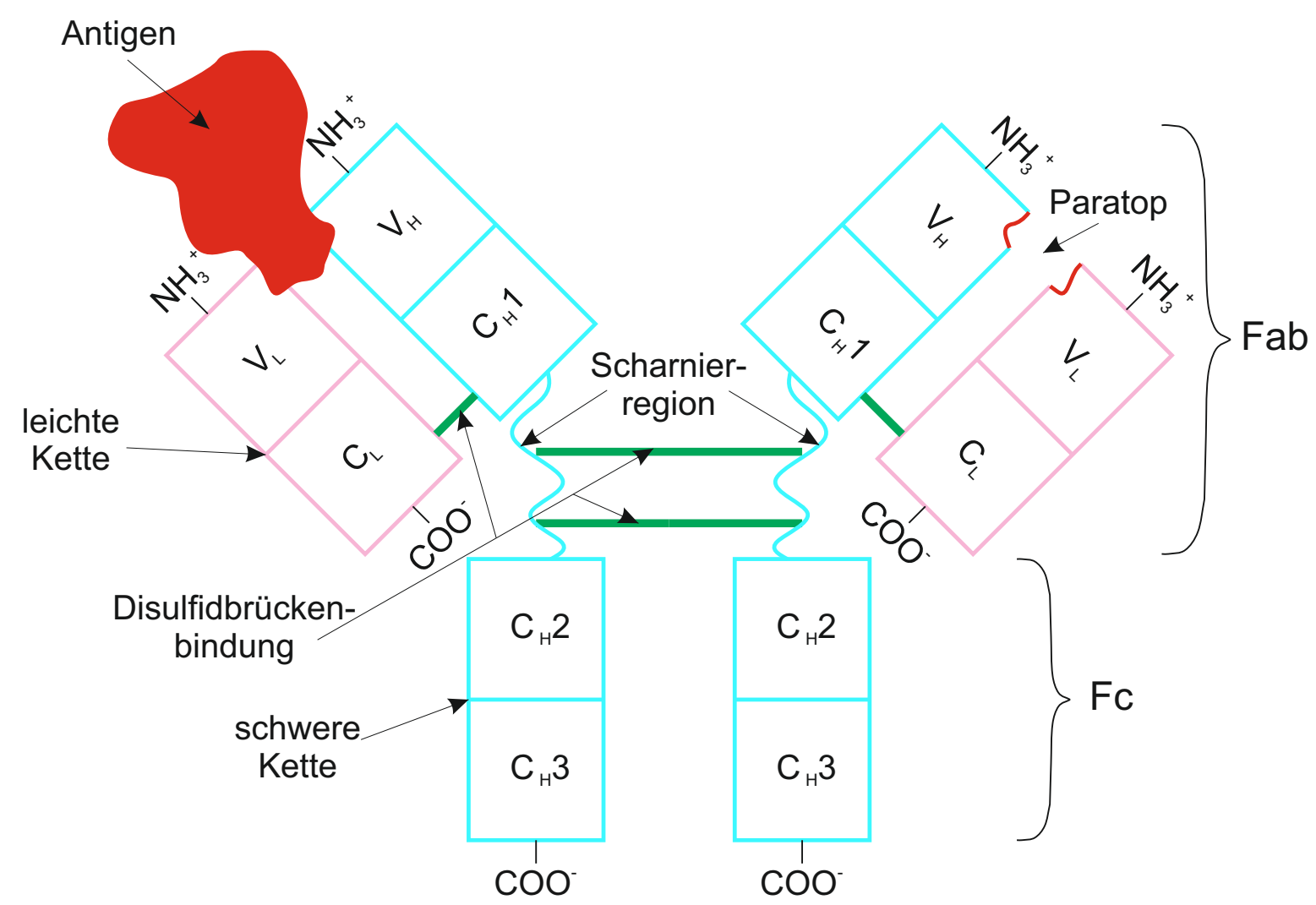

Abbildung 2: Struktureller Aufbau der IgG. Aufbau eines IgGs bestehend aus zwei leichten und zwei schweren Ketten. Die leichten Ketten beinhalten jeweils eine $\mathrm{V}_{\mathrm{L}^{-}}$und eine $\mathrm{C}_{\mathrm{L}^{-}}$Domäne, die schweren Ketten die $\mathrm{C}_{\mathrm{H}} 1,-2,-3$ und eine $\mathrm{V}_{\mathrm{H}}$-Domäne. Die konstanten Domänen befinden sich am C-Terminus (COO$\left.{ }^{-}\right)$, die variablen Domänen am N-Terminus $\left(\mathrm{NH}_{3}{ }^{+}\right)$. Die variablen Domänen der L- und H-Kette bilden gemeinsam das Paratop, das spezifisch an das jeweilige Antigen mit einer individuellen Affinität binden kann.

Die variablen Domänen $\left(\mathrm{V}_{\mathrm{H}}, \mathrm{V}_{\mathrm{I}}\right)$ bilden als Sekundärstruktur neun Betafaltblatt-Strukturen, die über sechs kanonische Schlaufen und eine Disulfidbrücke miteinander verbunden sind (Padlan 1994). Die $\mathrm{V}_{\mathrm{H}^{-}}$und $\mathrm{V}_{\mathrm{L}}$-Ketten umfassen jeweils drei der insgesamt sechs Bindungsschlaufen. Die Bindungsschlaufen enthalten Regionen, die aufgrund ihrer Hypervariabilität als Komplementär-determinierende Regionen (CDRs) bezeichnet werden. Die CDRs (CDR1, -2, -3) sind diejenigen Oberflächenstrukturen der Paratope, die befähigt sind mit der antigenen Determinante in Wechselwirkung zu treten (Kabat et al. 1977). Die umgebenden konservierten Rahmenregionen ( $F r)$ unterstützen die Strukturgebung. Aufgrund der zwei existierenden Fab-Fragmente sind IgG-Moleküle bivalent und können gleichzeitig an zwei identische Strukturen binden. Die monovalente Bindungsstärke zwischen dem Paratop und dem Epitop wird dabei als Affinität bezeichnet. Die Gesamtaffinität multivalenter Antikörper wird durch die Avidität beschrieben. Die Maßangabe erfolgt als Affinitätskonstante $\left(K_{D}\right)$.

Mithilfe proteolytischer Verdauung eignet sich der Aufbau der Antikörperstruktur zur Herstellung kleinerer Antikörper-Fragmente. Als eine wirksame Stelle dient dabei die Scharnierregion. 
Durch eine Proteolyse mit Papain kann die Struktur der IgGs in biologisch aktive Fragmente unterteilt werden (s. Abbildung 3). Während aus den Schenkeln die zwei monovalenten antigenbindenden Fab-Fragmente entstehen, bildet der Stamm das Fc-Fragment. Verdaut man Antikörper dagegen mit Pepsin, bleiben die beiden Fab-Fragmente und die Scharnierregion miteinander verbunden und es entsteht das bivalente $\mathrm{F}(\mathrm{ab})^{2}$-Fragment (Schroeder und Cavacini 2010).

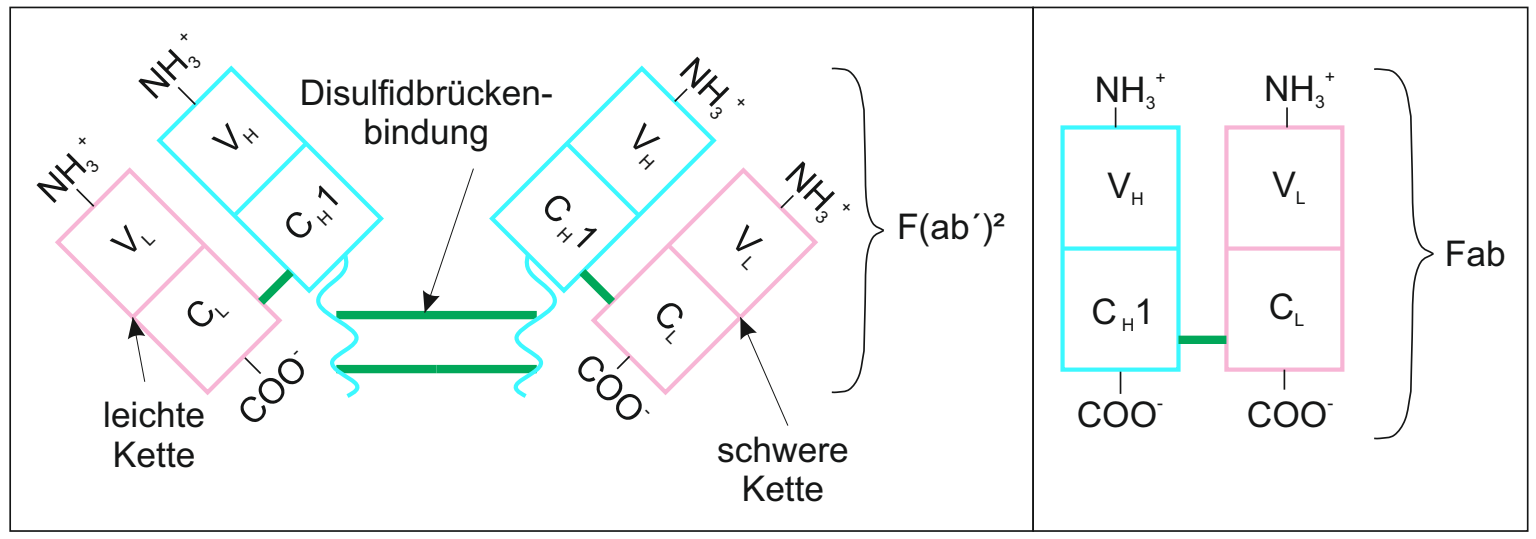

Abbildung 3: Derivate der konventionellen Antikörper. Das $F(a b)^{2}$-Fragment und FabFragment als Derivate nach der Verdauung mit Pepsin bzw. Papain.

\subsection{Nanobodies (Einzeldomänenantikörper)}

Im Serum der Camelidae-Familie (Camelius dromedarius) treten neben den konventionellen heterotetrameren IgGs (IgG1) zusätzlich homodimere Schwere-Ketten-Antikörper (HCAbs) auf. Die HCAbs weisen zwei Isoformen auf, die als IgG2 und IgG3 bezeichnet werden (s. Abbildung 4). Die Besonderheit ihrer Struktur liegt in dem fehlenden Auftreten der leichten Kette und der ersten konstanten Domäne $\left(\mathrm{C}_{\mathrm{H}} 1\right)$. Die IgG2 und $\mathrm{IgG} 3$ bestehen so nur aus zwei schweren (H-)Ketten. Die Abwesenheit der $\mathrm{C}_{\mathrm{H}} 1$ ist durch eine Punktmutation zu erklären (Hamers-Casterman et al. 1993; Conrath et al. 2003). Aufgrund eines in den $\mathrm{V}_{\mathrm{H}} \mathrm{s}$ stattgefundenen Austauschs von hydrophoben in hydrophile Aminosäuren ist das Fehlen der L-Ketten zu begründen. In der dadurch bedingten veränderten Struktur der H-Ketten fehlen nämlich die Bindungsstellen für Chaperon-Proteine, die für die Verknüpfung der L-Ketten mit den $\mathrm{H}$ Ketten verantwortlich wären (Padlan 1994). 


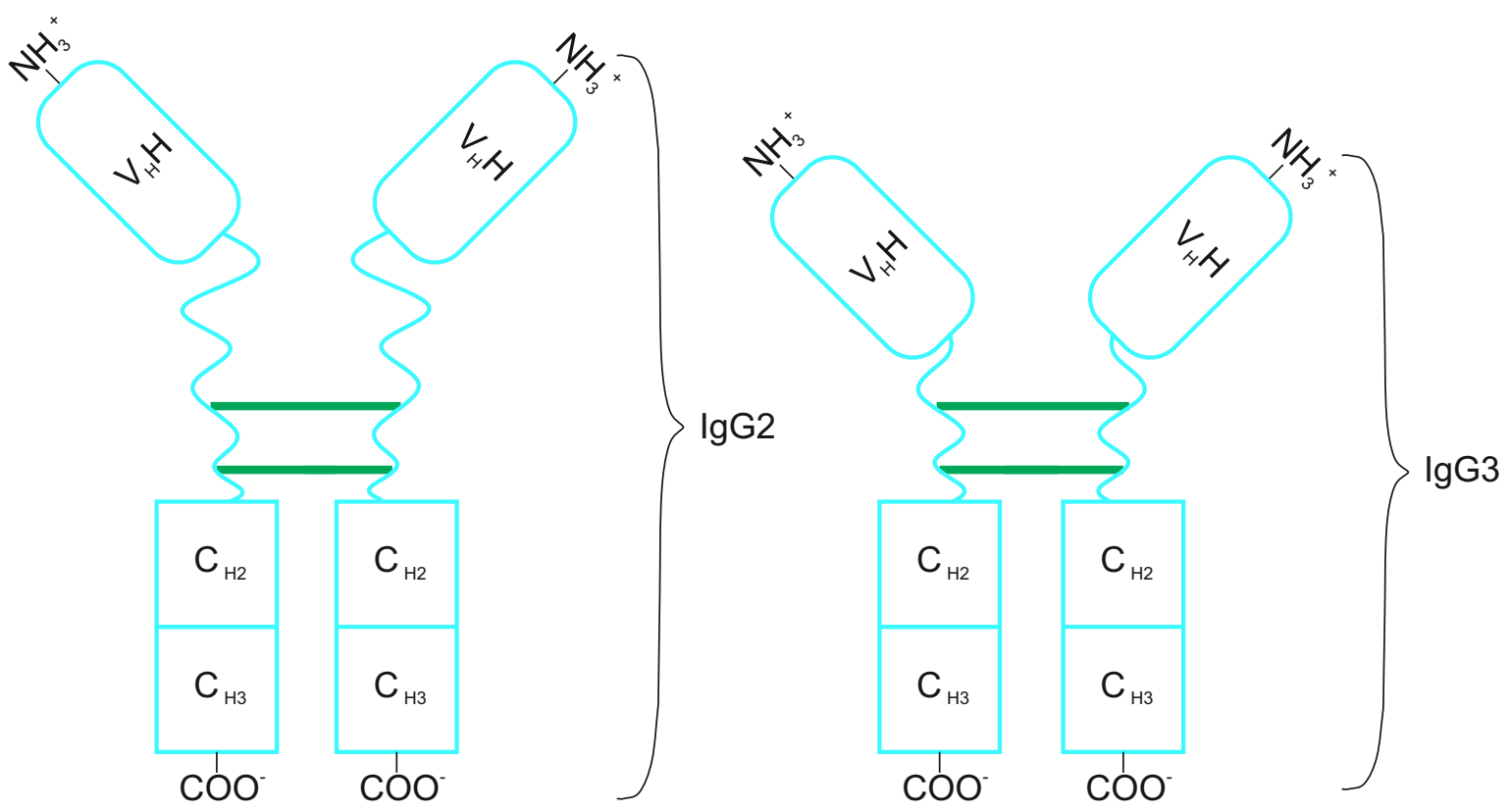

Abbildung 4: Schematische Darstellung der im Serum der Camelidae-Familie vorkommenden Antikörper-Isoformen. Die homodimeren Schwere-Ketten-Antikörper (HCABs) IgG2 und IgG3, die nur aus den schweren (H-) Ketten bestehen. Die schweren Ketten beider Isoformen setzen sich jeweils aus einer $\mathrm{V}_{\mathrm{H}} \mathrm{H}$-Domäne, einer Scharnierregion und einer $\mathrm{C}_{\mathrm{H}} 2$ und $\mathrm{C}_{\mathrm{H}} 3$-Domäne zusammen. Isolierte $\mathrm{V}_{\mathrm{H}} \mathrm{Hs}$ (Nanobodies) können von HCAbs abgeleitet werden und agieren als funktionelle antigenbindende Fragmente.

Der N-Terminus einer H-Kette umfasst eine variable Domäne $\left(\mathrm{V}_{\mathrm{H}} \mathrm{H}\right)$, die über eine Scharnierregion mit zwei konstanten Domänen $\left(\mathrm{C}_{\mathrm{H}} 2, \mathrm{C}_{\mathrm{H}} 3\right)$ am C-Terminus verbunden ist (s. Abbildung 4 B). Die $\mathrm{V}_{\mathrm{H}} \mathrm{Hs}$ übernehmen in der Struktur der HCAbs die Aufgabe des Paratops (Muyldermans 2013). Die $\mathrm{V}_{\mathrm{H}} \mathrm{Hs}$ werden als Einzeldomänenantikörper oder nach ihrem Erfinder Ablnyx auch als Nanobodies $(\mathrm{Nb})$ bezeichnet. Die Nanobodies setzen sich aus vier hochkonservierten Rahmenregionen (FR1-4) und drei CDRs zusammen (s. Abbildung 5). Die exprimierte Sekundärstruktur der FR liegt als Betafaltblatt organisiert vor, die über drei Bindungsschleifen, die drei CDRs enthalten, miteinander verbunden ist (Muyldermans 2013). 


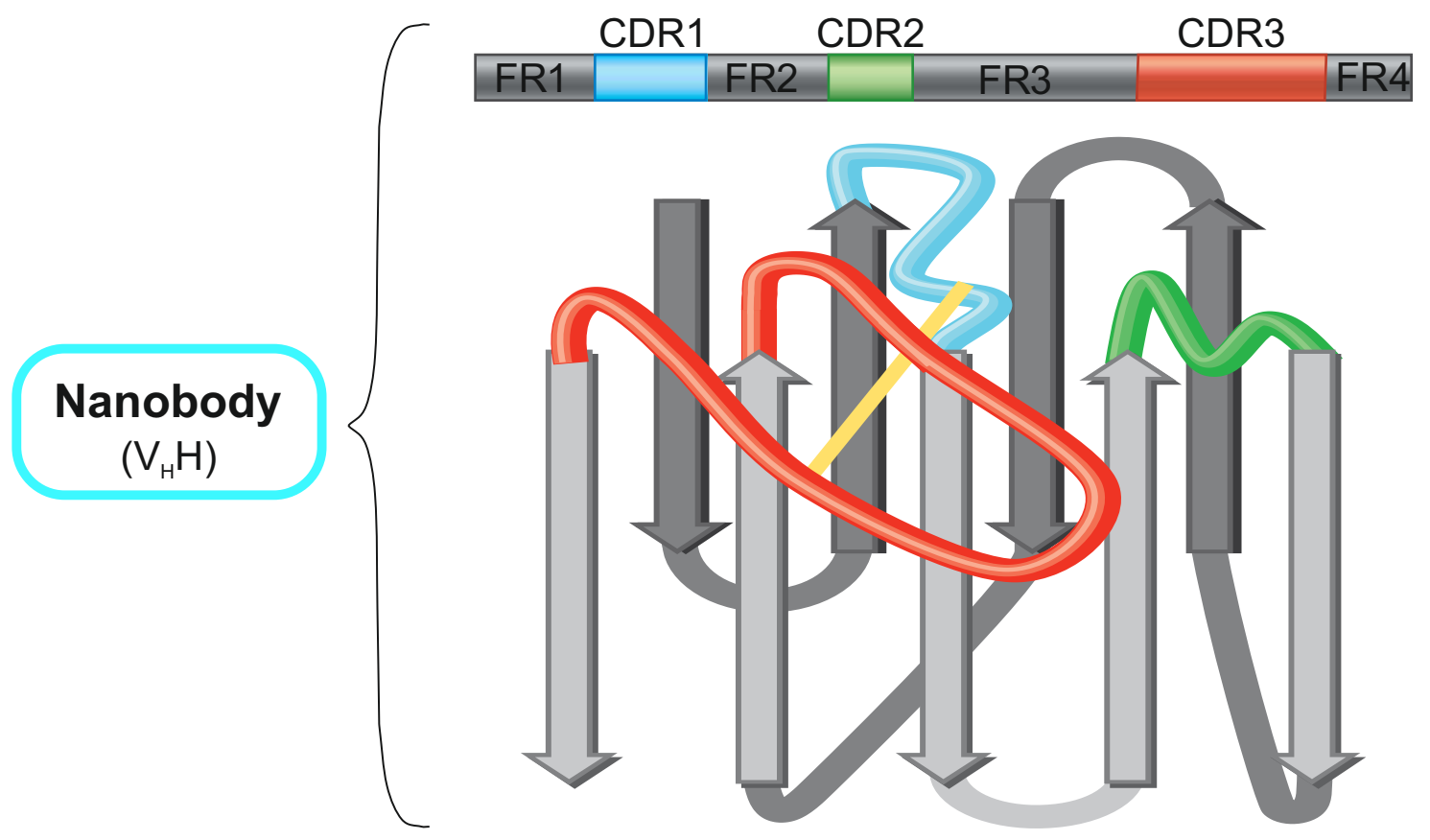

Abbildung 5: Schematische Strukturdarstellung eines Nanobodies. Nanobodies werden aus einer $\mathrm{V}_{\mathrm{H}} \mathrm{H}$-Domäne gebildet. Die Struktur der $\mathrm{V}_{\mathrm{H}} \mathrm{H}$-Domäne beinhaltet vier Rahmenregionen (FR1, FR2, FR3, FR4), sowie drei Komplementär-determinierende Regionen (CDR1, CDR2, CDR3). Die Betafaltblattstruktur (graue Pfeile) der FRs ist durch die aus den CDRs resultierenden Bindungsschleifen (colorierte Schlaufen) miteinander verbunden. Die CDR2 (grüne Schlaufe) und die CDR3 (rote Schlaufe) sind über eine Disulfidbrücke (gelber Strich) untereinander stabilisiert (nach Muyldermans 2013).

Die strukturellen Unterschiede zwischen den $\mathrm{V}_{\mathrm{H}} \mathrm{s}$ der Antikörper und den Nanobodies liegen sowohl in den CDRs als auch in der FR2 vor. Die FR2 in den $\mathrm{V}_{\mathrm{H}} \mathrm{s}$ ist eine hochkonservierte hydrophobe Region, deren Aminosäuren in Verbindung zu den $\mathrm{V}_{\mathrm{L}} \mathrm{s}$ stehen. In den $\mathrm{V}_{\mathrm{H}} \mathrm{Hs}$ sind in der FR2 die hydrophoben Aminosäuren durch hydrophile Aminosäuren ersetzt worden. Dadurch wird eine erhöhte Löslichkeit erreicht und es können keine Verknüpfungen zu den L-Ketten entstehen (Muyldermans et al. 1994; Vu et al. 1997; Harmsen et al. 2000). Des Weiteren führt der Verlust an $\mathrm{V}_{\mathrm{L}} \mathrm{s}$ zu einer verringerten Anzahl an CDRs, sodass nur noch drei von ehemals sechs Bindungsschlaufen zur Antigenerkennung zur Verfügung stehen (De Genst et al. 2006). Im Vergleich zu den $\mathrm{V}_{\mathrm{H}} \mathrm{s}$ wurde die Struktur der CDR1 der Nanobodies um vier Aminosäuren erweitert und die CDR2 in ihrer Schlaufenbildung verändert (Vu et al. 1997). Die Längenvergrößerung in der CDR3-Schlaufe (Abbildung 5, rote Bindungsschlaufe) vergrößert die verfügbare Oberfläche der Paratope. Diese Strukturveränderungen kompensieren die Auswirkungen der Reduzierung der Gesamtzahl der Bindungsschlaufen. Die Bindungsaffinität der Nanobodies wird trotz struktureller Veränderungen im Vergleich zu den konventionellen Antikörpern nicht verschlechtert (Muyldermans et al. 1994). Außerdem ermöglicht die CDR3 als hervorstehende Bindungsschlaufe den Zugang zu antigenen Determi- 
nanten, die mit konventionellen Antikörpern nicht erreicht werden können (Nguyen et al. 2000). Die reduzierte Gesamtgröße und die hervorstehende Form des CDR3-Paratopes eröffnen neue Möglichkeiten in der Vielfältigkeit der Antigenbindungs-Kapazität (Nguyen et al. 2002).

\section{$1.5 \quad$ Nanobody vs. Antikörper}

Aufgrund der in vivo stattfindenden somatischen Rekombinationen und der variablen Kombination der leichten und schweren Ketten untereinander besteht es eine hohe Diversität zwischen den Antikörpern. Diese Vielfältigkeit ermöglicht, dass innerhalb der verschiedenen Verfahren nahezu jedes ausgewählte Ziel spezifisch erkannt und dargestellt werden kann. Diese Eigenschaften sowie die Kopplungsmöglichkeiten mit verschiedenen Markern machen Antikörper zu den kommerziell am häufigsten verwendeten Sonden zur Detektion von Antigenen in den Feldern der Biologie und der Medizin. Im Vergleich zu den Antiköpern stellen Nanobodies eine Neuheit in der Anwendung biomedizinischer Verfahren dar. Aufgrund ihrer Herstellungsart, den strukturellen Gegebenheiten und ihrer hohen, spezifischen Affinität sind Nanobodies in vielen Anwendungsbereichen als eine wünschenswerte Alternative zu den Antiköpern zu sehen. Im Folgenden werden die zwei in den verschiedensten Verfahren verwendeten Sonden miteinander verglichen.

Für die Produktion von funktionellen Antikörpern eignen sich vor allem Säugetierzellen, deren Benutzung nach der Tierschutz-Richtlinie 3.04 einen „bewilligungspflichtigen Tierversuch“ darstellt. In mikrobiologischen Systemen, wie in E. coli, können nur nicht-glykosylierte IgGs hergestellt werden. Nur kleinere Antikörperfragmente, z. B. die Fab-Fragmente (57 kDa) oder die single-chain Fvs (scFv), können in mikrobiellen Zellen produziert werden (Holliger und Hudson 2005).

Dagegen erlaubt die monomere Struktur der Nanobodies im Vergleich zu den konventionellen IgGs unter anderem eine Produktion in E. coli (Arbabi-Ghahroudi et al. 1997) sowie in Saccharomyces cerevisiaem (Frenken et al. 2000). Des Weiteren wurden Nanobodies erfolgreich in Insekten und in transgenen Reissamen produziert (Vega et al. 2013). Die Produktionsmöglichkeit in mikrobiologischen Systemen verringert die Herstellungskosten und verkürzt die Entwicklungszeiten, die unter bewährten und skalierbaren Fermentationsbedingungen durchführbar sind (Arbabi-Ghahroudi et al. 1997; Nguyen et al. 2001). Bei der Herstellung von Nanobodies in Mikroorganismen muss jedoch beachtet werden, dass das Produktionslevel der einzelnen Klone um einen Faktor 100 variieren kann (Frenken et al. 2000). 
Die komplexe Struktur der Antikörper im Vergleich zu dem monomeren Aufbau der Nanobodies wirkt sich ebenfalls bei der Durchführung molekularer Manipulationen aus. Diese sollen die Produktion multivalenter Sonden bewirken, die bei aufwendigen Untersuchungen eine simultane Detektion mehrerer Antigene ermöglichen. Die Produktion solcher Moleküle aus konventionellen Antikörpern beherbergt viele Probleme hinsichtlich der Effizienz, der Stabilität und der Immunologie der bispezifischen Antikörper. Zu den produzierbaren, kleineren Antikörperfragmenten zählen die Fab-Fragmente $(57 \mathrm{kDa})$ oder die $\mathrm{scFv}$, die in mikrobiellen Zellen produziert werden können (Holliger und Hudson 2005). Das scFv besteht aus einem über eine Oligopeptidkette verbundenen $\mathrm{V}_{\mathrm{H}^{-}} \mathrm{V}_{\mathrm{L}}$-Paar und stellt das kleinstmögliche Antigenbindungsfragment dar, das von Antikörpern abgeleitet werden kann. Die notwendige Herstellung von multiplen Varianten dieser Fragmente ist allerdings trotzdem oft aufwendig und mit hohen Kosten verbunden (Harmsen und De Haard 2007). Außerdem ist der Prozess häufig mit dem Zustandekommen von Aggregationen verbunden, die aufgrund der fehlerhaften Bindung von $V_{H}$ und $V_{L}$-Domänen entstehen (Glockshuber et al. 1990). Des Weiteren besitzen die neuen multivalenten Moleküle meistens eine reduzierte Affinität (Whitlow et al. 1993).

Dagegen begünstigen die Einzeldomänenstrukturen der Nanobodies - neben den effizienten Produktionsmöglichkeiten - ebenfalls die Durchführung molekularer Manipulationen. Mithilfe molekularer Manipulationen können aus Nanobodies bi- oder trivalenten Formate konstruiert werden. Des Weiteren ermöglicht ihre Struktur die Produktion von flexiblen Linkern, die eine Grundvoraussetzungen für erfolgreiche simultane Bindungen multipler Antigene darstellen (Coppieters et al. 2006). Nanobodies stellen also eine Basis dar, aus der eine große Bandbreite an Sonden einfach und effizient produziert und anschließend effektiv in umfangreichen Untersuchungen eingesetzt werden kann.

Die strukturellen Gegebenheiten der Antikörper (ca. $15 \mathrm{kDa}$ schwer, $15 \mathrm{~nm}$ groß) stellen ebenfalls in einigen Anwendungsbereichen ein Hindernis dar, wie z. B. in dem Bereich der Super-Resolution-Mikroskopie. Die Super-Resolution-Techniken erfordern, dass sich die Fluorophore in direkter Nähe zu den Zielproteinen befinden (Ries et al. 1991). Diese Anforderung kann in den meisten der Antikörper-basierten Standardverfahren nicht gewährleistet werden. Typischerweise wird für die Bestimmung des Zielproteins der erste spezifische Antikörper zunächst mit einem zweiten farbstoffgekoppelten Antikörper detektiert. Durch diese Vorgehensweise können Lokalisierungsfehler auftreten, da zwischen dem eigentlichen Zielprotein und dem messbaren Fluorophor Abstände von ca. $30 \mathrm{~nm}$ bestehen. Mit steigender Größe der eingesetzten Sonden und bei bivalenter Affinität sinken sowohl die Markierungseffektivität als auch der Auflösungsgrad der Detektion (Opazo et al. 2012). Des Weiteren führt die Molekülgröße zu einer begrenzten Zieldurchdringungswirksamkeit (Hughes 2010) und 
einem hohen Hintergrundgehalt bei der Bildgebung (Hildebrant und Gambhir 2004). Darüber hinaus verursacht sie lange Serum-Halbwertszeiten, die dosislimitierende Myelotoxizitäten bewirken können (Litvak-Greenfeld und Benhar 2012).

Aufgrund dieser Einschränkungen geht der Trend ebenfalls zu der Entwicklung von Nanobodies. Die strukturellen Eigenschaften der Nanobodies, wie zum Beispiel ihre geringe Größe von ca. $15 \mathrm{kDa}$, stellen ein expandiertes Angebot an potentiellen Anwendungsgebieten dar. Die Größendimension im Nanometerbereich verringert den Abstand zwischen dem detektierbaren Farbstoff und dem Zielprotein, wodurch die Präzision der Detektion erhöht werden kann. Des Weiteren ermöglichen die reduzierte Gesamtgröße sowie die Ausweitung der CDR3 ein erweitertes Angebot an registrierbaren Epitopen. Aufgrund dieser Eigenschaften sind die Nanobodies ebenfalls befähigt, das aktive Zentrum von Enzymen zu blockieren und eignen sich daher als Inhibitoren von bestimmten biochemischen Reaktionen (Lauwereys et al. 1998). Im Bereich der Super-Resolution-Mikroskopie werden fluorophorgekoppelte Nanobodies (Chromobodies) für die Lokalisierung von einzelnen Molekülen innerhalb der Zelle verwendet. Ein weiterer Vorteil in der Anwendung der Nanobodies gegenüber der von Antikörpern ist die hohe Strukturstabilität (Perez et al. 2001) und die verbesserte Resistenz gegenüber Denaturierungen, sodass bei Werten von $90{ }^{\circ} \mathrm{C}$ die Funktionalität aufrechterhalten bleibt (van der Linden et al. 1999). Ebenfalls konnte eine erhöhte Widerstandfähigkeit gegen pHEinwirkungen festgestellt werden (Dumoulin et al. 2002). Diese Eigenschaften resultieren aus der im Vergleich zu den $\mathrm{V}_{\mathrm{H}} \mathrm{s}$ der Antikörper erhöhten Hydrophilie der Nanobodies (Davies und Riechmann 1995; Davies und Riechmann 1996).

Da die Anwendung von Nanobodies in vielen Bereichen anscheinend unbegrenzte Möglichkeiten verspricht, soll in diesem Projekt ein Verfahren entwickelt und geprüft werden, dass das Potenzial von Nanobodies als spezifische Sonden zur Detektion von Proteinen ausnutzt und damit die auf Antikörper beruhenden Defizite anderer Antigentest umgeht. 


\subsection{Zielstellung}

Die in der Einleitung beschriebenen Antikörper-basierten Verfahren zur Proteinmessung und -identifizierung erschweren die Etablierung multipler Proteomik-Untersuchungen von Proben. Vor dem Hintergrund, dass gegenwärtig multiple Proteindetektion nur begrenzt durchführbar sind, soll dieses Projekt eine neue, Antikörper-unabhängige Vorgehensweise aufzeigen. AuBerdem gilt das Bestreben eine hochauflösende, multiplexe Untersuchungsmethode von Zellen und Geweben zu ermöglichen. Das Ziel dieses Projekts ist die Etablierung der auf Nanobodies basierenden kombinatorischen Epitop-Analyse zur Proteinbestimmung.

Das Grundprinzip dieser Arbeit beruht auf der Idee, dass jedes Protein aufgrund eines in seiner Aminosäuresequenz enthaltenen einzigartigen Epitop-Satzes markiert ist. Der Epitop-Satz unterscheidet sich je nach Protein in Art, Anzahl und Kombination. Die Proteine sollen im Hinblick auf die jeweiligen Epitope durch das spezifische Bindungsverhalten von Nanobodies identifiziert werden. Für jedes zu identifizierende Protein wird ein dem Epitop-Satz entsprechender spezifisch gebundener Satz an Nanobodies ermittelt. Aufgrund des Nanobody-Satzes kann wiederum mithilfe der Epitop-Analyse ein Bezug zu dem jeweiligen Epitop-Satz erzielt werden, mit dem jedes Protein markiert ist. Anhand dessen kann jedes Protein identifiziert werden (s. Abbildung 6). Im Vergleich zu anderen auf Antikörpern-basierenden Verfahren stellt die Gesamtheit der Epitop-Analyse also eine neuartige multiplexe Basis dar. Dies gilt insbesondere vor dem Hintergrund, dass für die Identifizierung eines Proteins nicht jeweils ein Nanobody/Antikörper benötigt wird. Durch die Verwendung von „n“ Nanobodies können

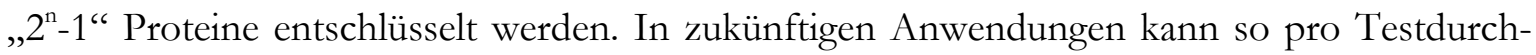
lauf die Gesamtzahl der Nanobodies reduziert und die in einer Probe zu identifizierenden Krankheitsmarker potenziert werden. In dieser Arbeit soll für die Etablierung der EpitopAnalyse die Identifizierung und hochauflösende Bildgebung von 15 künstlich designten Proteinkonstrukten mithilfe von vier Nanobodies erreicht werden. 


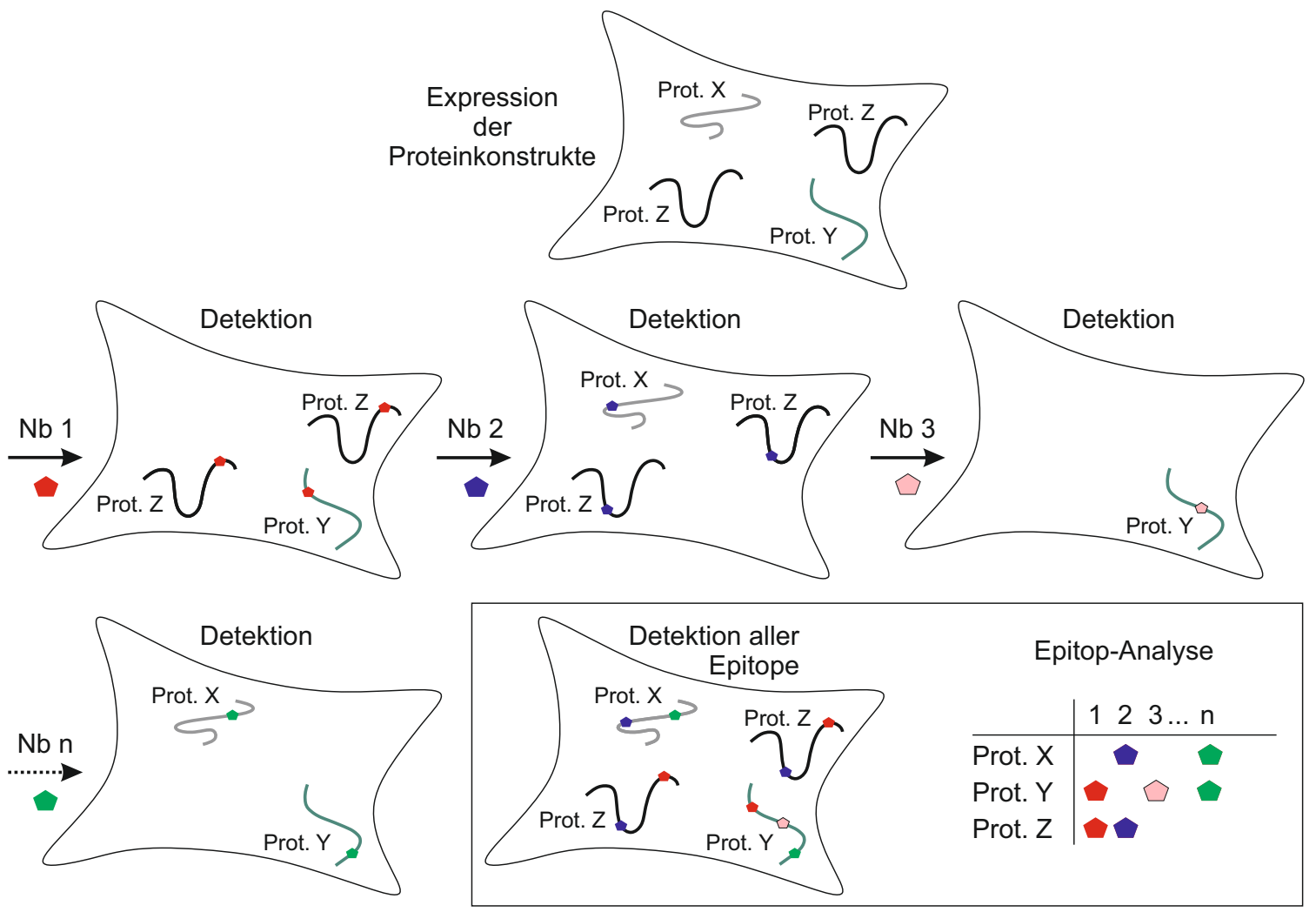

Abbildung 6: Kombinatorische Epitop-Analyse. In einer Zelle werden vier Proteinkonstrukte (Prot. X, $-\mathrm{Y}, 2 \mathrm{x}-\mathrm{Z}$ ) exprimiert. Anschließend werden nacheinander die eingesetzten Nanobodies $(\mathrm{Nb} 1-\mathrm{n})$ hinzugegeben und das jeweilige Bindungsverhalten wird detektiert. Im letzten Schritt erfolgt der kombinatorische Vergleich aller an den Proteinkonstrukten gebundenen Nanobody-Sätze. Mit der Durchführung der kombinatorischen Epitop-Analyse kann der in der Aminosäuresequenz enthaltende Epitop-Satz der Proteinen entschlüsselt werden, wodurch ein Rückschluss auf das zu identifizierende Protein ermöglicht wird.

Die vier in dieser Arbeit eingesetzten Nanobodies besitzen keine spezifische Affinität für ein einzelnes Protein, sondern nur für bestimmte Peptidsequenzen (Epitope). Sie sind daher in der Lage diejenigen Proteinkonstrukte zu binden, die innerhalb ihrer Aminosäuresequenz das entsprechende spezifische Epitop vertreten haben. Die 15 in dieser Arbeit eingesetzten Proteinkonstrukte (s. Abbildung 7) bestehen aus jeweils einem ausgewählten modifizierten Zielprotein. An jedes Protein wird jeweils eine bestimmte Kombination aus vier Epitopen gekoppelt. Jede Epitop-Kombination ist so nur einmalig in dem Verbund mit einem Protein vertreten. Jedes Proteinkonstrukt ist in seiner Epitop-Kombination somit einzigartig. Die Proteine wurden so ausgewählt, dass sie zum Teil anhand ihrer Lokalisation innerhalb der Zelle unterschieden werden können, wie es u. a. bei GalNact (Golgi), NLS (Nukleus), SNAP25 (Plasmamembran), Mitglieder der Syntaxin-Familie (Plasmamembran), Endobrevin und VAMP 4 (Vesikelmembran) der Fall ist. Diese Auswahl gewährleistet, dass die 15 Proteine innerhalb der Zelle nicht akkumulieren und so getrennt voneinander identifiziert und dargestellt werden können. 


\begin{tabular}{|c|c|c|}
\hline Epitope & $\underline{\text { Nanobodies }}$ & Proteinkonstrukte: \\
\hline mCherry & LaM-2 & $\begin{array}{l}\text { 1. GalNact-GFP-syn87 } \\
\text { 2. NLS-mCherry-GFP-syn2 } \\
\text { 3. TOM70-mCherry } \\
\text { 4. Tubulin-mCherry-syn } 87\end{array}$ \\
\hline GFP & GFPNb & $\begin{array}{l}\text { 5. mCherry-GFP-SNAP25 } \\
\text { 6. mCherry-GFP-syn87-KDEL } \\
\text { 7. Lifeact-mCherry-syn2 }\end{array}$ \\
\hline Syn2 & NbSyn2 & $\begin{array}{l}\text { 8. GFP (Cytosol) } \\
\text { 9. Vti1a- syn2 } \\
\text { 10.VAMP4-mCherry-GFP-syn87-syn2 }\end{array}$ \\
\hline & & 11.Syntaxin 7-GFP-syn2 \\
\hline Syn87 & NbSyn87 & $\begin{array}{l}\text { 12. Syntaxin 13-mCherry-syn87-syn2 } \\
\text { 13. Syntaxin } 6 \text {-syn } 87-\text { syn2 } \\
\text { 14. Syntaxin } 4 \text {-syn } 87 \\
\text { 15. Endobrevin-GFP-syn87-syn2 }\end{array}$ \\
\hline
\end{tabular}

\begin{abstract}
Abbildung 7: Instrumente der Epitop-Analyse. Es sind die vier verschiedenen Epitope mit den entsprechend dazugehörigen Nanobodies gezeigt (links und mitte). Auf Basis der zur Verfügung stehenden Epitope wurden 15 verschiedene Proteine jeweils an eine einzigartige Kombination aus den vier Epitopen gekoppelt. Durch diese Vorgehensweise konnten 15 Proteinkonstrukte erschaffen werden (rechts).
\end{abstract}

Ein wichtiger Punkt für die Umsetzung der Arbeit beruht auf der Verfügbarkeit und Funktionalität der Nanobodies. Der erste Schritt der Arbeit beinhaltet die Gewinnung und Aufreinigung der Nanobodies aus E. coli. Anschließend soll mithilfe eines Funktionstests ihr Bindungsverhalten zu den jeweiligen Epitopen einzeln an verschiedenen Plasmiden überprüft werden.

Die produzierten 15 Proteinkonstrukte werden anschließend in HEK-293-Zellen transfiziert und letztendlich exprimiert. Anhand der an den Proteinkonstrukten spezifisch gebundenen Nanobody-Sätze soll die Epitop-Analyse die Identifizierung jedes einzelnen Konstrukts ermöglichen und damit ihre Eignung als neues wissenschaftliches Verfahren bestätigen (singleplexe Epitop-Analyse).

Neben dem multiplexen Grundprinzip der Epitop-Analyse, also der Annahme, dass mit „n“

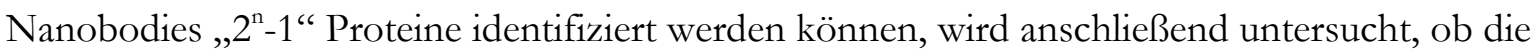
Epitop-Analyse auch als Ersatz anderer multiplexer Verfahren dienen kann. Multiplex bedeutet in diesem Fall, dass mehrere Proteine gleichzeitig während nur eines Versuchsdurchlaufs identifiziert werden.

Eine Überprüfung der Epitop-Analyse als multiplexes Verfahren setzt dabei Verhältnisse voraus, die eine solche Untersuchung überhaupt ermöglichen. Für diese Bedingungen soll eine 
Zelle erschaffen werden, die eine größere Anzahl an Proteinkonstrukten exprimieren kann. Zum einen soll untersucht werden, ob eine multitransfekte Zelle durch die Fusion von mehreren Ein-Transfekt-Zellen erschaffen werden kann. Die Fusion soll dabei mithilfe des HVJeVirus durchgeführt werden. Zum anderen soll eine auf dem Gibson-Assembly basierte Klonierung von zehn der 15 Plasmide durchgeführt werden. Dadurch kann die Zahl der zu transfizierenden Proteinkonstrukte reduziert werden. Als dritter Ansatz wird untersucht, ob eine Transfektion von multiplen Plasmiden in eine Zelle möglich ist.

Durch eine Kombination aus den drei zu untersuchenden Methoden sollen Zellen kreiert werden, die jeweils mehrere der designten Proteinkonstrukte exprimieren. Unter den geschaffenen Umständen soll anschließend die Verifizierung der auf Nanobodies basierenden EpitopAnalyse als ein multiplexes Verfahren autorisiert werden. 


\section{$2 \quad$ Material und Methoden}

In diesem Kapitel werden die untersuchten Zellkulturen, der experimentelle Ablauf sowie die für den Nachweis benötigten und in den Untersuchungen verwendeten Utensilien und Hilfsmittel beschrieben.

\subsection{Zellkultur: buman embryonic kidney (HEK)-293-Zellen}

Das für die Zellkultur verwendete Medium wurde aus Dulbecco's Modified Egale's Medium (DMEM mit 4,5 g/l Glukose) unter Zugabe von $10 \%$ fetal calf serum (FCS), $1 \%$ L-Glutamine und $1 \%$ Penicillin/Streptomycin hergestellt. Die HEK-293-Zellen wurden mit diesem Zellkulturmedium (P/S-Medium) auf 14,5 cm Zellkulturschalen im Inkubator bei $37^{\circ} \mathrm{C}, 5 \% \mathrm{CO}_{2}$ und $90 \%$ Luftfeuchtigkeit kultiviert.

Zum Passagieren wurden die Zellen nach der Entfernung des alten Mediums mithilfe von $3 \mathrm{ml}$ Trypsin/EDTA und leichtem Klopfen, von der Zellkulturschale gelöst. Anschließend wurden sie mit $9 \mathrm{ml} \mathrm{P} / \mathrm{S}$-Medium resuspendiert und zentrifugiert. Nach der Absaugung des Überstandes erfolgte eine erneute Resuspension in $1 \mathrm{ml}$ P/S-Medium. Daraufhin wurden die Zellen mit neuem Medium im Verhältnis von 1:9 (z. B. 2 ml Zell-Suspension in 18 ml Medium) auf neue sterile Zellkulturschalen verteilt. Die Zelldichte sollte eine Konfluenz von 80 \% nicht übersteigen. Hierbei waren regelmäßige Überprüfungen der Zelldichte sowie Kontrollen auf mögliche Kontaminationen mit Pilzen oder Bakterien notwendig. 


\subsection{Puffer und Lösungen}

Die in dieser Arbeit verwendeten Puffer und Lösungen sind in der Tabelle 1 aufgelistet.

Tabelle 1: Puffer und Lösungen sowie ihre Zusammensetzungen

\begin{tabular}{|c|c|}
\hline Puffer/Lösung & Zusammensetzung \\
\hline Anodenpuffer & $2 \mathrm{M}$ Tris mit $\mathrm{HCl}$ auf $\mathrm{pH} 8,9$ einstellen \\
\hline $\begin{array}{l}\text { DMEM (+) für HEK-293- } \\
\text { Zellen }\end{array}$ & $\begin{array}{l}10 \% \text { FCS, } 4 \text { mM L-Glutamine, } 60 \mathrm{U} / \mathrm{ml} \text { Penicillin und } \\
60 \mathrm{U} / \mathrm{ml} \text { Streptomycin in DMEM }\end{array}$ \\
\hline Fixierungsmittel & $0,2 \%$ Glutaraldehyd, $4 \%$ PFA in PBS \\
\hline Gelpuffer & 3 M Tris, $0,3 \%$ SDS, mit HCL auf $\mathrm{pH} 8,45$ einstellen \\
\hline bigh-salt-PBS & $500 \mathrm{mM} \mathrm{NaCl}, 20 \mathrm{mM} \mathrm{Na}_{2} \mathrm{PO}_{4}, \mathrm{pH} 7,4$ \\
\hline His-Lysepuffer & $\begin{array}{l}50 \mathrm{mM} \text { HEPES, } 500 \mathrm{mM} \mathrm{NaCl}, 4,5 \mathrm{mM} \mathrm{MgCl}_{2}, 30 \mathrm{mM} \text { Imid- } \\
\text { azol, pH 7,4 }\end{array}$ \\
\hline His-Elution & $\begin{array}{l}50 \mathrm{mM} \text { HEPES, } 500 \mathrm{mM} \mathrm{NaCl}, 4,5 \mathrm{mM} \mathrm{MgCl}{ }_{2}, 500 \mathrm{mM} \mathrm{Im-} \\
\text { idazol, pH 7,4 }\end{array}$ \\
\hline Kathodenpuffer & $\begin{array}{l}1 \mathrm{M} \text { Tris, } 1 \mathrm{M} \text { Tricin, } 1 \% \text { SDS, pH 8,25 (stellt sich von selbst } \\
\text { ein) }\end{array}$ \\
\hline Mowiol & $\begin{array}{l}\text { 9,6 g Mowiol 4-88 Reagent (Merck), } 24 \mathrm{~g} \text { Glycerol, 62,4 ml } \\
\text { destilliertes Wasser, 9,6 ml } 1 \text { M Tris, pH 8,5 }\end{array}$ \\
\hline Paraformaldehyde (PFA) & $4 \%$ PFA (Merck in PBS) \\
\hline $\begin{array}{l}\text { phosphatgepufferte Salzlö- } \\
\text { sung (PBS) }\end{array}$ & $\begin{array}{l}137 \mathrm{mM} \mathrm{NaCl}, 2,7 \mathrm{mM} \mathrm{KCl}, 10 \mathrm{mM} \mathrm{Na}_{2} \mathrm{HPO}_{2}, 2 \mathrm{mM} \\
\mathrm{KH}_{2} \mathrm{PO}_{4}, \mathrm{pH} 7,3\end{array}$ \\
\hline Permeabilization-Lösung & $0.1 \%$ Triton $\mathrm{X}-100$ in PBS \\
\hline Probenpuffer & $\begin{array}{l}50 \mathrm{mM} \text { Tris/HCl, } 4 \% \text { SDS, } 0,01 \% \text { Serva Blue G, } 12 \% \text { Glyc- } \\
\text { erol, } 2 \% \text { Mercaptoethanol, pH 6,8 }\end{array}$ \\
\hline Quenching-Lösung & $\begin{array}{l}100 \mathrm{mM} \mathrm{NH}_{4} \mathrm{Cl} \text { und } 100 \mathrm{mM} \text { Glycine in PBS oder } 100 \mathrm{mM} \\
\mathrm{NH}_{4} \mathrm{Cl}\end{array}$ \\
\hline $\begin{array}{l}\text { Super Optimal broth with Cata- } \\
\text { bolite repression (SOC)- } \\
\text { Medium }\end{array}$ & $\begin{array}{l}2 \% \text { Trypton, } 0,5 \% \text { Hefeextrakt, } 10 \mathrm{mM} \mathrm{NaCl}, 2,5 \mathrm{mM} \mathrm{KCl} \text {, } \\
10 \mathrm{mM} \mathrm{MgCl}_{2}, 20 \mathrm{mM} \text { Glukose }\end{array}$ \\
\hline $\begin{array}{l}10 \times \text { TRIS-Borat-EDTA- } \\
\text { (TBE)-Puffer }\end{array}$ & $\begin{array}{l}\text { 107,8 g Tris-Base, } 55 \mathrm{~g} \text { Borsäure, } 20 \mathrm{mM} \text { EDTA, auf } 1000 \mathrm{ml} \\
\text { doppelt destilliertes Wasser }\left(\mathrm{ddH}_{2} \mathrm{O}\right) \text { auffüllen, mit Phosphor- } \\
\text { säure auf } \mathrm{pH} 7,5 \text { einstellen }\end{array}$ \\
\hline
\end{tabular}




\subsection{Nanobodies}

Die in dieser Arbeit verwendeten Nanobodies sind in Tabelle 2 aufgelistet. Die drei GFPNanobodies 1H1B-5461, H2B-633 und FluoTag-Q anti-GFP-488 werden in diesem Projekt verallgemeinert als NbGFP bezeichnet.

Tabelle 2: Verwendete Nanobodies als Instrumente der auf Nanobodies basierenden EpitopAnalyse

\begin{tabular}{|l|l|l|}
\hline Nanobody & Epitop & Hersteller \\
\hline $\begin{array}{l}\text { 1H1B-546 } \\
\text { NbGFP) }\end{array}$ & GFP & $\begin{array}{l}\text { NanoTag Bio- } \\
\text { technologies }\end{array}$ \\
\hline $\begin{array}{l}\text { 1H2B-633 } \\
\text { NbGFP) }\end{array}$ & GFP & $\begin{array}{l}\text { NanoTag Bio- } \\
\text { technologie }\end{array}$ \\
\hline $\begin{array}{l}\text { FluoTag-Q anti- } \\
\text { GFP-488 } \\
\text { NbGFP) }\end{array}$ & GFP & $\begin{array}{l}\text { NanoTag Bio- } \\
\text { technologie }\end{array}$ \\
\hline LaM-2 & mCherry & Fridy et al. 2014 \\
\hline NbSyn2 & $\alpha$-Synuclein & $\begin{array}{l}\text { De Genst et al. } \\
2010\end{array}$ \\
\hline NbSyn87 & $\alpha$-Synuclein & $\begin{array}{l}\text { Gulliams et al. } \\
2013\end{array}$ \\
\hline
\end{tabular}

\subsection{Proteinreinigung}

Die Reinigung des Nanobody87 erfolgte aus dem SynNb87-Cys-Plasmid (C-Term Cystein on SynNb87) nach Anleitung der zugehörigen Protokolle (Guilliams et al. 2013; Conrath et al. 2001). Im ersten Schritt wurden die SynNb87-Cys-Plasmide in Shuffle-Bakterien transformiert, einem zu E. coli gehörenden Stock zur Proteinexpression. Die transformierten Plasmide waren mit einem Resistenzgen gegen Kanamycin sowie einem 14x-Polyhistidine-tag (His ${ }_{14}$-tag) am N-Terminus ausgestattet. Der His ${ }_{14}$-tag diente als Grundbaustein der nachfolgenden Reinigungsmethode. Diese beruht auf affinitäre tags, die an dem zu reinigenden Protein gekoppelt wurden. Die Hauptkultur wurde mit $100 \mathrm{ml}$ TB (terrific broth medium) und $100 \mu \mathrm{l}$ Kanamycin angeimpft und bei $30^{\circ} \mathrm{C}$ über Nacht bei ständiger Durchmischung proliferiert. Durch die Kultivierung in dem kanamycinhaltigen Medium konnte eine Auslese der resistenten Mikroorganismen gegenüber den Nativen erzielt werden. Zur Vervielfältigung der E. coli wurde die Vorkultur mit einem Medium bestehend aus 1:1000 TB und Kanamycin verdünnt und bei 25- 
$30{ }^{\circ} \mathrm{C}$ bis zu einer $\mathrm{OD}_{600}$ von 1-2 wachsen gelassen. Anschließend wurde die Kultur mit $1 \mathrm{mM}$ IPTG (Isopropyl- $\beta$-D-thiogalactopyranosid) induziert und über Nacht weiter kultiviert. IPTG wurde benutzt, um die erwünschten Proteine durch Expression von den klonierten Genen herzustellen. Nach dem Erreichen einer $\mathrm{OD}_{600}$ von 12 bis 15, wurde die Kultur abzentrifugiert (60 min) und in einem Lysepuffer resuspendiert. Der Aufschluss erfolgte nach der Zugabe von $1 \mathrm{mM}$ PMSF (Phenylmethylsulfonylfluorid) mittels einer dreimaligen Ultraschallbehandlung von $5 \mathrm{~s}$ mit dem SFX250 Sonifer Cell Disrupter (Branson Ultrasonics). PMSF wurde verwendet, um bei dem Aufschluss einen Proteinabbau durch ebenfalls im Lysat befindliche Proteasen zu verhindern. Anschließend wurde das Lysat für eine Stunde bei $4{ }^{\circ} \mathrm{C}$ mit $14000 \mathrm{Um}$ drehungen zentrifugiert und der Überstand gewonnen.

Die Reinigung erfolgte unter Verwendung der Protino ${ }^{\circledR}$ Ni-NTA (Nickel-Nitrilotriessigsäure) Ionenaustauschersäule (Macherey-Nagel, $5 \mathrm{ml}$ ) mit dem Reinigungssystem Äkta-Prime FPLC system (GE Healthcare, Schweden). Über eine immobilisierte Metallaffinitätschromatographie (immobilized metal affinity chromatography, IMAC) lässt sich mithilfe des fusionierten $\mathrm{His}_{14}$-tags das zu untersuchende Protein reinigen. Das Kation $\mathrm{Ni}^{2+}$ ist an die Agarosematrix mit NTA als Chelatligand gebunden. Von sechs möglichen Bindungsstellen sind vier von der NTA besetzt. Bei neutralem bis basischen $\mathrm{pH}$ liegen die Stickstoff-Atome der Imidazolringe der Histidine des $\mathrm{His}_{14}$-tag deprotoniert vor und können so koordinative Bindungen zu den restlichen freien Bindungstellen der $\mathrm{Ni}^{2+}$-Kationen eingehen. Da der pK-Wert von Histidin bei 6,0 liegt, wurde der Bindungsschritt bei einem $\mathrm{pH}$ von 8,0 durchgeführt. Die Elution erfolgte dagegen bei einem $\mathrm{pH}$ von unter 6,0, damit die daraufhin protonierten Histidin-Reste von der Ni-NTAMatrix abdissoziieren.

Die Äquilibrierung der Säule wurde zunächst mit einem His-Lysepuffer durchgeführt. Nach dem Laden der Probe in die Protino® Ni-NTA Ionenaustauschersäule konnten die Proteine mit einem $\mathrm{His}_{14}$-tag an die Säule gebunden werden. Alle anderen Anteile konnten ungehindert durchfließen. Die Elution der gebundenen Proteine wurde über einen Gradienten mit dem His-Elutionpuffer durchgeführt, bei dem Imidazol als Elutant diente. Das Imidazol verdrängt das His-tag-Protein von der Ni-NTA-Matrix. Der Puffer der eluierten Lösung wurde im letzten Schritt mithilfe einer Sephadex G-25 in PD-10 Desalting Column (GE Healthcare Life Sciences) durch PBS ersetzt. Anschließend wurde die Lösung auf eine SDS-PolyacrylamidGelelektrophorese (SDS-PAGE) aufgetragen (10\% Acrylamid, 15 min bei $70 \mathrm{~V}$ und $60 \mathrm{~min}$ bei 120 V), damit der Reinheitsgrad der enthaltenden Proteinfraktion analysiert werden konnte. 


\subsubsection{SDS-Page}

Die SDS-PAGE dient zur Auftrennung von Proteinen entsprechend ihrem Molekulargewicht (Laemmli 1970). Das ionische Detergenz Natriumdodecylsufat (SDS) dient der Denaturierung von Proteinen. Die SDS-Anionen binden an die Hauptketten der Proteine, wodurch die Proteine mit einer einheitlichen negativen Ladung versehen werden, die proportional zur Masse des jeweiligen Proteins ist. Die Auftrennung erfolgt so nur noch aufgrund des Molekulargewichts.

Die SDS-Page läuft in zwei Phasen. Zunächst wird die Probe im Sammelgel konzentriert und im Trenngel letztendlich nach ihrem Molekulargewicht aufgetrennt. Die SDS-Page wurde nach dem Protokoll von Hermann Schägger und Gerhard von Jagow (Schägger und von Jagow 1987) durchgeführt.

Der Probenpuffer (1 x) setzt sich aus $50 \mathrm{mM}$ Tris/HCl, $4 \%$ SDS, 0,01\% Serva Blue G, $12 \%$ Glycerol und $2 \%$ Mercaptoethanol zusammen ( $\mathrm{pH}$ 6,8). Die eingesetzte Gelmatrix besteht aus Polyacryamid, das durch die radikalische Reaktion aus Acrylamid und N,N'Methylenbisacrylamid entsteht. Die Reaktion wird durch den Zerfall von Ammoniumperoxidsulfat (APS) gestartet, welches in Lösung freie Radikale bildet. TEMED (N, N, N', N'Tetramethylethylendiamin) dient dabei als Katalysator.

Das polymerisierte Gel wurde in die Elektrophoresekammer eingespannt und die Anodenund Kathodenkammer mit den entsprechenden Puffern befüllt. Zur vollständigen Denaturierung der Proteine wurden je 9,75 $\mu$ l Proteinprobe (aus den Eluaten) mit 3,75 $\mu 14$ x Probenpuffer sowie $1,5 \mu \mathrm{l} 1 \mathrm{M}$ Dithiothreitol (DTT) versetzt und für $10 \mathrm{~min}$ bei $95{ }^{\circ} \mathrm{C}$ erhitzt. DTT diente dabei als Reduktionsmittel, welches die für die Tertiärstruktur wichtigen Schwefelbrücken zwischen Cystein-Resten reduziert und damit aufbricht. Zusätzlich wurden $5 \mu$ Marker in jedem Blot zur Größenbestimmung der Proteine verwendet. Die ersten 30 min betrug die Laufzeit $90 \mathrm{~V}$, die nächsten 30 min wurde die Volt-Zahl auf $120 \mathrm{~V}$ erhöht.

In Tabelle 3 und sind die Bestandteile und Mengenabgaben des Trenn- und Sammelgels aufgeführt. 
Tabelle 3: Mengenbestandteile des Trenngels (12,5\%)

\begin{tabular}{|l|l|}
\hline Zusammensetzung & Mengenangabe \\
\hline $\begin{array}{l}\text { Monomerlösung }(30 \% \text { Acrylamid, } \\
0,8 \% \text { Bisacryamid) }\end{array}$ & $1,66 \mathrm{ml}$ \\
\hline Trenngelpuffer & $1,675 \mathrm{ml}$ \\
\hline $50 \%$ Glycerin & $1,06 \mathrm{ml}$ \\
\hline $\mathrm{ddH}_{2} \mathrm{O}$ & $570 \mu \mathrm{l}$ \\
\hline APS $(10 \%)$ & $25 \mu \mathrm{l}$ \\
\hline TEMED & $3 \mu \mathrm{l}$ \\
\hline
\end{tabular}

Tabelle 4: Mengenbestandteile des Sammelgels (4\%)

\begin{tabular}{|l|l|}
\hline Zusammensetzung & Mengenangabe \\
\hline $\begin{array}{l}\text { Monomerlösung }(30 \% \text { Acrylamid, } \\
0,8 \% \text { Bisacryamid) }\end{array}$ & $200 \mu \mathrm{l}$ \\
\hline Sammelgelpuffer & $375 \mu \mathrm{l}$ \\
\hline $50 \%$ Glycerin & - \\
\hline dd $_{2} \mathrm{O}$ & $925 \mu \mathrm{l}$ \\
\hline APS $(10 \%)$ & $10 \mu \mathrm{l}$ \\
\hline TEMED & $2 \mu \mathrm{l}$ \\
\hline
\end{tabular}

\subsubsection{Coomassie-Färbung}

Nach erfolgreich durchgeführter SDS-Page konnte das Sammelgel entfernt und das Trenngel über Nacht in $50 \%$ Methanol, $10 \%$ Essigsäure und 0,2\% Coomassie Brilliant Blue R-250 unter ständiger Durchmischung gefärbt werden. Die Färbung beruht auf der reversiblen Anlagerung des Farbstoffs an Amino-Gruppen $\left(-\mathrm{NH}_{2}\right)$ der Proteine. Für die Anlagerung wird ein saures Milieu benötigt. Der Farbstoff-Protein-Komplex wird dabei durch ionische Wechselwirkungen und Van der Waals Kräfte gebildet. Anschließend wurde das Gel in $50 \%$ (Vol-\%) 
Methanol, $10 \%$ Essigsäure und $40 \% \mathrm{H}_{2} \mathrm{O}$ so lange entfärbt, bis nur noch die Protein-Bänder zu erkennen waren.

\subsection{Transfektion}

Die Transfektion von HEK-293-Zellen erfolgte mit dem Kit Lipofectamine TM 2000 Transfection Reagenz. Bei dieser Methode bilden die kationischen Lipiden im wässrigen Milieu Mizellen oder Lipsomen, mit denen die DNA komplexiert. Die gebildeten DNA-LipidKomplexe werden endozytotisch aufgenommen und nach dem Zerfall des Endosoms gelangt die DNA schließlich in das Zytoplasma.

Um HEK-293-Zellen zu transfizieren, wurden die zu $80 \%$ konfluenten Zellen in einem nichtantibiotischen Transfekt-Medium gesplittet (s. Kapitel 2.1) und in well-Platten mit $24 \mathrm{~mm} \emptyset$ Deckgläser ausgesät werden. Nach der Inkubation über Nacht (max. 48 h) bei $37^{\circ} \mathrm{C}$ und $5 \%$ $\mathrm{CO}_{2}$ waren die Zellen ausreichend angewachsen, um mit der Transfektion zu beginnen. Der erste Schritt beinhaltete pro well eine Vermengung von DNA und Lipofectamine im Verhältnis von 1:1,5 mit jeweils $50 \mu \mathrm{l}$ OptiMEM und einer anschließenden fünfminütigen Einwirkungszeit. Danach wurde die Lipofectamine-OptiMEM-Lösung langsam mit der DNA-OptiMEMLösung vereint und es fand eine weitere Inkubationszeit von 20 min bei Raumtemperatur statt. Anschließend wurden pro well einer 12-well-Platte jeweils $100 \mu \mathrm{l}$ des Transfektionsansatzes tröpfchenweise dazu pipettiert. 


\subsubsection{Plasmide für die Vorexperimente bzw. für den Funktionstest}

Die in dieser Kontrollphase verwendeten Plasmide sind in der Tabelle 5 aufgelistet.

Tabelle 5: Verwendete Plasmide für Voruntersuchungen

\begin{tabular}{|l|l|l|}
\hline Kodierungssequenz & Vektor & Hersteller \\
\hline$\alpha$-Synuclein-HA & pcDNA3.1 & Thermo Fisher Scientific \\
\hline Hum WT $\alpha$-Synuclein & pcDNA3.1 & Thermo Fisher Scientific \\
\hline $\begin{array}{l}\text { Hum } \alpha \text {-Synuclein- } \\
\text { mCherry }\end{array}$ & pcDNA3.1 & Thermo Fisher Scientific \\
\hline mCherry & N1 & Clontech \\
\hline SNAP25-GFP & pcDNA3.1 & Thermo Fisher Scientific \\
\hline TOM70-EGFP & N1 & Clontech \\
\hline
\end{tabular}

\subsection{Fusion: Suspensions-Methode}

Zunächst wurden die in den 12-well-Platten mit $24 \mathrm{~mm} \emptyset$-Deckgläser zu $70 \%$ konfluierten Zellen transfiziert (s. Kapitel 2.5). 24 Stunden später konnte mit dem Fusions-Experiment begonnen werden. Die Zellen wurden zunächst einmal mit PBS gewaschen, anschließend in kaltem Medium gesammelt und je nach Art der Transfektion in unterschiedliche Falcons verteilt. Nach einer 5 min Zentrifugierung bei $4{ }^{\circ} \mathrm{C}$ mit 1000 Umdrehungen wurde das Zellpellet in einem Fusionbuffer (1:20 verdünnt mit destilliertem Wasser) resuspendiert. Danach wurden diejenigen Zelllinien, die später fusionieren sollten, in einem neuen Falcon miteinander gemischt und es wurde die passende Menge an HVJe-Virus (Lamb und Kolakofsky 1996) hinzugegeben. Nach einer 15 minütigen Lagerung auf Eis wurde anschließend mit 2000 Umdrehungen/min bei $4{ }^{\circ} \mathrm{C}$ zentrifugiert. Daraufhin erfolgte eine Inkubation bei $37^{\circ} \mathrm{C}$ für $15 \mathrm{~min}$, während der alle 5 min das Pellet durch manuelles Klopfen gegen das Falcon leicht durchmischt wurde. Anschließend fand eine erneute Zentrifugierung mit 1000 Umdrehungen/min bei Raumtemperatur statt. Im letzten Schritt wurden die verschiedenen Zell-Virus-Mischungen mit $500 \mu \mathrm{l}$ Medium pro well resuspendiert und erneut ausgesät. Nach zwölf Stunden konnten die Zellen fixiert werden. 


\subsection{Färbungsprotokolle}

\subsubsection{Fluorophor-Kopplung}

Das verwendete Protokoll beruhte auf dem Verfahren der Maleimid-Markierung von Proteinen. Die verwendeten Fluorophore sind auf Maleimid-Basis. Das Grundprinzip der Kopplung beruht darauf, dass die Maleimide eine hohe Selektivität für Thiole aufwiesen. Die Thiole waren in den Nanobodies in Form freier Cysteinreste vertreten.

Der erste Schritt für die Kopplung beinhaltete eine 15-minütige Mischung einer $30 \mathrm{nmol} \mathrm{Na-}$ nobody-Lösung mit einer 3000 nmol TCEP-Lösung. So bestand ein Überschuss (100 x) an Tris-2-chlorethyl-posphat (TCEP). Das TCEP diente zur Reduzierung der Disulfidbrücken der Proteine und bildete stattdessen freie Cysteinreste. Anschließend wurde die Nb-TCEPLösung mithilfe einer zuvor dreifach mit PBS equilibrierten Sephadex G-25 in PD-10 Desalting Column (GE Healthcare Life Sciences) entsalzt. Da mindestens $500 \mu \mathrm{l}$ Flüssigkeit zugegeben werden sollte, musste gegebenenfalls der Restbetrag mit PBS aufgefüllt werden. Bei einer NbTCEP-Lösung von $500 \mu \mathrm{l}$ wurde nachträglich $1 \mathrm{ml}$ PBS auf die Kolumne gegeben. Im letzten Schritt konnte $1 \mathrm{ml}$ der verdünnten Nb-TCEP-Lösung nach Durchlauf durch die Kolumne aufgefangen werden.

Die aufgefangene Lösung wurde mit einem Fluorophor gemischt, der in einer drei- bis vierfach so hohen Mol-Konzentration vorlag. Das Mischen erfolgte abgedunkelt für 45 min bei Raumtemperatur.

In der Zwischenzeit wurde eine neue Säule mit Sephadex G-25-Pulver vorbereitet, welche zur Trennung des freien vom gebundenen Farbstoff diente. Dazu wurde $5 \mathrm{ml}$ Sephadex G-25Pulver mit $50 \mathrm{ml}$ PBS in einem Falcon vermengt und anschließend auf einem Rotator durchmischt. Die Sephadex G-25-PBS-Lösung wurde anschließend in eine leere Säule gefüllt und unter Druck verdichtet. Nach beendeter Mischzeit von 45 min wurde zunächst die mit Fluorophoren gekoppelte Nb-TCEP-Lösung auf die gefüllte, verdichtete Säule getropft. Anschließend wurde die Säule mit mindestens $1 \mathrm{ml}$ PBS aufgefüllt. Während des Durchlaufes entstanden zwei separate Bänder. Da die Auftrennung anhand des Molekulargewichts erfolgte, enthielt das tiefere Band die gefärbten Nanobodies. Die Lösung wurde in einem kleinen Gefäß (Eppendorf) aufgefangen, eins zu eins mit Glycerol verdünnt und anschließend bei $-20{ }^{\circ} \mathrm{C}$ gelagert.

In der Tabelle 6 sind die verwendeten Fluorophore für die Kopplung mit Nanobodies aufgelistet. 
Tabelle 6: Fluorophore für die Markierung von Nanobodies

\begin{tabular}{|l|l|l|}
\hline Farbstoff & Fluoreszenz & Hersteller \\
\hline Alexa Fluor 488 C Maleimide & $\lambda_{\mathrm{ex}} 493 \mathrm{~nm} ; \lambda_{\mathrm{em}} 516 \mathrm{~nm}$ & ThermoFisher Scientific \\
\hline Alexa Fluor ${ }^{\mathrm{TM}} 546 \mathrm{C}_{5}$ Maleimide & $\lambda_{\text {ex }} 554 \mathrm{~nm} ; \lambda_{\mathrm{em}} 570 \mathrm{~nm}$ & ThermoFisher Scientific \\
\hline AMCA C2 Maleimide & $\lambda_{\mathrm{ex}} 353 \mathrm{~nm} ; \lambda_{\mathrm{em}} 455 \mathrm{~nm}$ & AAT Bioquest \\
\hline CF 350 Maleimide & $\lambda_{\mathrm{ex}} 347 \mathrm{~nm} ; \lambda_{\mathrm{em}} 448 \mathrm{~nm}$ & SIGMA-Aldrich \\
\hline CF 633 Maleimide & $\lambda_{\mathrm{ex}} 630 \mathrm{~nm} ; \lambda_{\mathrm{em}} 650 \mathrm{~nm}$ & SIGMA-Aldrich \\
\hline Dylight 405 Maleimide & $\lambda_{\mathrm{ex}} 400 \mathrm{~nm} ; \lambda_{\mathrm{em}} 420 \mathrm{~nm}$ & ThermoFisher Scientific \\
\hline
\end{tabular}

\subsubsection{Indirekte Immunzytochemie (Antikörperfärbung)}

Die Methode der indirekten Immunzytochemie wurde mit Antikörpern durchgeführt.

Die transfizierten und/oder fusionierten Zellen wurden nach einer Inkubation von zwölf Stunden mit angewärmten PBS gewaschen und anschließend 30 Minuten in $4 \%$ Paraformaldehyd (PFA) fixiert. Da die Permeabilität der Membran in einem späteren Schritt für Antikörper erhöht wurde, gewährleistete die Anwendung von PFA eine stabile Form der Zelle. So sollte ein Austreten des Zellinneren in das Medium verhindert werden. Nach dem Entfernen des PFAs erfolgte eine 15-minütige Inkubation in einer Quenching-Lösung $\left(\mathrm{NH}_{4} \mathrm{Cl}\right)$. Aufgrund der Behandlung mit $\mathrm{NH}_{4} \mathrm{Cl}$ konnten die Aldehyd-Gruppen des PFAs reduziert werden. Dadurch wurde sichergestellt, dass nur möglichst geringe Restbeträge an PFA hinterbleiben. Anschließend wurden die Zellen dreimal mit PBS gewaschen.

Die erhöhte Permeabilität wird durch die Zugabe von 0,1\% Triton X-100 hervorgerufen. Dieses war in einem frisch zubereiteten Blocking Buffer enthalten. Für die Herstellung des Blocking Buffers für eine 12-wvell-Platte wurde $30 \mathrm{ml}$ PBS + 0,1 \% Triton X-100 mit 0,6 g BSA miteinander vermischt. Nach Entfernung des PBS, wurden die Zellen das erste Mal ohne, das zweite Mal mit einer Inkubationszeit von 15 min auf einer Rotationsplatte mit dem Blocking Buffer gewaschen. In der Zwischenzeit konnte die erste Antikörper-Lösung vorbereitet werden. Für eine 12-well-Platte benötigt man 1,3 ml total, bestehend aus $50 \%$ PBS, 50 \% Blocking Buffer sowie dem ersten Antikörper (Verdünnungsangaben s. Tabelle 7). Der Epitopspezifische Antikörper, der an das zu untersuchende Protein band, war in der indirekten Immunfluoreszenz unmarkiert, also nicht mit einem Fluorophor versehen. Die auf den Deck- 
gläschen fixierten Zellen wurden nun jeweils in $95 \mu$ der Lösung für eine Stunde in einer abgedunkelten Kammer auf der Rotationsplatte inkubiert. Nach dreimaligem Waschen mit PBS und einer anschließenden Inkubationszeit von 10 min wurde die zweite Antikörper-Lösung zubereitet. Die Zubereitung entsprach der ersten Antikörper-Lösung. Die fixierten Zellen wurden in der zweiten Antikörper-Lösung für 45 min im Dunkeln inkubiert. Die Färbung erfolgte in diesem Schritt, bei dem ein zweiter markierter Antikörper aufgebracht wird, der spezifisch an den ersten Antikörper band. Anschließend wurde dreimal mit PBS gewaschen und danach für $10 \mathrm{~min}$ in high-salt-PBS auf der Rotationsplatte inkubiert, um möglichst alle ungebundenen Antikörper zu entfernen. Im letzten Schritt wurde nochmal mit PBS gewaschen.

Zum Schluss erfolgte die Befestigung der Deckgläschen auf Objektträger mittels Mowiol. Nach einer Trocknungszeit von 30 min bei $37^{\circ} \mathrm{C}$ wurden die fertigen Gläschen bei $4{ }^{\circ} \mathrm{C}$ gelagert.

Die für die indirekte Immunzytochemie verwendeten Antikörper und die angewendeten Verdünnungen sind in Tabelle 7 aufgelistet. 
Tabelle 7: Antikörper und die angewendete Verdünnung

\begin{tabular}{|l|l|l|l|l|}
\hline Antikörper & Zielprotein & Wirt & Anwendung & Hersteller \\
\hline Anti- $\alpha$-Tubulin & $\alpha$-Tubulin & Rabbit monoclonal & ICC 1:300 & Synaptic Systems \\
\hline Anti- $\alpha$-Synuclein & $\alpha$-Synuclein & Rabbit polyclonal & ICC 1:500 & Synaptic Systems \\
\hline Anti-Beta-Actin & Beta-Actin & Mouse polyclonal & ICC 1:75 & Sigma-Aldrich \\
\hline Anti-Endobrevin & Endobrevin & Rabbit polyclonal & ICC 1:300 & Synaptic Systems \\
\hline Anti-GM130 & GM130 & Rabbit polyclonal & ICC 1:300 & Sigma-Aldrich \\
\hline $\begin{array}{l}\text { Anti-HA-Tag- } \\
\text { C29F4 }\end{array}$ & $\begin{array}{l}\text { HA-Tag } \\
\text { C29F4 }\end{array}$ & Rabbit monoclonal & ICC 1:1000 & $\begin{array}{l}\text { Cell Signaling } \\
\text { Technologie }\end{array}$ \\
\hline Anti-KDEL & KDEL & Rabbit polyclonal & ICC 1:500 & Enzolifesciences \\
\hline $\begin{array}{l}\text { Anti-mouse-IgG- } \\
\text { Cy5 }\end{array}$ & $\begin{array}{l}\text { mouse } \\
\text { IgG Cy5 }\end{array}$ & Donkey & ICC 1:500 & Dianova \\
\hline $\begin{array}{l}\text { Anti-rabbit-IgG- } \\
\text { Cy5 }\end{array}$ & $\begin{array}{l}\text { rabbit } \\
\text { IgG Cy5 }\end{array}$ & Donkey & ICC 1:500 & Dianova \\
\hline Anti-SNAP25 & SNAP25 & Rabbit polyclonal & ICC 1:500 & Synaptic Systems \\
\hline Anti-Syntaxin 4 & Syntaxin 4 & Rabbit polyclonal & ICC 1:300 & Synaptic Systems \\
\hline Anti-Syntaxin 6 & Syntaxin 6 & Mouse polyclonal & ICC 1:500 & Synaptic Systems \\
\hline Anti-Syntaxin 7 & Syntaxin 7 & Rabbit polyclonal & ICC 1:300 & Synaptic Systems \\
\hline Anti-VAMP 4 & VAMP 4 & Rabbit polyclonal & ICC 1:300 & Synaptic Systems \\
\hline Anti-Vti1a & Vti1a & Rabbit polyclonal & ICC 1:500 & Synaptic System \\
\hline
\end{tabular}




\subsubsection{Direkte Immunzytochemie (Nanobody-Färbung)}

Die Methode der direkten Immunzytochemie erfolgte mit Nanobodies, die direkt an Fluorophore gekoppelt waren. Die verwendeten Nanobodies und ihre angewendeten Verdünnungen sind in Tabelle 8 aufgelistet.

Tabelle 8: Nanobodies und die angewendete Verdünnung

\begin{tabular}{|l|l|l|}
\hline fluoreszierender Nanobody & Epitop & Anwendung \\
\hline 1H1B-546 & GFP & ICC 1:500 \\
\hline 1H2B-633 & GFP & ICC 1:500 \\
\hline 1H1-488 & GFP & ICC 1:500 \\
\hline LaM-2-AMCA & mCherry & ICC 1:100 \\
\hline LaM-2-488 & mCherry & ICC 1:200 \\
\hline LaM-2-546 & mCherry & ICC 1:100 \\
\hline NbSyn2-AMCA & syn2 & ICC 1:50 \\
\hline NbSyn2-488 & syn2 & ICC 1:200 \\
\hline NbSyn2-633 & syn2 & ICC 1:50 \\
\hline NbSyn2-Dylight405 & syn2 & ICC 1:50 \\
\hline NbSyn2-AMCA & syn87 & ICC 1:50 \\
\hline NbSyn87-488 & syn87 & ICC 1:200 \\
\hline NbSyn87-633 & syn87 & ICC 1:50 \\
\hline NbSyn87-Dylight405 & ICC 1:50 \\
\hline
\end{tabular}

\subsubsection{Simultane Färbungsmethode}

Das Protokoll der simultanen Färbungsmethode der direkten Immunfärbung entsprach zum größten Teil dem Verfahren der indirekten Immunzytochemie (s. Kapitel 2.7.2). Die einzige Abweichung in der Vorgehensweise lag darin, dass nur die erste Inkubationszeit (60 min) mit 
den jeweiligen Nanobodies notwendig war. Anschließend konnte die abwechselnde Waschung und Inkubation mit PBS und high-salt-PBS durchgeführt werden.

\subsubsection{Sequenzielle Färbungsmethode}

Die Fixierung der transfizierten und/oder fusionierten Zellen entspricht dem Protokoll der indirekten Immunfärbung. Das Objektgläschen mit den fixierten Zellen wurde in eine live imaging-Kammer übertragen, die anschließend mit einem hergestellten Blocking Buffer gefüllt wurde. Das Mischungsverhältnis des Blocking Buffers entsprach dem der direkten Immunfärbung. Der nächste Schritt beinhaltete die Bleichung ausgewählter Zellen mittels des AXIO LSM710. Daraufhin konnte die Lösung für die erste Nanobody-Färbung aus $50 \%$ PBS und $50 \%$ Blocking Buffer (1 ml total) und dem jeweiligen Nanobody hergestellt werden (s. Tabelle 8). Der Blocking Buffer wurde aus der Live Imaging-Kammer pipettiert, die daraufhin mit der hergestellten Nanobody-Lösung gefüllt wurde. Es folgte eine Inkubation von 60 min. Nach Ablauf der Inkubationszeit wurden mit dem AXIO LSM710 die vor der Nanobodyfärbung gebleichten Zellen auf dem Coverslip in den Fokus gestellt. Aufgrund einer spezifischen Anregung entsprechend dem für die Färbung verwendeten fluoreszierenden Nanobody konnten die entsprechenden Signale aufgenommen werden. Daraufhin wurden die zuvor gebleichten bzw. danach gefärbten Zellen erneut gebleicht.

Anschließend konnte mit der nächsten Nanobodyfärbung begonnen werden, indem aus der Kammer die „alte“ Nanobodylösung herauspipettiert wurde und diese dreimal mit PBS gewaschen wurde. Daraufhin konnte eine neu hergestellte Nanobodylösung (50 \% PBS und 50 \% Blocking Buffer + Nanobody) hinein pipettiert werden. Der weitere Ablauf der zweiten (bis vierten) Nanobodyfärbung entsprach dem der ersten Nanobodyfärbung. Nach der letzten erfolgten Färbung wurde das Objektgläschen entsorgt und die Kammer gereinigt.

\subsubsection{Konfokales Laser-Scanning-Mikroskop}

Die mit den konfokalen Mikroskopen LSM510 und dem AXIO LSM710 von Zeiss aufgenommenen Bilder (1024 x 1024) hatten eine Pixelgröße von 0,140 $\mu \mathrm{m}$. Die verwendeten Setups sind in der Tabelle 9 und in der Tabelle 10 dargestellt. 
Tabelle 9: Zeiss LSM510

\begin{tabular}{|l|l|l|}
\hline \multicolumn{1}{|c|}{ Laser } & \multicolumn{1}{c|}{ Anregungswellenlänge } & \multicolumn{1}{c|}{ Filter } \\
\hline Argon $/ 2(30 \mathrm{~mW})$ & $458 \mathrm{~nm}, 477 \mathrm{~nm}, 488 \mathrm{~nm}, 514 \mathrm{~nm}$ & BP $505-550 \mathrm{~nm}$ \\
\hline HeliumNeon1 $(1 \mathrm{~mW})$ & $543 \mathrm{~nm}$ & BP $560-615 \mathrm{~nm}$ \\
\hline HeliumNeon2 $(5 \mathrm{~mW})$ & $633 \mathrm{~nm}$ & LP $650 \mathrm{~nm}$ \\
\hline
\end{tabular}

Tabelle 10: Zeiss AXIO LSM710

\begin{tabular}{|l|l|l|}
\hline \multicolumn{1}{|c|}{ Laser } & \multicolumn{1}{|c|}{ Anregungswellenlänge } & \multicolumn{1}{c|}{ Filter } \\
\hline Argon $/ 2(30 \mathrm{~mW})$ & $458 \mathrm{~nm}, 477 \mathrm{~nm}, 488 \mathrm{~nm}, 514 \mathrm{~nm}$ & BP 420-480 \\
\hline Diode $405-30(30 \mathrm{~mW})$ & $405 \mathrm{~nm}$ & LP 505 \\
\hline HeliumNeon543 $(1,2 \mathrm{~mW})$ & $543 \mathrm{~nm}$ & LP 560 \\
\hline HeliumNeon633 $(5 \mathrm{~mW})$ & $633 \mathrm{~nm}$ & LP 650 \\
\hline
\end{tabular}

\subsubsection{Olympus-Konfiguration}

Für die meisten Standardanwendungen wurde ein invertes Olympus IX71-Mikroskop verwendet, das mit einer F-View II CCD Kamera ausgestattet war. Die aufgenommen Bilder (1376 x 072 pixel) hatten eine Pixelgröße von 6,45 $\mu \mathrm{m}$. Die benutzten Objektive und die jeweilige Spezifierung sind Tabelle 11 aufgelistet.

Tabelle 11: Objektivspezifizierung

\begin{tabular}{|c|c|c|c|}
\hline Größe & $\begin{array}{c}\text { Nummerische } \\
\text { Apperatur }\end{array}$ & Immersionstyp & Linse \\
\hline $60 \mathrm{x}$ & 1,4 & Öl & UPlanSApo \\
\hline $20 \mathrm{x}$ & 1,4 & Luft & UPlanSApo \\
\hline
\end{tabular}


2.7.5.1 Das Prinzip der Epifluoreszenzmikroskopie

Bei der Epifluoreszenzmikroskopie handelt es sich um ein Spezialverfahren der Lichtmikroskopie, bei der das zu untersuchende Präparat über dem Vergrößerungsobjektiv sitzt und von basal bestrahlt wird. Das Präparat wurde mit bestimmten Fluorophoren beladen, die die Eigenschaft der Fluoreszenz besitzen. Die Fluorophore wurden mit einem Licht einer bestimmten Wellenlänge bestrahlt (kurzwelliges, energiereiches Anregungslicht), welches von ihnen absorbiert wurde. Anschließend erfolgte die Emission eines langwelligen, energieärmeren Lichtes. Mit der angeschlossenen Messapparatur war es möglich, diese Fluoreszenzstrahlung zu messen.

\subsection{Aufbau der designten Proteinkonstrukte}

Die Proteinkonstrukte bestehen jeweils aus einem Protein und einer bestimmten Kombination von bis zu vier Epitopen, die gemeinsam an das Protein gekoppelt wurden. Bei den Epitopen handelt es sich um ein GFP-, ein mCherry-, ein syn87- und ein syn2-Epitop. Die Epitope stellen jeweils die antigene Determinante für einen der vier Nanobodies dar. Die Epitope sind untereinander sowie mit dem Protein über einen Linker (L) miteinander verbunden. Jedes Konstrukt unterscheidet sich in seinem Protein sowie in der Anzahl und der Kombination der angehängten Epitope. Jedes Proteinkonstrukt ist so durch einen einzigartigen Epitop-Satz markiert. In Tabelle 12 ist die Struktur der 15 konstruierten Proteine dargestellt. 
Tabelle 12: Proteine mit verschiedenen Epitop-Kombinationen

\begin{tabular}{|l|l|l|l|l|}
\hline \multicolumn{1}{|c|}{ Protein } & $\begin{array}{c}\text { Epitop 1 } \\
\text { GFP-Nb }\end{array}$ & $\begin{array}{c}\text { Epitop 2 } \\
\text { LAM2-Nb }\end{array}$ & $\begin{array}{c}\text { Epitop 3 } \\
\text { Nb-87 }\end{array}$ & \multicolumn{1}{|c|}{$\begin{array}{c}\text { Epitop 4 } \\
\text { Nb-2 }\end{array}$} \\
\hline Endobrevin & GFP & & Syn87 & Syn2 \\
\hline VAMP 4 & GFP & mCherry & Syn87 & Syn2 \\
\hline Syntaxin 4 & & & Syn87 & \\
\hline Vti1a & & mCherry & & Syn2 \\
\hline SNAP25 & GFP & & Syn87 & \\
\hline GalNact & GFP & & & Syn2 \\
\hline Syntaxin 7 & GFP & & Syn87 & Syn2 \\
\hline Syntaxin 6 & & mCherry & & Syn2 \\
\hline Lifeact & & mCherry & Syn87 & Syn2 \\
\hline Syntaxin 13 & & mCherry & & Syn2 \\
\hline NLS & GFP & mCherry & Syn87 & \\
\hline KDEL & GFP & GFP & & \\
\hline & & mCherry & & \\
\hline Tom 70 & & & & \\
\hline
\end{tabular}

\subsection{Polymerase-Kettenreaktion (PCR)}

Die PCR ist eine In-vitro-Technik zur Amplifikation definierter DNA-Sequenzen. Die Spezifität der Methode beruht auf der Komplementarität der Primer zu bestimmten Zielsequenzen. Die PCR-Prozedur beinhaltet das wiederholte Aufschmelzen der Doppelstrang-DNA (Denaturierung), die Anlagerung der Primer (annealing) und die Neusynthese des zur Matrize komplementären DNA-Strangs (elongation). Dadurch wird theoretisch eine exponentielle Konzentrationszunahme der gewünschten DNA-Sequenz erreicht (Saiki et al. 1985). In dieser Arbeit diente die PCR zur Vervielfältigung der Proteinkonstrukte. Die Amplifizierung war die Voraussetzung zur anschließenden Durchführung des Gibson Assemblys.

Fünf Proteinkonstrukte sollten als Vektoren und fünf weitere Konstrukte als deren Inserts dienen. Es wurden spezielle Primer designt, damit die erwünschten Vektoren und Inserts mit komplementären überhängenden Regionen vervielfältigt werden konnten. Oligo 7 demo (Molecular Biology Insights, Inc. Cascade, CO, USA) wurde zur Bestimmung der Hybridisierungstemperatur $\left(\mathrm{T}_{\mathrm{m}}\right)$ sowie zur Analyse von hairpin- und duplex-Strukturen verwendet. 
Die verwendeten Primer für die PCR der Vektoren und Inserts sind in Tabelle 13 und in Tabelle 14 aufgelistet.

Tabelle 13: Vektoren und Primer-Sequenzen

\begin{tabular}{|l|l|l|}
\hline Vektoren & Vorwärts-Primers & Rückwärts-Primers \\
\hline $\begin{array}{l}\text { Endobrevin_GFP_ } \\
\text { Syn87_Syn2 }\end{array}$ & TGGCGGCCGCTCGAGACC & CTGTGCTGGATATCTGCA \\
\hline $\begin{array}{l}\text { Lifeact_mCherry_ } \\
\text { Syn2 }\end{array}$ & TGGCGGCCGCTCGAGACC & CTGTGCTGGATATCTGCA \\
\hline $\begin{array}{l}\text { NLS_GFP_mCherry_ } \\
\text { Syn2 }\end{array}$ & TGGCGGCCGCTCGAGACC & CTGTGCTGGATATCTGCA \\
\hline $\begin{array}{l}\text { Syntaxin6_Syn87_ } \\
\text { Syn2 }\end{array}$ & TGGCGGCCGCTCGAGACC & CTGTGCTGGATATCTGCA \\
\hline Syntaxin7_GFP_Syn2 & TGGCGGCCGCTCGAGACC & CTGTGCTGGATATCTGCA \\
\hline
\end{tabular}

Tabelle 14: Inserts und Primer-Sequenzen

\begin{tabular}{|l|l|l|}
\hline \multicolumn{1}{|c|}{ Inserts } & \multicolumn{1}{c|}{ Vorwärts-Primer } & \multicolumn{1}{c|}{ Rückwärts-Primer } \\
\hline GalNact_GFP_Syn87 & $\begin{array}{l}\text { TGCAGATATCCAGCACA- } \\
\text { GAT- } \\
\text { GCGGCGGCGCTCGCGG }\end{array}$ & $\begin{array}{l}\text { GGTCTCGAGCGGCCGCCA } \\
\text { GTCTTGATACCCTTCCT- } \\
\text { CAGAAGGCATTCA- } \\
\text { TAAGCCTCATTGTCAGG }\end{array}$ \\
\hline $\mathbf{G F P}$ & $\begin{array}{l}\text { TGCAGATA- } \\
\text { TCCAGCACAGGCCACCA- } \\
\text { TGGTGAGCAAG }\end{array}$ & $\begin{array}{l}\text { GGTCTCGAGCGGCCGCCA } \\
\text { CTTGTACAGCTCGTCCATG }\end{array}$ \\
\hline $\begin{array}{l}\text { SNAP25_GFP_ } \\
\text { mCherry }\end{array}$ & $\begin{array}{l}\text { TGCAGATA- } \\
\text { TCCAGCACAGGCCACCA- } \\
\text { TGGTGAGCAAGG }\end{array}$ & $\begin{array}{l}\text { GGTCTCGAGCGGCCGCCA } \\
\text { ACCACTTCCCAGCCGGGC }\end{array}$ \\
\hline Syntaxin4_Syn87 & $\begin{array}{l}\text { TGCAGATA- } \\
\text { TCCAGCACAGGCCACCA- } \\
\text { TGCGCGACAGG }\end{array}$ & $\begin{array}{l}\text { GGTCTCGAGCGGCCGCCA } \\
\text { GTCTGATACCCTTCCT- } \\
\text { CAGAAGGC }\end{array}$ \\
\hline TOM70_mCherry & $\begin{array}{l}\text { TGCAGATA- } \\
\text { TCCAGCACAGGCCACCA- } \\
\text { TGAAGAGCTTC }\end{array}$ & $\begin{array}{l}\text { GGTCTCGAGCGGCCGCCA } \\
\text { CTTGTACAGCTCGTCCATG }\end{array}$ \\
\hline
\end{tabular}




\subsubsection{PCR-Ansätze und -Programme}

Bei den PCR-Reaktionen wurden $100 \mu \mathrm{l}$ PCR-Ansätze pro Genkonstrukt verwendet, die entsprechend dem PCR Master Mix KIT (Q5 Biolabs) zusammengesetzt waren:

$20 \mu \mathrm{l} \mathrm{Q}$ Reaction Buffer, $2 \mu \mathrm{l}$ dNTPs, $20 \mu \mathrm{l}$ Enhancer, $45 \mu \mathrm{l}$ autoklaviertes Wasser, jeweils $5 \mu \mathrm{l}$ des Vorwärts- und Rückwärtsprimers, $10 \mathrm{ng}$ der zu vervielfältigenden DNA und $1 \mu \mathrm{l} \mathrm{Q}_{5}{ }^{-}$ Enzym.

Die angewendeten Parameter für die Durchführung der PCR sind in Tabelle 15 aufgelistet.

Tabelle 15: Parameter des PCR-Protokolls

\begin{tabular}{|c|c|c|c|}
\hline Schritte & PCR Protokoll & Vektoren & Inserts \\
\hline 1. & Aufheizen & 30 s bei $98^{\circ} \mathrm{C}$ & 30 s bei $98^{\circ} \mathrm{C}$ \\
\hline 2. & Denaturierung * & 10 s bei $98^{\circ} \mathrm{C}$ & 30 s bei $98^{\circ} \mathrm{C}$ \\
\hline 3. & $\mathrm{~T}_{\mathrm{m}}$ (annealing) $*$ & 20 s bei $65^{\circ} \mathrm{C}$ & 30 s bei $77^{\circ} \mathrm{C}$ \\
\hline 4. & DNA-Synthese $*$ & 210 s bei $72^{\circ} \mathrm{C}$ & 68 s bei $72{ }^{\circ} \mathrm{C}$ \\
\hline 5. & $*$ Anzahl der Zyklen & 35 & 35 \\
\hline 6. & Abkühlung & 4 min bei $72{ }^{\circ} \mathrm{C}$ & 2 min bei $72{ }^{\circ} \mathrm{C}$ \\
\hline
\end{tabular}

\subsubsection{Nachweis der PCR-Produkte (Elektrophorese)}

Nach Abschluss der PCR wurde die Qualität der PCR-Produkte mittels einer AgaroseGelelektrophorese kontrolliert, in dem die DNA-Fragmente nach ihrer Größe aufgetrennt und anschließend angefärbt wurden. Entsprechend ihrer negativen Ladung wandert die DNA in einem elektrischen Gleichspannungsfeld von der Kathode zu der Anode. Die Wanderungsgeschwindigkeit erfolgt gemäß der Größe der Moleküle, sodass eine Auftrennung erzielt werden kann. Für die Auftrennung wurde ein 1\%-iges Agarosegel verwendet. Die Agarose wurde durch Erhitzen in der Mikrowelle in 1 x TBE-Puffer vollständig gelöst. Nach leichter Abkühlung wurde das Agarose-Gel mit zwei Tropfen Ethidiumbromid pro $50 \mathrm{ml}$ versetzt. AnschlieBend wurde das Gel in eine Gelschale gegossen und ein Kamm mit der erforderlichen Zahnung eingesetzt. Nach der Erkaltung der Gels wurde der Kamm gezogen und in jede Geltasche wurde eine Lösung bestehend aus $1 \mu \mathrm{l}$ PCR-Produkt, $1 \mu \mathrm{l} 6$ x loading dye und $4 \mu \mathrm{l}$ Wasser 
pipettiert. Als Molekulargewichtsmarker wurde ein $1 \mathrm{~kb}$ Marker benutzt. Die Trennung der DNA-Fragmente erfolgte bei einer Spannung von $90 \mathrm{~V}$ für $40 \mathrm{~min}$.

Nach Ablauf der Elektrophorese konnten die Gelbänder unter UV-Licht (302 nm) dargestellt und mit einer Sofortbild-Kamera fotografiert werden.

Die anschließende Aufreinigung der Produkte wurde anhand des QIAquick ${ }^{\circledR}$ PCR Purification Kit (Qiagen) durchgeführt. Die Konzentration konnte mit dem NanoDrop ${ }^{\text {TM }}$ bestimmt werden.

\subsection{Gibson Assembly}

Bei dieser Klonierungsmethode können mehrere überlappende DNA-Moleküle in einer isothermalen Reaktion unabhängig von Restriktionsschnittstellen in einem Arbeitsschritt zusammengefügt werden. Für das Gibson Assembly sollten fünf Konstrukte als Vektoren und fünf als Inserts dienen. Die als Vektoren dienenden Genkonstrukte waren zuvor mit dem pcDNA3.1(+)-Vektor (ThermoFisher) ausgestattet worden. Die ausgewählten Konstrukte wurden im vorherigen Schritt mittels spezieller Primer mit komplementären überhängenden Regionen amplifiziert. Anschließend erfolgte nach dem Gibson Assembly® Cloning Kit die Klonierung der Inserts in die jeweiligen pcDNA3.1(+)-Vektoren, indem in jedem Vektor ein bestimmtes Insert-Konstrukt eingefügt wurde.

Insgesamt war in dieser Arbeit die Herstellung von fünf Gibson-Cloning-Paare geplant (s. Tabelle 16 und Abbildung 8).

Tabelle 16: Inserts und die dazugehörigen Vektoren

\begin{tabular}{|l|l|}
\hline Inserts & Vektoren \\
\hline Syntaxin4_Syn87 & Endobrevin_GFP_Syn87_Syn2 \\
\hline SNAP25_GFP_mCherry & Lifeact_mCherry_Syn2 \\
\hline GFP & NLS_GFP_mCherry_Syn2 \\
\hline GalNact_GFP_Syn87 & Syntaxin6_Syn87_Syn2 \\
\hline TOM70_mCherry & Syntaxin7_GFP_Syn2 \\
\hline
\end{tabular}




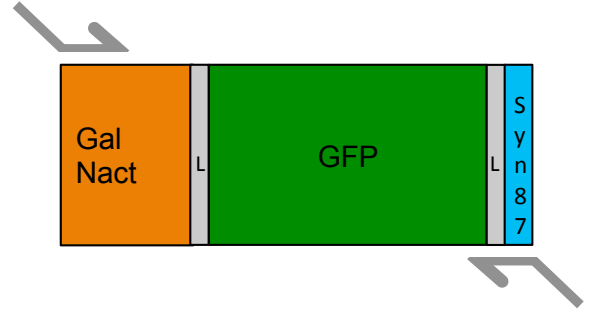

A

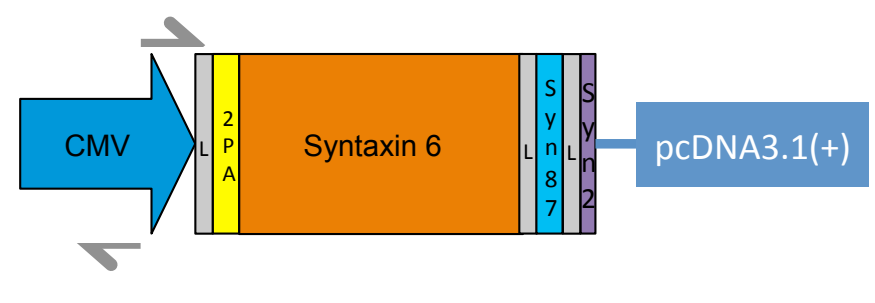

B

Abbildung 8: Schematische Darstellung der Vektoren und Inserts an dem Beispiel des GalNact_GFP_syn2_Syntaxin6_syn87_syn2-Paares. An dem Insert und dem Vektor wurden jeweils überhängende zueinander komplementäre Regionen hinzugefügt (s. dunkelgraue Häkchen). (A) Den Insert stellt das PCR-Produkt des Proteinkonstrukts GalNact_L_GFP_L_syn87 dar. (B) Der Vektor besteht aus dem PCR-Produkt des Konstrukts Syntaxin6_L_syn87_syn2 mit seinem pcDNA3.1(+)-Rückgrat.

Eine $5 \mu$ l-Mischlösung, bestehend aus äquivalente Mengen an Vektor-DNA und Insert-DNA und Wasser, wurden mit $5 \mu \mathrm{l}$ des 2x Gibson Assembly-Master-Mix vermischt und für $60 \mathrm{~min}$ bei $37^{\circ} \mathrm{C}$ inkubiert. Für die Transformation der hergestellten Klone wurde der E. coli-Stamm Alpha-Select Bronze Efficiency von Bioline (London, England) als kompetente Zellen verwendet. $50 \mu \mathrm{l}$ der kompetenten Zellen wurden mit jeweils $5 \mu \mathrm{l}$ der Gibson Reaktion gemischt und für $30 \mathrm{~min}$ auf Eis inkubiert. Nach abgeschlossener Inkubationszeit wurde für $30 \mathrm{~s}$ bei $42{ }^{\circ} \mathrm{C}$ eine Hitzeschockreaktion in einem Thermomixer durchgeführt und danach erfolgte eine weitere Lagerung auf Eis für $2 \mathrm{~min}$. Anschließend wurden jeweils $450 \mu \mathrm{l}$ SOC-Medium zu den einzelnen Mischungen pipettiert und diese wieder im Thermomixer bei 300 Umdrehungen/min für $1 \mathrm{~h}$ bei $37^{\circ} \mathrm{C}$ inkubiert. Die transformierten Bakterien wurden bei 10000 Umdrehungen/min für $20 \mathrm{~s}$ zentrifugiert, damit drei Viertel des Überstandes entfernt und das Pellet in der restlichen Lösung wieder resuspendiert werden konnte. Daraufhin erfolgte die Plattierung der Bakterien auf eine Agarplatte, die das entsprechende Antibiotikum enthielt (Ampillicin) und eine anschließende Inkubation über Nacht bei $37^{\circ} \mathrm{C}$. Am nächsten Tag wurde eine einzelne Kolonie aufgenommen und für 24 Stunden bei $37^{\circ} \mathrm{C}$ bei $250 \mathrm{Umdrehungen/min} \mathrm{in} 5 \mathrm{ml} \mathrm{LB}$ Medium (Lennox Sigma-Aldrich) wachsen gelassen. Anschließend konnte das gewünschte Plasmid durch Anwendung des GeneJET Plasmid Miniprep Kit (ThermoFischer Scientific) extrahiert werden. 


\section{Ergebnisse}

Das Ziel dieser Arbeit ist die Etablierung der auf Nanobodies basierenden kombinatorischen Epitop-Analyse zur Proteinbestimmung. Der Identifizierungsansatz beruht auf der Idee, dass jedes Proteinkonstrukt aufgrund eines in seiner Aminosäuresequenz enthaltenden einzigartigen Epitop-Satzes markiert ist. Die Epitop-Sätze unterscheiden sich je nach Protein in Kombination, Anzahl und Vorkommen. Die Proteinkonstrukte sollen auf Basis des spezifischen Bindungsverhaltens von Nanobodies im Hinblick auf die jeweiligen Epitope identifiziert werden. Für jedes zu identifizierende Proteinkonstrukt wird ein dem Epitop-Satz entsprechender spezifisch gebundener Satz an Nanobodies ermittelt. Aufgrund des Nanobody-Satzes kann wiederum mithilfe der Epitop-Analyse ein Bezug zu den jeweiligen Epitop-Sätzen erzielt werden. Nach diesem Prinzip kann jedes Protein identifiziert werden.

Da die Arbeit auf vier Nanobodies und 15 Proteine beruht, wurde zunächst deren Funktionalität bezüglich Spezifität, Transfizierbarkeit und Exprimierbarkeit überprüft. Anschließend wurde die Epitop-Analyse als Methode zur Identifizierung von Proteinen verifiziert. Des Weiteren wurde ebenfalls der multiplexe Ansatz der kombinatorischen Epitop-Analyse zur Identifizierung von multiplen Proteinen überprüft. Dafür wurden Methoden getestet werden, damit die Zellen letztendlich mehrere Proteinkonstrukte gleichzeitig exprimierten. Dadurch konnte die Testung der multiplexen Epitop-Analyse erst ermöglicht werden.

\subsection{Transfektion von Plasmiden: Ein-Plasmid-Transfektion}

Die Untersuchungen wurden auf Basis der HEK-293-Zelllinie durchgeführt. Bevor die Genkonstrukte in die HEK-293-Zellen transfiziert werden konnten, musste die Eignung der HEK-293-Zellen als transfizierbare Zellen überprüft werden. Die Kontrolle der Transfizierbarkeit erfolgte mittels ausgewählter Plasmide. Bei der Auswahl der Plasmide war entscheidend, dass sie sich entweder in ihrer Emissionswellenlänge oder in ihrer Lokalisation innerhalb der Zelle unterscheiden. Zu den verwendeten Plasmiden gehörten TOM70-GFP, SNAP25GFP, mCherry- $\alpha$-Synuclein und $\alpha$-Synuclein-HA.

In dieser Testphase wurde untersucht, ob eine Ein-Plasmid-Transfektion der HEK-293-Zellen mit den aufgelisteten Plasmiden ohne Komplikationen durchzuführen ist. Da das Protein $\alpha$ Synuclein-HA keine spezifische Fluoreszenz aufwies, wurde in diesem Fall nach der Transfektion ein indirekte Immunfärbung mit dem Fluorophor Cy5 durchgeführt (s. Tabelle 7). An- 
schließend wurden die vier transfizierten Versuchsreihen fixiert und die Transfektion mit dem Epifluoreszenzmikroskop Olympus IX71 überprüft. Die Ergebnisse der Transfektion mit jedem der vier Plasmide sind in der Abbildung 9 dargestellt.

Die in Abbildung 9 aufgeführten Signale des exprimierten mCherry- $\alpha$-Synucleins und des mit Cy5 gefärbten $\alpha$-Synuclein-HAs wurden bei $610 \mathrm{~nm}$ (in Rot) bzw. bei $670 \mathrm{~nm}$ (in Blau) detektiert. Die Fluoreszenz des dargestellten SNAP25-GFPs mit $509 \mathrm{~nm}$ ist identisch mit dem des TOM70-GFPs (beide in Grün). Die Differenzierung zwischen den GFP-gekoppelten Proteinen ist anhand der unterschiedlichen Lokalisation der Proteine innerhalb der Zelle möglich. TOM70 ist als mitochondriale Import-Rezeptor-Untereinheit in den Mitochondrien lokalisiert, während SNAP25 als Mitglied der t-SNAREs in der Plasmamembran zu finden ist.
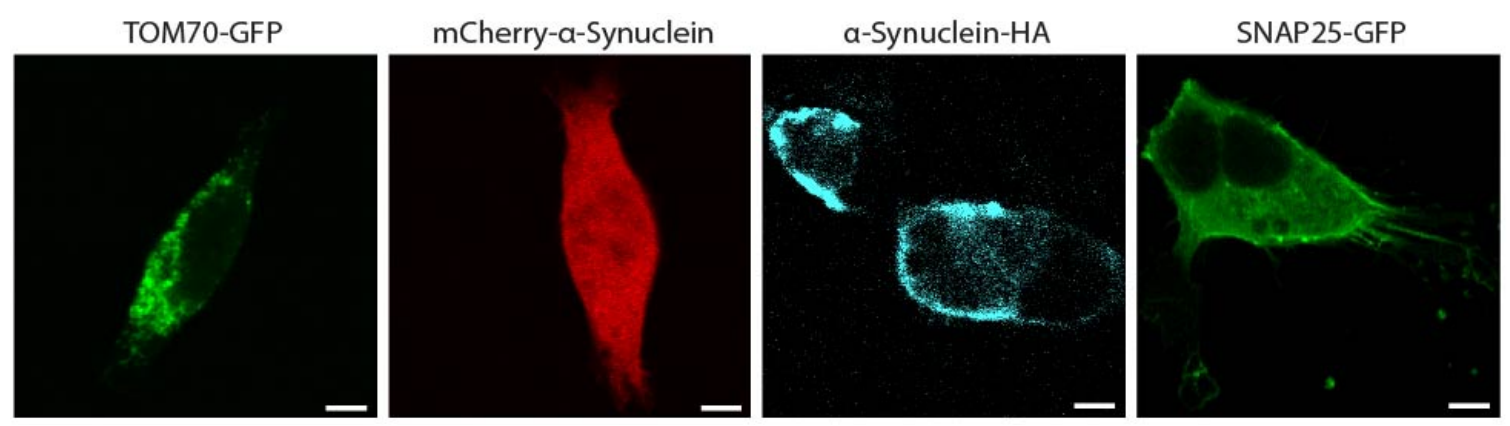

Abbildung 9: Ein-Plasmid-Transfektion von HEK-293-Zellen. Vier Versuchsreihen von HEK-293-Zellen wurden mit einem bestimmten Plasmid transfiziert. Nach einer spezifischen Anregung für GFP (488 nm), mCherry und das Fluorophor Cy5 (633 nm) konnte in allen Kanälen ein Signal gemessen werden. Die detektierten Signalen sind auf TOM70-GFP (in Grün, Lokalisation in den Mitochrondrien), mCherry- $\boldsymbol{\alpha}$-Synuclein (in Rot), Anti-Cy5- $\boldsymbol{\alpha}$-SynucleinHA (in Blau) und SNAP25-GFP (in Grün, Lokalisation in der Zellmembran) zurückzuführen. Die Balkenbreite beträgt $5 \mu \mathrm{m}$.

\subsection{Reinigung des NbSyn87}

Die Herstellung des NbSyn87 erfolgte durch Expression in einem E. coli Expressionsvektor, der das zu exprimierende Protein N-terminal mit einem His ${ }_{14}$-tag modifizierte. Die spezifische Bindung der $\mathrm{His}_{14}$-getaggten Nanobodies ermöglichte die Reinigung durch Affinitätschromatographie an einer Ni-NTA-Matrix. Die Reinigung erfolgte mit dem Äkta-Prime FPLC system und beruhte auf den Schritten der Lyse der Zellen, dem Binden der gelösten Proteine an die Ni-NTA-Matrix, dem Waschen zur Entfernung unspezifisch gebundener Proteine und letztendlich der Elution der gewünschten gebundenen Proteine von der Matrix.

Während des Reinigungsprozesses wurde die Absorption bei $280 \mathrm{~nm}$ aufgezeichnet. Der aufgezeichnete Wert entspricht der Proteinkonzentration innerhalb der Probe. Während der Eluierung des in der Säule gebundenen NbSyn87 mithilfe des His-Elutionpuffers, konnte eine 
einzelne Absorptionsspitze bei $280 \mathrm{~nm}$ detektiert werden (s. Abbildung 10). Die Form des Peaks deutete auf eine leichte Verunreinigung hin. Die eluierte Protein-Fraktion wurde gesammelt und anschließend mit einer SDS-PAGE analysiert. Innerhalb der SDS-PAGE stellte sich die Absorptionsspitze als breites Band bei dem erwarteten Molekulargewicht von $41 \mathrm{kDa}$ dar (s. Abbildung 11, roter Pfeil). Des Weiteren wurden in der Probe, nach Illustration des Peaks, bestehende Kontaminationen bei ca. 37 kDa aufgedeckt (s. Abbildung 11, Sternchen).

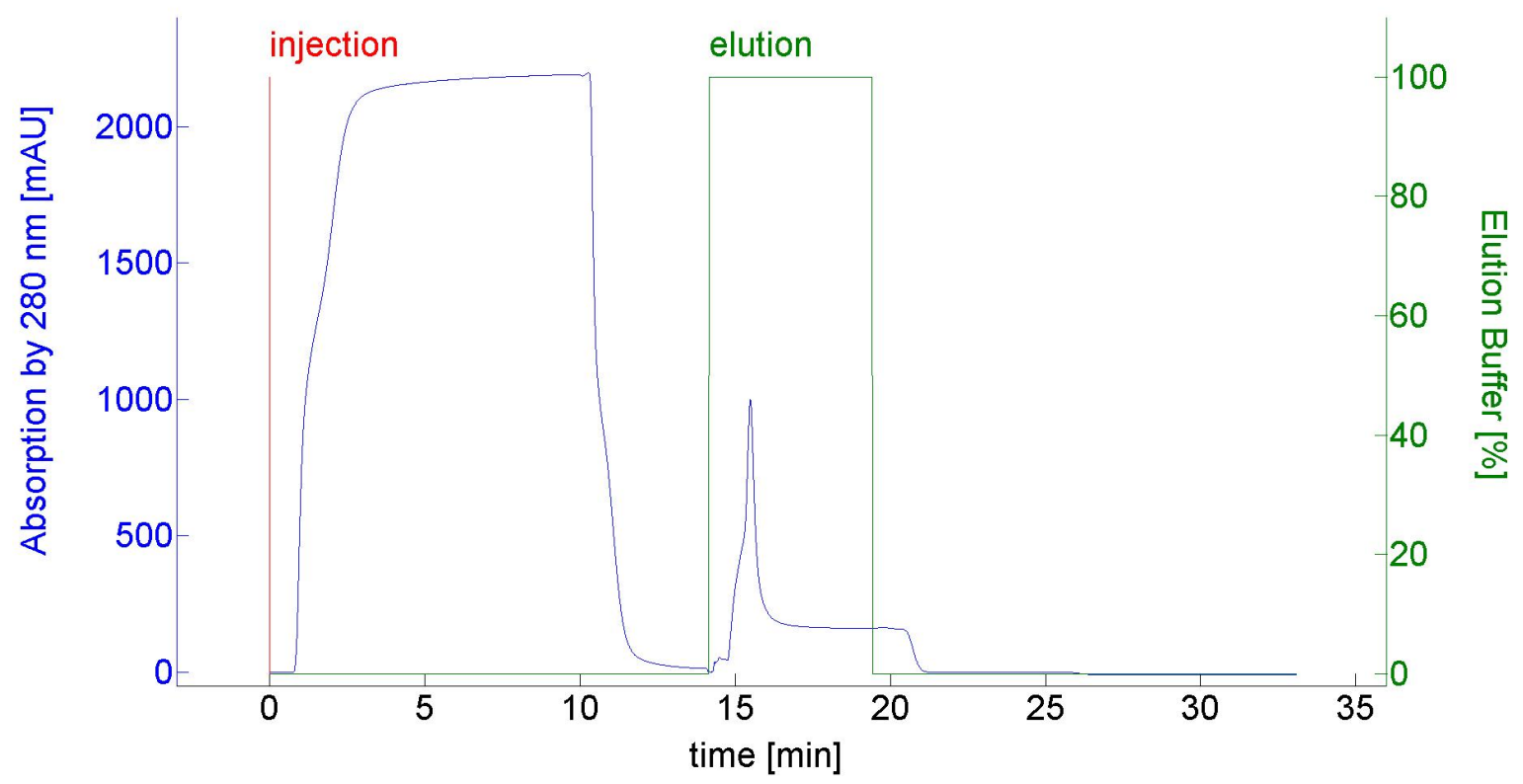

Abbildung 10: Reinigung des NbSyn87 aus E. coli. Nach der Injektion der Probe (rote Linie) in die Protino ${ }^{\circledR}$ Ni-NTA Ionenaustauschersäule konnte eine Eluierung mithilfe des His-Elutionpuffers erfolgen. Die blaue Linie entspricht der Absorption bei $280 \mathrm{~nm}$ und spiegelt die Konzentration der in der Probe vorhandenen Proteine wider. Die grüne Linie stellt die Konzentration des His-Elutionpuffers dar. Die Durchflussrate betrug $5 \mathrm{ml} / \mathrm{min}$. 


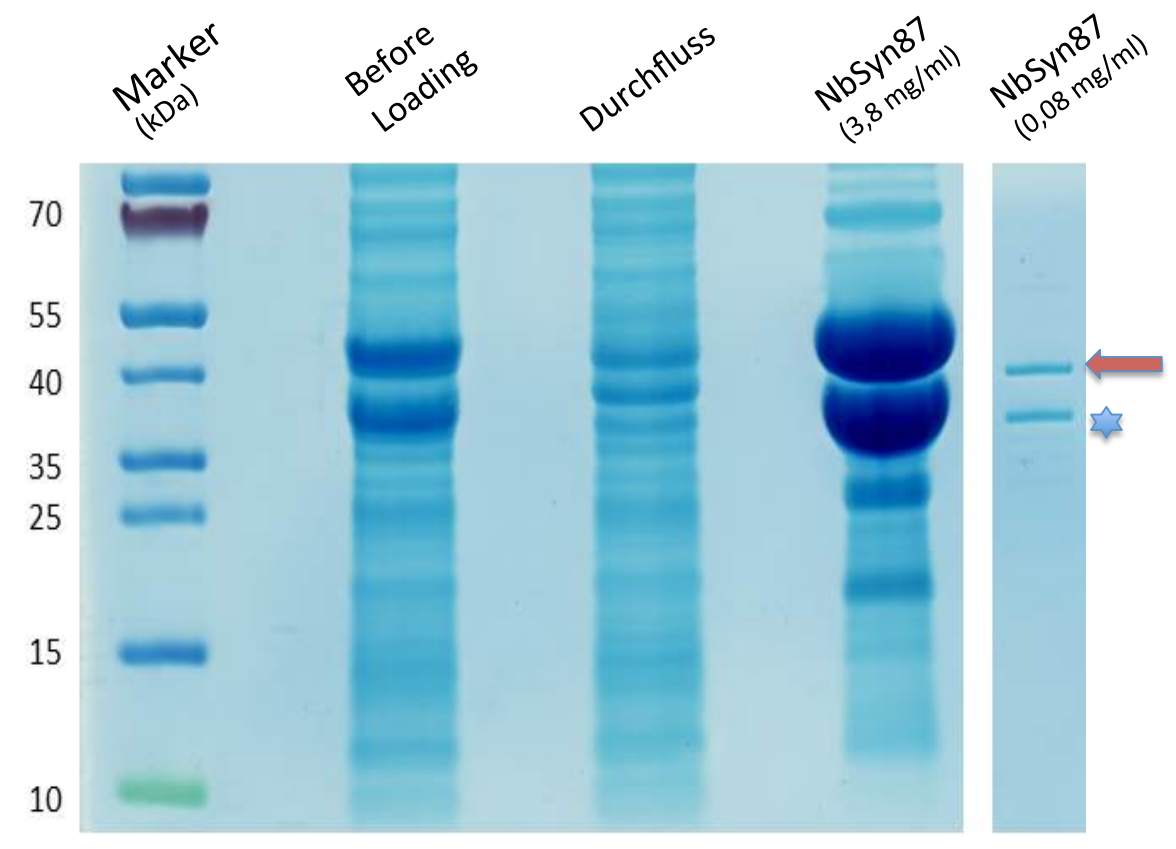

Abbildung 11: Trenngel nach der SDS-PAGE. Die Gelfraktionen enthalten die verschiedenen Reinigungs-Zustände der Probe des NbSyn87. Die Fraktion Before Loading entspricht der ungereinigten Probe und die Fraktion Durchfluss jenem Anteil der Probe, die nicht in der Protino ${ }^{\circledR}$ Ni-NTA Ionenaustauschersäule aufgefangen wurde, d. h. diejenigen Proteine, die

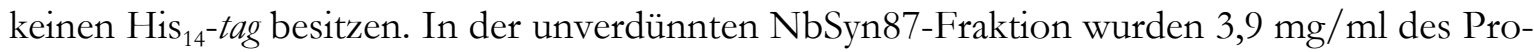
teins und in der verdünnten nur $0,08 \mathrm{mg} / \mathrm{ml}$ des Proteins aufgetragen, wodurch ein deutliches Band bei ca. $41 \mathrm{kDa}$ (roter Pfeil) detektiert werden konnte, die dem erwarteten molekularen Gewicht des Proteins entspricht. In beiden NbSyn87-Fraktionen wurde eine Kontamination festgestellt, die als zusätzliches Band bei ca. 38 kDa (blaues Sternchen) erscheint.

\subsection{Funktionstest der verwendeten Nanobodies}

Das Design der 15 Proteinkonstrukte beruhte auf der Verfügbarkeit von vier Nanobodies. Diese konnten mit einem der vier in den Proteinkonstrukten vertretenen Epitope spezifisch in Wechselwirkung treten. Bei den Nanobodies handelte es sich um einen GFP-Nanobody, den mCherry bindenden Nanobody LaM-2 und die NbSyn2 und NbSyn87, die jeweils spezifisch eine Sequenz am C-Terminus (die Aminosäuren 118 - 131 bzw. Aminosäuren 1371 - 140) in dem Protein $\alpha$-Synuclein binden (Guilliams et al. 2013). Im Folgenden wurde die spezifische Bindung der Nanobodies an ihre Epitope überprüft. Die Spezifität der Bindung ist eine Voraussetzung, um Rückschlüsse auf den in der Aminosäuresequenz der Proteine enthaltenen Epitop-Satz zu ermöglichen und damit die Grundlage der auf Nanobodies basierten EpitopAnalyse zu schaffen.

Für die Durchführung eines Funktionstests wurden im ersten Schritt drei der vier Nanobodies an Fluorophore gekoppelt (s. Kapitel 2.7.1). Die Nanobodies LaM-2 und NbSyn87 wurden 
unter anderem an Alexa-488 gekoppelt und der NbSyn2 an das Fluorophor CF633. Der GFPNanobody konnte in verschiedenen Variationen (Nano'Tag Biotechnologie) erworben werden.

Im nächsten Schritt wurden HEK-293-Zellen mit für die Nanobodies jeweils spezifischen Proteinen transfiziert. Zu den verwendeten Plasmiden gehörten TOM70-GFP, mCherry und $\alpha$-Synuclein WT (Wildtyp). Nach der Durchführung einer direkten Immunfärbung (s. Kapitel 2.7.3) mit den entsprechenden Nanobodies und der anschließenden Fixierung konnte die Spezifität der Bindung mit einem Konfokalmikroskop (siehe 2.7.4) kontrolliert werden. Die Ergebnisse dieses Funktionstests sind in Abbildung 12 dargestellt.

In Teil A sind die jeweils transfizierten Plasmide dargestellt. Die fluoreszenten Signale der Plasmide TOM70-GFP und mCherry konnten aufgrund der spezifischen Anregung mittels eines LSM510 mit 488 nm bzw. 543 nm detektiert werden. Das Plasmid $\alpha$-Synuclein WT besaß keine fluoreszierenden Eigenschaften. Deshalb wurde zur Kontrolle der Transfektion zunächst in beiden Fällen eine indirekte Immunfärbung (Anti- $\alpha$-SynWT und Anti-rabbit IgG Cy5) gegen das Protein $\alpha$-Synuclein WT durchgeführt.

Teil B dient der Kontrolle der spezifischen Bindungsfähigkeit der Nanobodies an ihre Epitope. Nach der Anregung in den Wellenlängenbereichen für GFP (488 nm) und den mit dem Farbstoff Alexa-546 markierten NbGFP (546 nm), konnte unter Verwendung des Konfokalmikroskops LSM510 überprüft werden, ob eine spezifische Bindung vorlag. Anhand der Aufnahmen ist zu erkennen, dass sich das fluoreszierende Signal der GFP-Sequenz in der Lokalisation vollständig mit dem Signal des NbGFP 1H2B-546 überlagert. Somit kann auf eine spezifische Bindung des NbGFP geschlossen werden. Die spezifische Bindung des LaM-2-488 an mCherry konnte ebenso anhand der dargestellten fluoreszierenden Signale nach der Anregung in den jeweiligen Kanälen (543 nm und $488 \mathrm{~nm}$ ) bestätigt werden. Die Funktionsüberprüfung konnte mit der Bestätigung der spezifischen Bindung der NbSyn87-488 und NbSyn2-688 an $\alpha$-Synuclein wildtyp erfolgreich abgeschlossen werden.

Die in dem Funktionstest ermittelten und in Abbildung 12 dargestellten Signalüberlagerungen bestätigen die spezifischen Bindungseigenschaften der vier Nanobodies. Das erzielte Ergebnis verifiziert die Nutzung des NbGFP, des LaM-2, des NbSyn2 und des NbSyn87 als Grundbaustein des angestrebten Verfahrens einer auf Nanobodies-basierenden Epitop-Analyse. 
A

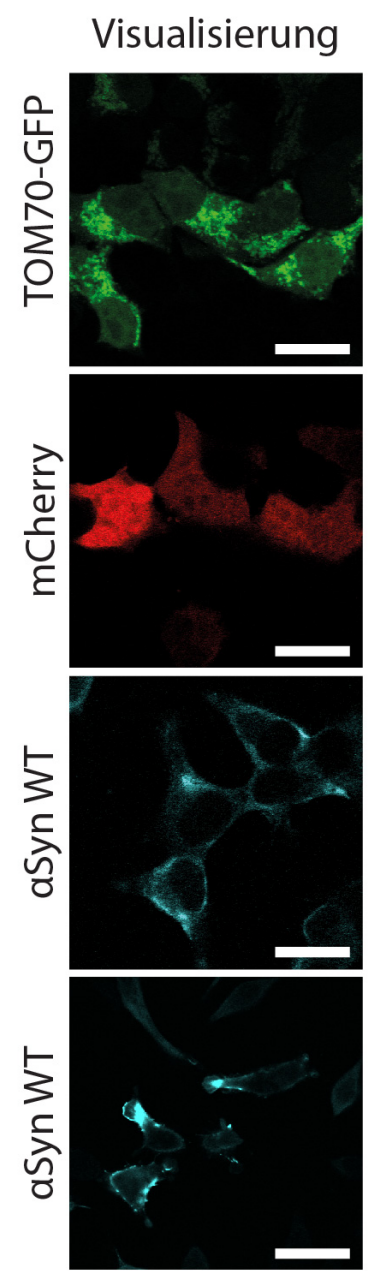

B

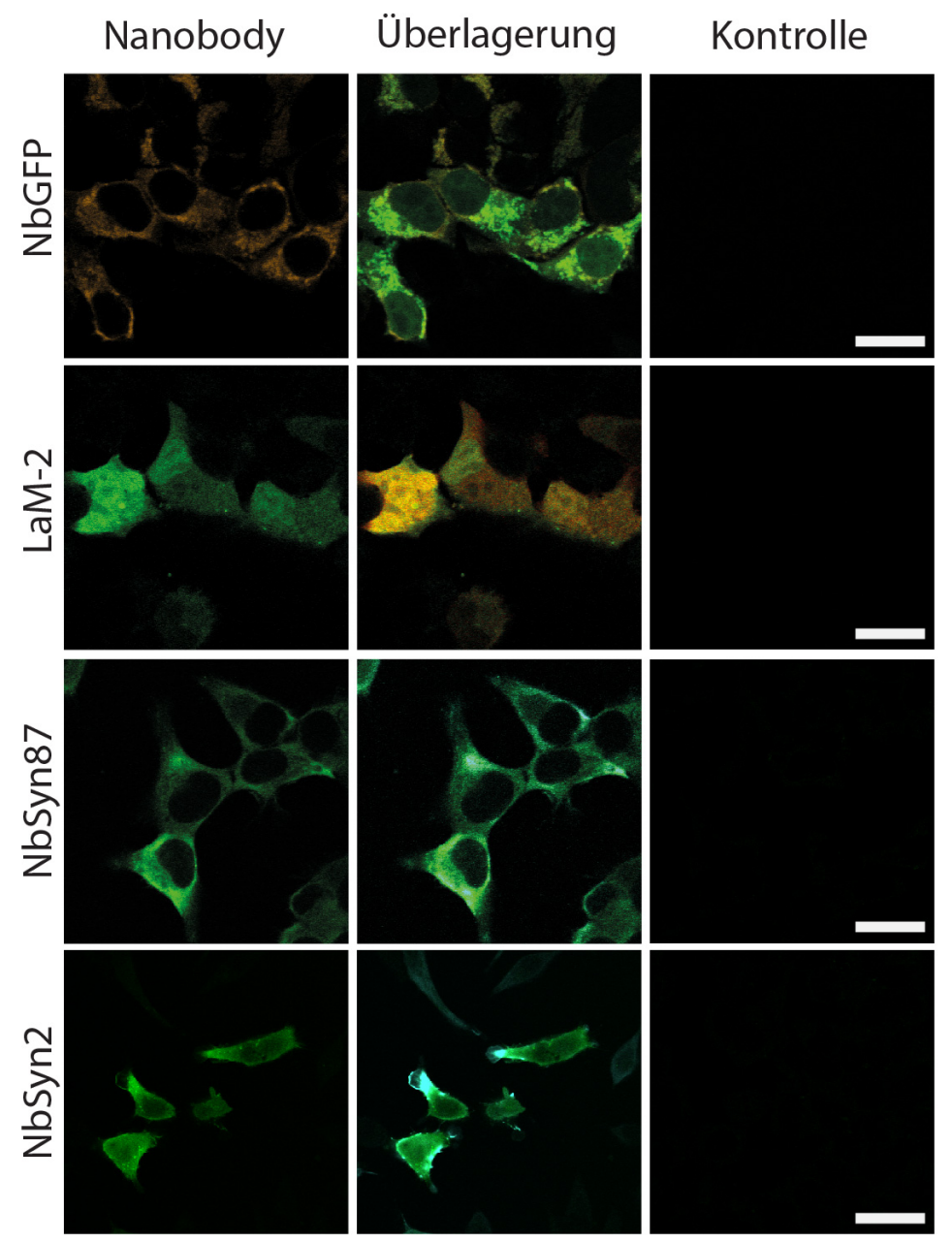

Abbildung 12: Spezifische Bindung der Nanobodies an ihre Epitope. Gezeigt ist die Kolokalisierung (s. Signalüberlagerung) (A) der fluoreszierenden Proteine bzw. der Anti- $\boldsymbol{\alpha}$ Synuclein-Antiköper mit dem (B) Signal des NbGFP, des LaM-2, des NbSyn87 und des NbSyn2. Die Balkenbreite beträgt $20 \mu \mathrm{m}$.

\subsection{Singleplexe Epitop-Analyse zur Einzeltestung der Genkonstrukte}

In dieser Testreihe sollte der neue Ansatz bestätigt werden, dass eine auf dem Bindungsverhaltens von Nanobodies basierende Epitop-Analyse die Identifizierung und Bildgebung von Proteinen ermöglichen kann (s. Abbildung 13). Es musste gewährleistet werden, dass die designten Proteinkonstrukte in HEK-293-Zellen transfiziert und anschließend vollständig und korrekt exprimiert werden konnten. Eine korrekte Strukturfaltung der Epitope innerhalb der Proteinkonstrukte war die Voraussetzung dafür, dass die Nanobodies auch innerhalb der Proteinkonstrukte an ihren spezifischen Epitopen binden konnten. Bei der Expression der Proteinkonstrukte wurde festgestellt, dass das Konstrukt $\alpha$-Tubulin_mCherry-syn87 nicht exprimiert werden kann. 
Für die Realisierung der in dem ersten Abschnitt der Testreihe (s. Abbildung 13, Teil A) durchgeführten Epitop-Analyse wurden für die Identifizierung der Konstrukte vier fluorophorgekoppelte Nanobodies eingesetzt. Dazu zählten der NbGFP, der LaM-2, der NbSyn87 und der NbSyn2 (s. Kapitel 0). Die Nanobodies waren jeweils für eines der vier für die Konstruktbildung verwendeten Epitope (GFP-, mCherry-, syn87- und syn2-Epitop) spezifisch. Da in dieser Phase die Genkonstrukte nach dem Prinzip der ein-Plasmid-Transfektion in die Zellen übertragen wurden, konnte die Eignung der Epitop-Analyse zunächst als singleplexes Verfahren überprüft werden.

Der zweite Abschnitt der Testreihe (s. Abbildung 13, Teil B) diente dem Zweck, die Ergebnisse der ersten Reihe zu bestätigen, indem eine indirekte Immunfärbung mit Antikörpern durchgeführt wurde. Die eingesetzten Antikörper wurden dahingehend ausgewählt, dass sie spezifisch mit dem Protein des jeweiligen exprimierten Genkonstrukts (z. B. Syntaxin6, -7, VAMP usw.) reagieren konnten (Teil B).

Teil A der Abbildung 13 stellt zunächst die Aufnahmen (s. Kapitel 2.7.5) der fluoreszierenden Signale der vier Nanobodies nach deren Bindung an die jeweiligen Epitope dar. Zur Aufnahme der Bilder wurden die Genkonstrukte einzeln transfiziert. Anschließend wurde eine direkte Immunfärbung mit Nanobodies (s. Kapitel 2.7.3) gegen die entsprechenden Epitope durchgeführt. Die Signale konnten nach der spezifischen Anregung der an die Nanobodies gekoppelten Fluorophore mithilfe des Olympus IX71-Mikroskop (s. Kapitel 2.7.5) gemessen werden. Die dargestellten fluoreszierenden Signale der Nanobodies spiegeln die an die Proteine gekoppelten Epitope wider. Innerhalb eines Konstrukts kolokalisieren die Signale der Epitopgebundenen Nanobodies. Des Weiteren geben die Signale Auskunft über die Lokalisation der jeweiligen Proteine in der Zelle. Die Signale der Nanobodies, die z. B. an die Epitope des NLS-GFP-mCherry-Syn2-Konstrukts gebunden hatten, sind angesichts der physiologischen Lokalisation von NLS ausschließlich im Kern zu finden.

Mithilfe der Durchführung der Epitop-Analyse konnte auf der Basis der gemessenen Nanobody-Signale ein Ausschlussverfahren bezüglich der vorhandenen Epitope durchgeführt werden. Anhand gegebener Signalüberlagerungen bzw. Kolokalisation innerhalb der Zelle konnte festgestellt werden, welche Epitope Teil des zu identifizierenden Konstrukts waren. Da jedes Proteinkonstrukt mit einem einmaligen Epitop-Satz markiert worden war, konnte anhand des entschlüsselten Epitop-Satzes auf das transfizierte Proteinkonstrukt geschlossen werden. War ein Epitop in dem Konstrukt nicht vertreten, wurde kein spezifisches Signal mit dem entsprechenden Nanobody festgestellt (s. Abbildung 13, weiße Kästchen). Das Ergebnis der Epitop- 
Analyse der Genkonstrukte ermöglichte somit die Identifizierung und Bildgebung des dazugehörenden Proteins.

Zur Ergebnis-Bestätigung der in Teil A durchgeführten Epitop-Analyse wurde zusätzlich eine Antikörper-Färbung durchgeführt. Teil B stellt die fluoreszierenden Signale der jeweils an das Fluorophor Cy5 gekoppelten Antikörper dar. Die Antikörper wurden in Abhängigkeit von den Ergebnissen der Epitop-Analyse ausgewählt und richteten sich spezifisch gegen die in den Konstrukten vertretenen Proteinen (zum Beispiel gegen das Protein NLS in dem NLS-GFPmCherry-Syn2-Konstrukt). Angesichts der dargestellten spezifischen Antikörper-Signale pro Konstrukt, bestätigen die vorliegenden Aufnahmen die mittels der Epitop-Analysen getroffenen Identifizierungen der Proteinkonstrukte. 
A

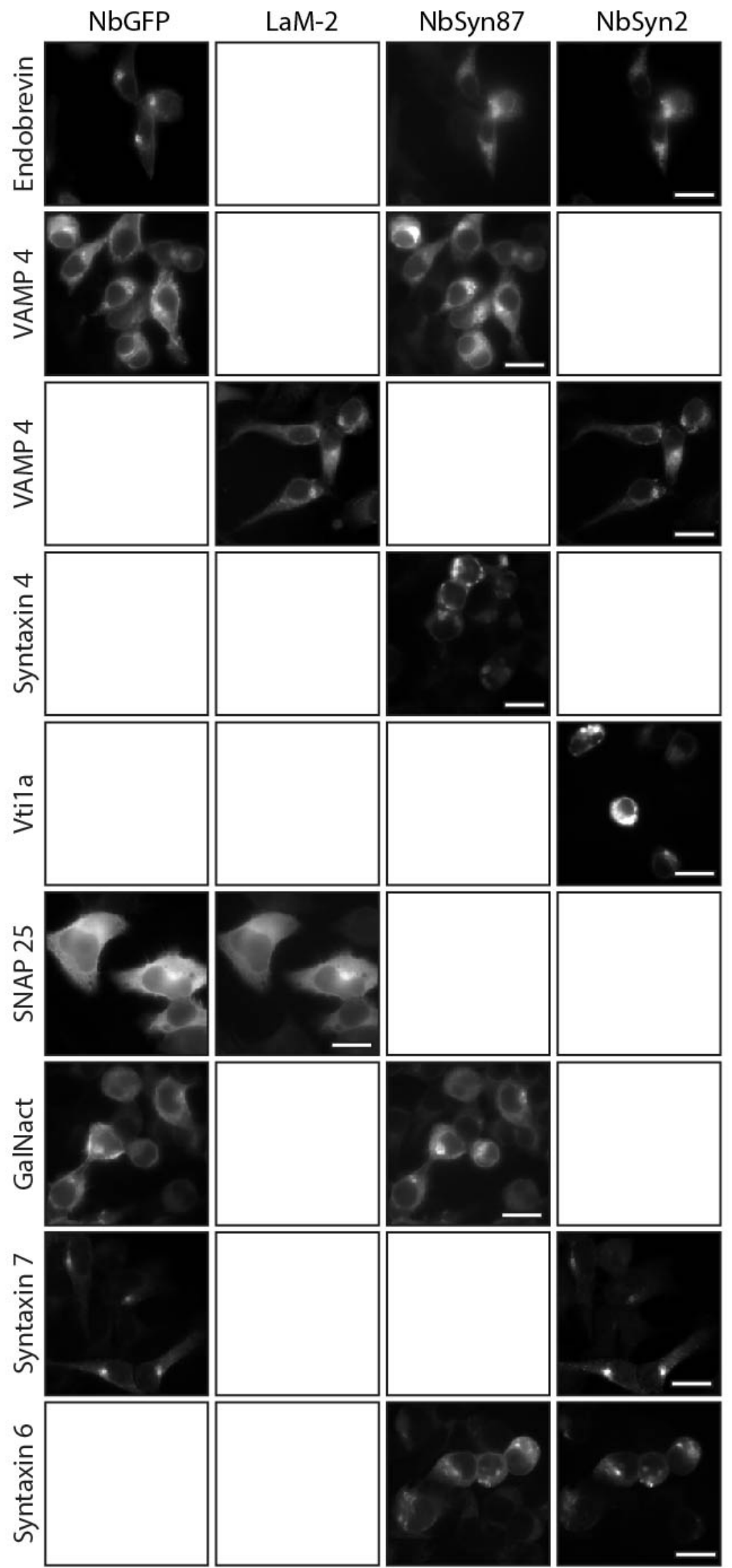

B
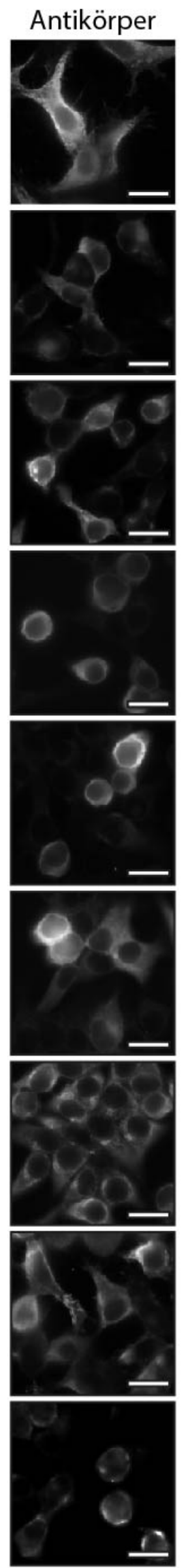
A

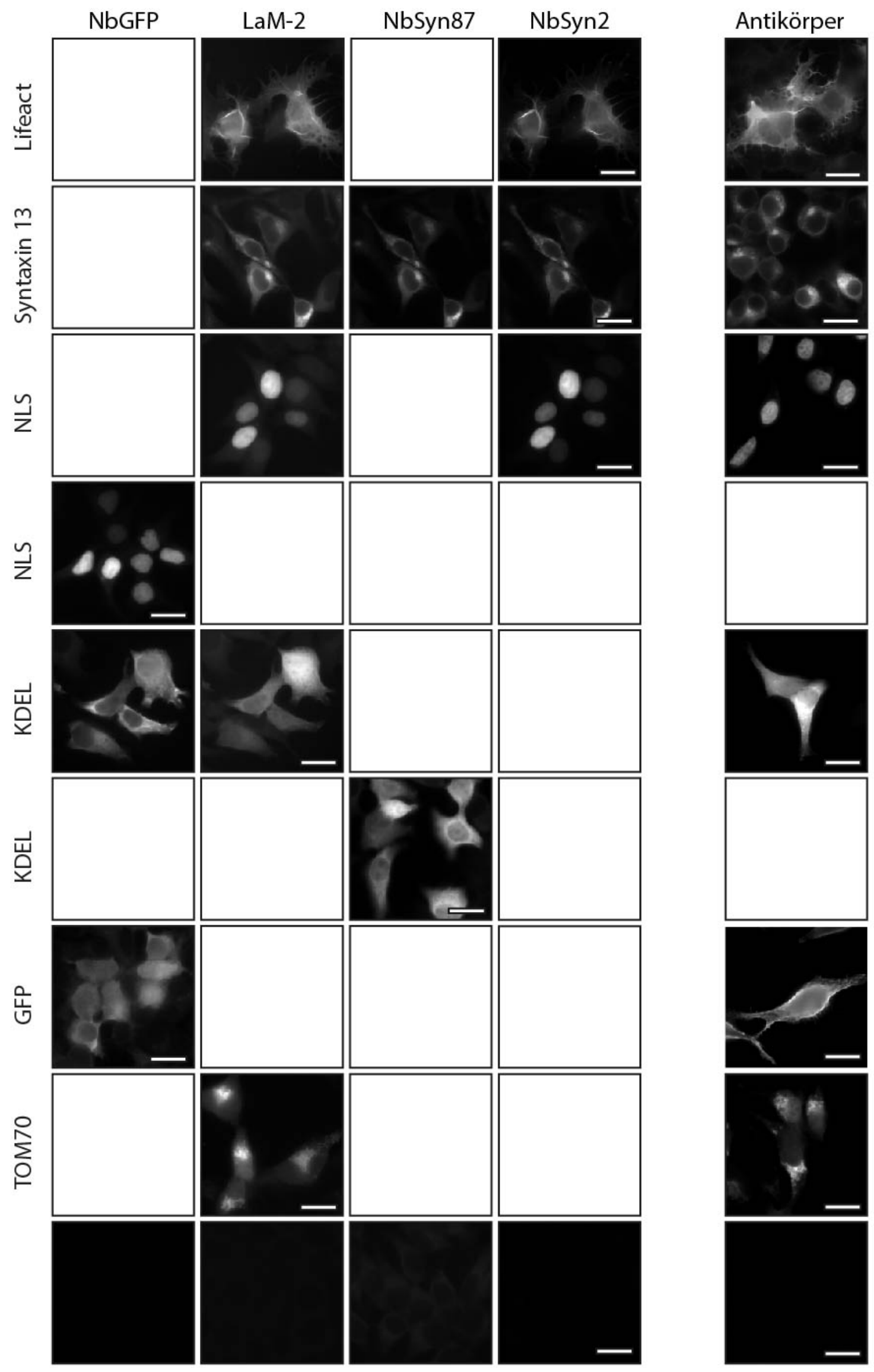


Abbildung 13: Proteinidentifizierung mittels kombinatorischer Epitop-Analyse durch (in)-direkte Immunzytochemie. Die 15 Genkonstrukte wurden einzeln in HEK-293-Zellen transfiziert (s. Kapitel 2.5). Anschließend wurde eine Nanobody- bzw. Antikörperfärbung durchgeführt. Jede Reihe (A und B) stellt den Aufbau eines Genkonstrukts dar (EpitopKombination (A) mit Protein (B)) dar. (A) Die Aufnahmen zeigen die durch eine spezifische Anregung und mithilfe des Olympus IX71-Mikroskops detektierten spezifischen Signale der fluorophorgekoppelten Nanobodies nach der Bindung an ihre entsprechenden Epitope. Auf Basis der gemessenen Nanobody-Signale konnte ein Ausschlussverfahren bezüglich der vorhandenen Epitope durchgeführt werden. Anhand dessen konnte festgestellt werden, welche Epitope Teil des zu identifizierenden Konstrukts waren, sodass auf das jeweilige Konstrukt geschlossen werden konnte. Bei fehlenden Epitopen wurden unspezifische Signale ermittelt (weiße Kästchen). Die in (B) dargestellten Signale der Antikörper nach Bindung an das dazugehörige Protein des Gesamtkonstrukts wurden ebenfalls mit dem Olympus IX71-Mikroskop detektiert. Aufgrund der spezifischen Signale bestätigen die Aufnahmen die in Teil A ermittelten Ergebnisse. Die Balkenbreite beträgt $20 \mu \mathrm{m}$.

Mithilfe dieser Testreihe konnte belegt werden, dass eine auf dem Bindungsverhalten von Nanobodies basierende Epitop-Analyse die Identifizierung und Bildgebung von Proteinen ermöglicht. Des Weiteren wurde die spezifische Reaktion der Nanobodies mit den in den Proteinkonstrukten integrierten Epitope bestätigt.

\subsection{Methoden zur Kreierung einer Multitransfekt-Zelle}

Nach der erfolgreichen Testung der neu entwickelten Epitop-Analyse zur Identifizierung von Proteinen ist die Eignung der Epitop-Analyse als multiplexes Verfahren überprüft worden. Multiplex bedeutet in diesem Fall, dass mehrere transfizierte Proteinkonstrukte in einer Zelle detektiert werden sollten. Die Voraussetzung dafür war, dass Umstände kreiert werden konnten, die eine multiplexe Testung überhaupt erst möglich machen. Diese Basis sollte durch eine Kombination von drei verschiedenen Methoden (Fusion, Gibson Assembly und multiple Transfektion) geschaffen werden.

Da die Ein-Plasmid-Transfektion an HEK-293-Zellen erfolgreich durchgeführt werden konnte, wurde zunächst die darauf aufbauende Methode der Fusion mittels HVJe-Virus getestet. Das Ziel dieser Testphase bestand darin, eine Zelle mit vier unterschiedlichen Plasmiden zu kreieren, die durch die Fusion von mindestens vier verschiedenen einfach-transfizierten Zellen entsteht.

Der nächste Schritt befasste sich mit dem Gibson Assembly. Auf der Grundlage der Technik des Gibson Assembly sollte eine Klonierung von zehn der 15 Plasmide stattfinden, sodass die Gesamtzahl der zu transfizierenden Plasmide auf insgesamt zehn begrenzt werden konnte. 
Die dazu ausgewählten Genkonstrukte mussten zunächst mittels PCR amplifiziert werden, damit anschließend das Gibson Assembly durchgeführt werden konnte.

In dem dritten Versuchsexperiment wurde eine multiple Transfektion von Plasmiden in HEK293-Zellen getestet. Dieses Experiment soll eine Alternative zu dem in dem ersten Versuchsexperiment getesteten Weg der Fusion darstellen.

\subsubsection{Erstes Versuchsexperiment: Fusion von Zellen}

Die in diesem Versuchsexperiment zu beantwortende Frage war, ob nach vier Einzeltransfektionen in HEK-293-Zellen und einer anschließend durchgeführten Fusion dieser Zellen, eine Zelle erschaffen werden kann, die jedes der einzeln transfizierten Plasmide exprimiert. Die Zellen wurden dabei entweder mit GFP-TOM70, GFP-SNAP25, mCherry- $\alpha$-Synuclein oder mit $\alpha$-Synuclein-HA transfiziert. Jede Zelle exprimierte so eines der Proteine. Anschließend erfolgte mittels des HVJe-Virus eine Fusion dieser Zellen (s. Kapitel 2.6). Danach wurde eine indirekte Immunfärbung mit einem an das Fluorophor Cy5 gekoppelten Antikörper gegen $\alpha$ Synuclein-HA (s. Tabelle 7) durchgeführt. Die Überprüfung, ob eine Fusion von mindestens vier Zellen stattgefunden hat, wurde durch die Messung der Fluoreszenz nach einer spezifischen Anregung (bei 488 nm, 543 nm und 633 nm) mit dem LSM510 ermöglicht. Die Abbildung 14 (A) stellt eine Zelle dar, in der anhand der detektierten Signale die Proteine GFPTom70, GFP-SNAP25, mCherry- $\alpha$-Synuclein und $\alpha$-Synuclein-HA nachgewiesen werden konnten. Die Proteine mCherry- $\alpha$-Synuclein und $\alpha$-Synuclein-HA (in Verbund mit Anti-HATag C29F4 und Anti-Rabbit IgG Cy5) konnten aufgrund ihrer spezifischen Fluoreszenz voneinander und in Bezug auf GFP-Tom70 und GFP-SNAP25 differenziert werden. GFPTom70 und GFP-SNAP25 emittierten die gleiche Fluoreszenz (488 nm), konnten jedoch infolge ihrer divergierenden Lokalisation innerhalb der Zelle unterschieden werden. GFPTom70 ist Teil der Mitochondrien, während GFP-SNAP25 seinen Aufenthaltsort in der Plasmamembran hat. Die in Teil B dargestellte Aufnahme zeigt die übereinander gelagerten Signale der zuvor gemessenen Kanäle. Das in Abbildung 14 dargestellte Ergebnis bestätigt die Annahme, dass durch eine Fusion von einfach-transfizierten Zellen eine Multitransfekt-Zelle hergestellt werden kann. 
A
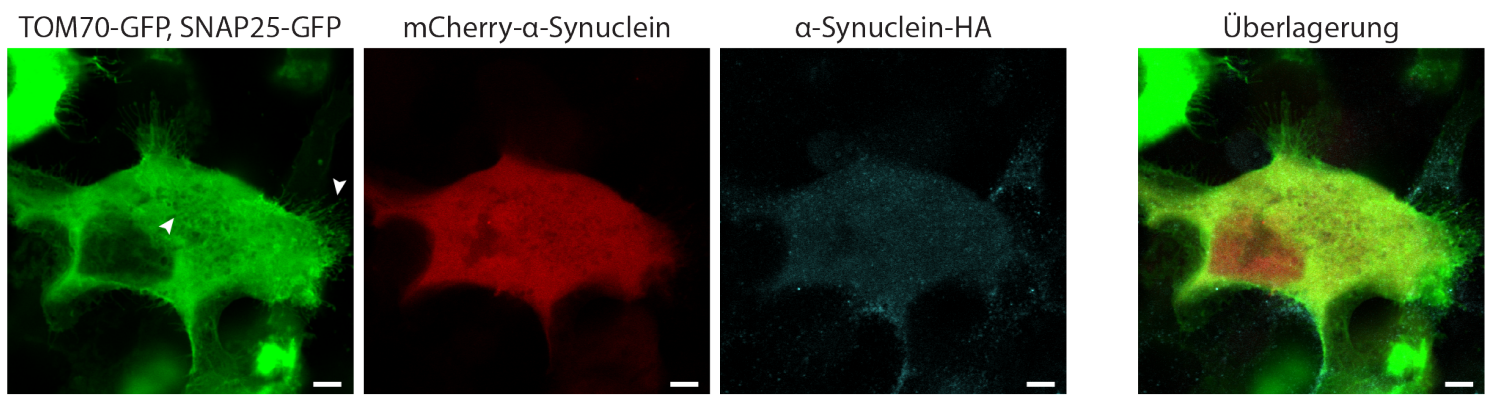

Abbildung 14: Fusion von mindestens vier transfizierten HEK-293-Zellen. Vier Versuchsreihen von HEK-293-Zellen wurden nach dem Protokoll der ein-Plasmid-Transfektion (s. Kapitel 2.5) mit GFP-TOM70, GFP-SNAP25, mCherry- $\alpha$-Synuclein oder $\alpha$-Synuclein-HA transfiziert und anschließend mittels HVJe-Virus fusioniert (s. Kapitel 2.6). (A) Darstellung der gemessenen fluoreszierenden Signale in den einzelnen Kanälen nach einer spezifischen Anregung (488-, 543-, 633 nm). Eine Abgrenzung zwischen GFP-TOM70 und GFP-SNAP25 konnte aufgrund der unterschiedlichen Lokalisation innerhalb der Zelle getroffen werden (s. weiße Pfeile). (B) Überlagerung der in (A) dargestellten Einzelkanäle. Die in der dargestellten HEK-293-Zelle detektierten Signale verifizierten eine Fusion von mindestens vier einfachtransfizierten Zellen. Die Balkenbreite beträgt $5 \mu \mathrm{m}$.

\subsubsection{Zweites Versuchsexperiment: Gibson Assembly}

\subsubsection{PCR (Polymerase-Kettenreaktion) zur Vervielfältigung der Proteinkonstrukte}

Mit dem Start des Gibson Assemblys wurde mit der Umsetzung der zweiten Methoden begonnen, die der Zusammenstellung einer multitransfekten Zelle dienen sollte. Von den für das Gibson Assembly vorgesehenen Proteinkonstrukten wurden fünf Konstrukte als Inserts und fünf weitere als Vektoren verwendet (s. Tabelle 13 und Tabelle 14). Um mit dem eigentlichen zweiten Versuchsexperiment zu starten, mussten die dafür vorgesehenen Genkonstrukte zunächst mithilfe der PCR amplifiziert werden.

Die zu amplifizierenden PCR-Vektoren unterschieden sich mit ca. 6000 - 7200 Basenpaaren (bp) deutlich in ihren Größen von denen der Inserts (ca. 800 - 1700 bp). Wie in Abbildung 15 und Abbildung $16 \mathrm{zu}$ sehen ist, wurden spezifische PCR-Fingerprints beobachtet, die eine klare Zuordnung der zu amplifizierenden Vektoren und Inserts anhand der erwarteten Größe gestatten. In den Fällen der Inserts GalNact und SNAP25 konnten Kontaminationen in Form von Balken geringerer Basenpaaren-Größe festgestellt werden (s. Abbildung 16, 4. und 5.). 

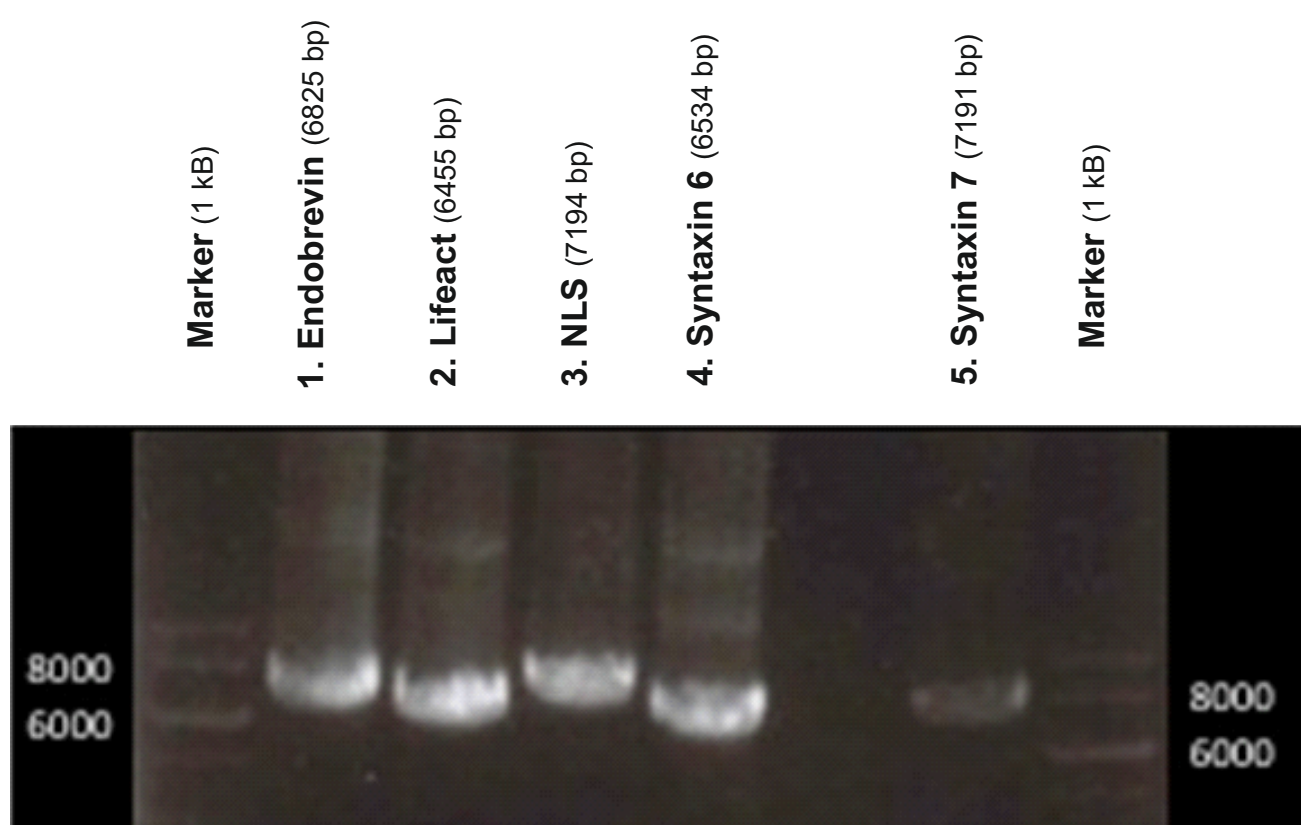

Abbildung 15: Amplifizierung der Vektoren. Zu den Vektoren zählen fünf Proteinkonstrukte, die sich nur geringfügig in ihrer Größe unterschieden. 1. Endobrevin_GFP_syn87_syn2 mit 6825 bp, 2. Lifeact_mCherry_syn2 mit 6455 bp, 3. NLS_GFP_mCherry_syn2 mit 7194 bp, 4. Syntaxin 6_syn87_syn2 mit 6534 bp und 5. Syntaxin 7_GFP_syn2 mit 7191 bp. Als Molekulargewichtsmarker wurde ein $1 \mathrm{kB}$ Marker benutzt.
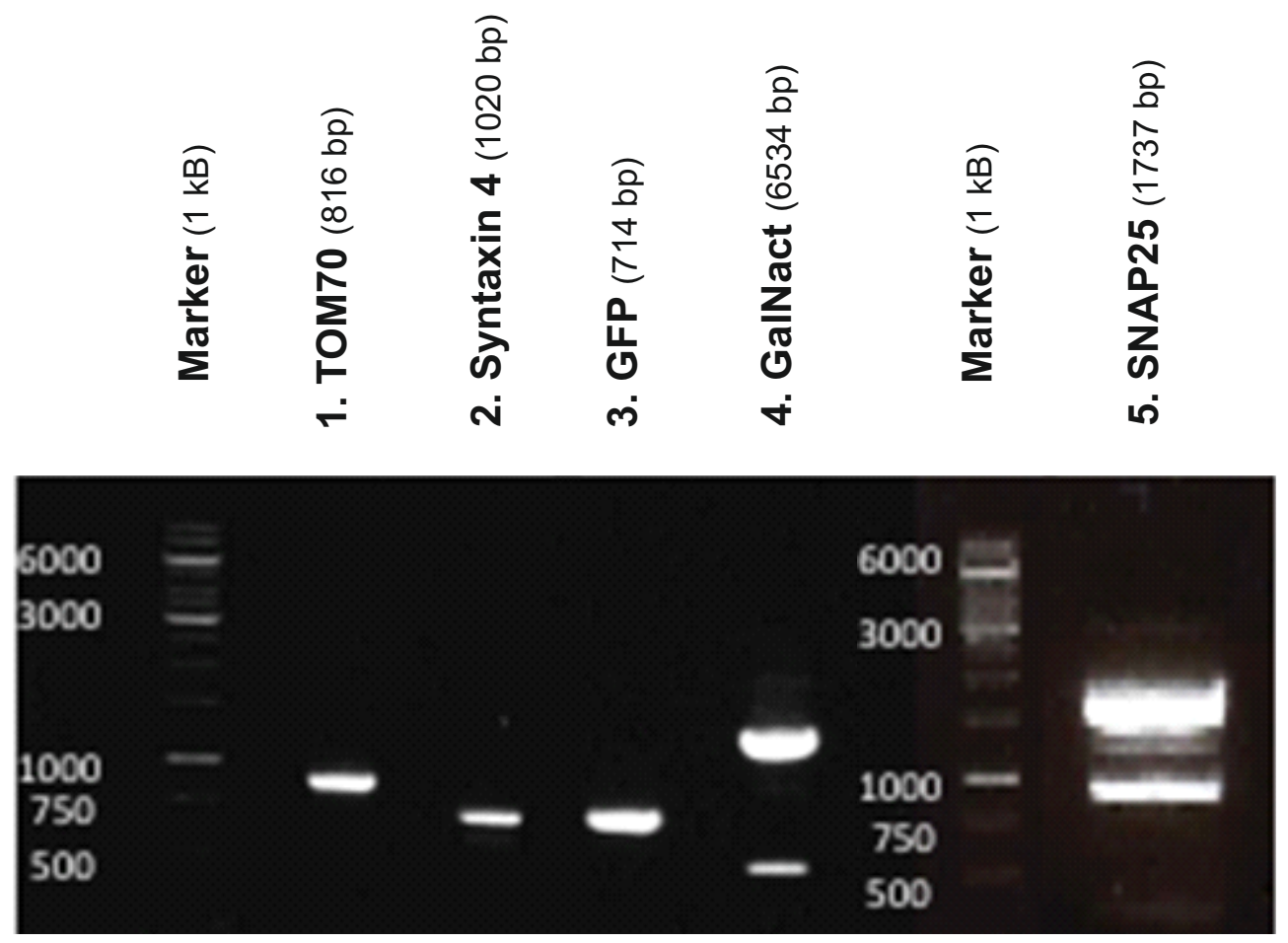

Abbildung 16: Amplifizierung der Inserts. Zu den Inserts zählen ebenfalls fünf Genkonstrukte. 1. TOM70_mCherry mit 816 bp, 2. Syntaxin 4_syn87 mit 1020 bp, 3. GFP mit 714 bp, 4. GalNact_GFP_syn87 mit 1224 bp und 5. mCherry_GFP_SNAP25 mit 1737 bp. Als Molekulargewichtsmarker wurde ein $1 \mathrm{kB}$ Marker benutzt. 


\subsubsection{Gibson Assembly}

Die Zielvorstellung dieser Arbeit ist, die auf Nanobodies basierende Epitop-Analyse zu einem multiplexen Verfahren zu erweitern. Nach dem erfolgreich abgeschlossenen ersten Versuchsexperiment zählt das Gibson Assemblys zum Hauptteil des zweiten Versuchsexperiments. Dieses stellt ebenfalls eine Methode zur Kreierung einer Multitransfekt-Zelle dar. Die auf dem Gibson Assembly basierte Klonierung fand an den zehn mittels der PCR zuvor amplifizierten Vektoren und Inserts statt. Insgesamt sollte so die Gesamtzahl der zu transfizierenden Plasmide von 15 auf insgesamt zehn begrenzt werden.

Nach Ablauf des Gibson Assemblys (s. Kapitel 2.10) wurden die fünf produzierten GibsonKonstrukte einer Sequenzierung (Seqlab, Sequence Laboratories Göttingen) unterzogen. Von den geplanten fünf Gibson-Cloning-Paaren (s. Tabelle 16) konnten im Laufe der experimentellen Phase nur das Paar GFP_NLS_mCherry_GFP_syn2 insoweit erfolgreich kloniert werden, dass nach den Ergebnissen der Sequenzierung das in Abbildung 17 dargestellte Konstrukt erwartet wurde.

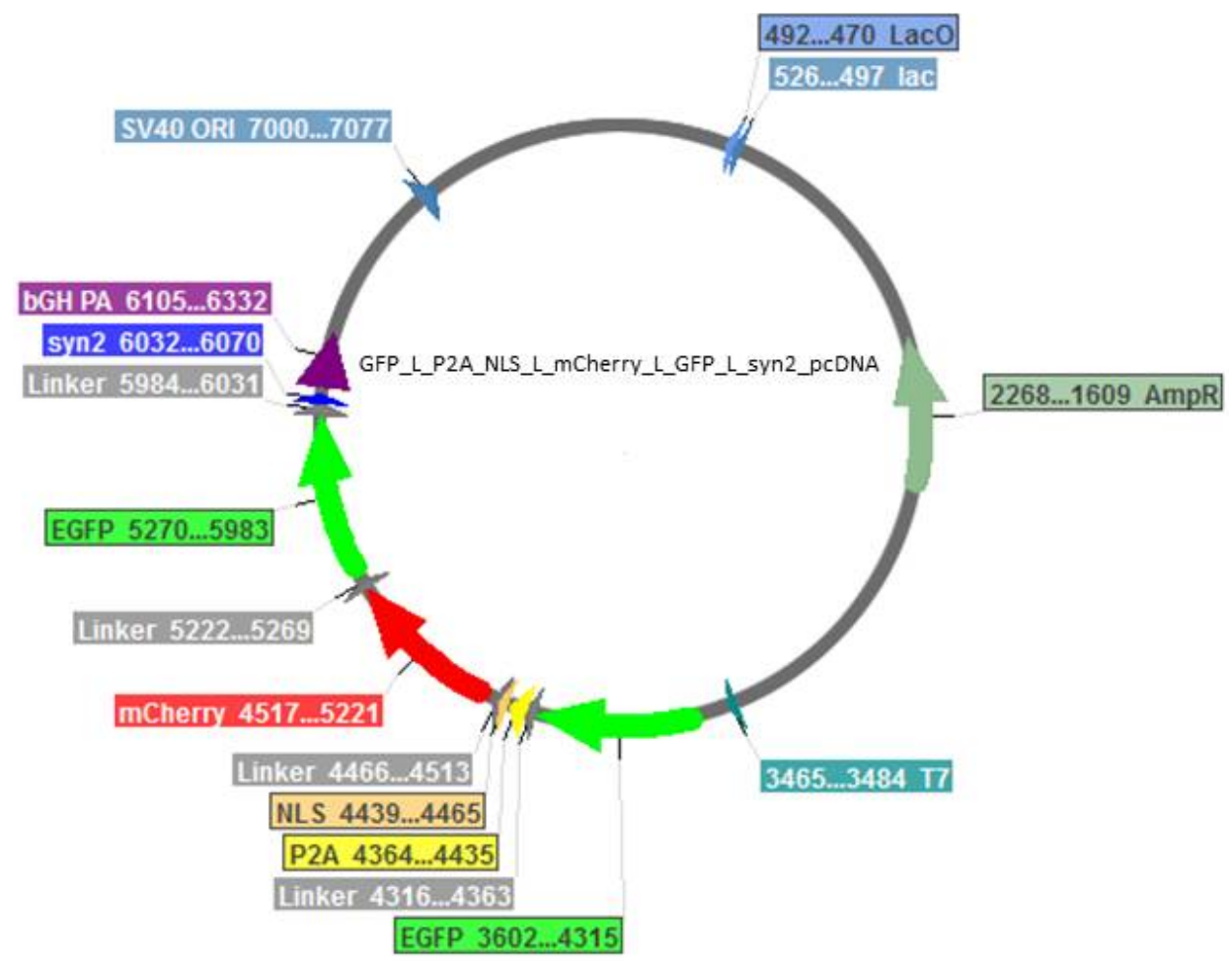

Abbildung 17: Plasmidkarte für das GFP_NLS_mCherry_GFP_syn2-Gibsonkonstrukt. Das erzeugte Gibson-Plasmid besteht aus dem pcDNA3.1(+)-Rückgrat, das die üblichen Komponenten für eine sachgemäße Replikation enthält: die T7 Promoter-Stelle (T7, in Türkis), die BGH Polyadenylations-Sequenz (bGH, in Violett), den SV40 early promoter and origin (SV40 ori, in Blaugrau), einem Ampicillin Resistenzgen (AmpR, in Dunkelgrün) als Selektionsmarke und dem Lac-Operon (LacO, in Hellblau). Des Weiteren enthält das GibsonKonstrukt die Gene für GFP (ehemaliges Insert) und für NLS_mCherry_GFP_syn2 (ehemaliger Vektor). 
Das hergestellte Plasmid wurde in HEK-293-Zellen transfiziert (s. Kapitel 2.5). Das Plasmid enthielt die mCherry_GFP_syn2-Epitope als Bestandteil des NLS-Konstrukts sowie das eingefügte GFP-Konstrukts als ehemaliges Insert. Daraufhin wurden - ohne vorherige Immunfärbung - nach einer spezifischen Anregung bei $488 \mathrm{~nm}$ und $543 \mathrm{~nm}$ mit dem LSM510 (s. Kapitel 2.7.4) fluoreszente Signale im grünen und roten Kanal erwartet. Wie in Abbildung 18 (Teil A) zu erkennen ist, konnte für das neu hergestellte GFP_NLS_mCherry_GFP_syn2Plasmids nach der spezifischen Anregung nur eine Emission im grünen Kanal detektiert werden. Diese steht stellvertretend für die GFP-Sequenz. Nach der Anregung mit 543 nm konnte kein Signal gemessen werden. In dem klonierten Konstrukt konnte also kein mCherry nachgewiesen werden.

Im Teil B der Abbildung 18 wird das eigentlich erwartete Ergebnis dargestellt. Dieses wurde in diesem Fall durch zwei Einzeltransfektionen von GFP und NLS_mCherry_GFP_syn2 in eine Zelle erreicht. Nach einer spezifischen Anregung (bei $488 \mathrm{~nm}$ und $543 \mathrm{~nm}$ ) konnte sowohl ein GFP- als auch ein mCherry-Signal detektiert werden.

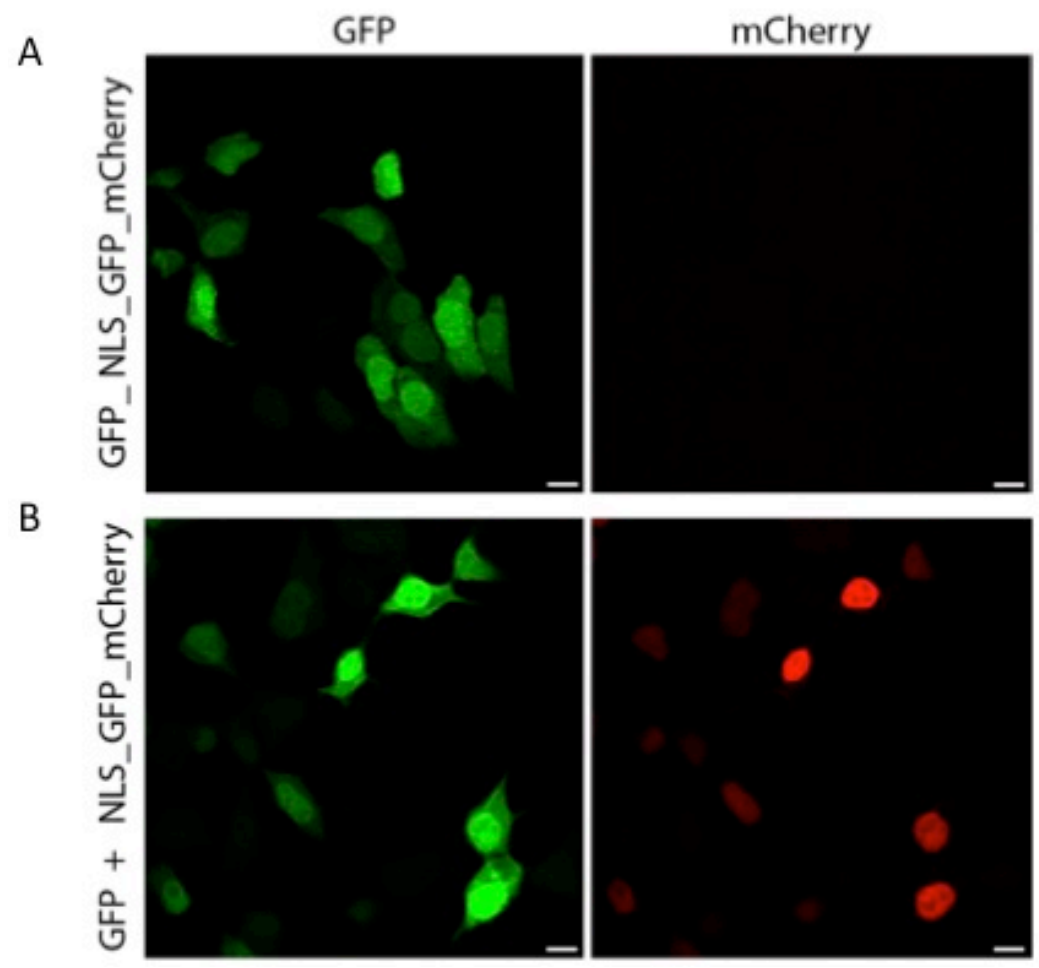

Abbildung 18: Gibson-Plasmid vs. 2-Plasmid-Transfektion. (A) Gezeigt sind die GFPund mCherry-Signale nach spezifischer Anregung (488 nm und $543 \mathrm{~nm}$ ) des in HEK-293Zellen transfizierten GFP-NLS_mCherry_GFP_syn2-Plasmids. Es konnte nur eine Emission im grünen Kanal (ca. 509 nm) festgestellt werden. (B) Die Proteinkonstrukte GFP und NLS_mCherry_GFP_syn2 wurden einzeln transfiziert und anschließend mit den gleichen Wellenlängen wie in (A) angeregt. Es konnten sowohl GFP- als auch mCherry-Signale detektiert werden. 


\subsubsection{Drittes Versuchsexperiment: Vier-Plasmid-Transfektion}

Mit dem dritten Versuchsexperiment wurde eine weitere Versuchsreihe durchgeführt um zu überprüfen, ob neben den erfolgreichen Ein-Plasmid-Transfektionen (s. Kapitel 3.1) auch multiple Transfektion möglich sind. Das Ziel war es HEK-293-Zellen mit vier Plasmiden (TOM70-GFP, SNAP25-GFP, mCherry- $\alpha$-Synuclein und $\alpha$-Synuclein-HA) gleichzeitig zu transfizieren.

Nach der erfolgten Transfektion und einer indirekter Immunfärbung (s. Kapitel 2.5 und 2.7.2) mit anschließender Fixierung der Testzellen konnte das Ergebnis der Vier-PlasmidTransfektion unter Verwendung eines LSM510 (s. Kapitel 2.7.4) überprüft werden. Die in Abbildung 19 (A) dargestellte HEK-293-Zelle wurde aufeinanderfolgend mit Lasern der Wellenlängen von $488 \mathrm{~nm}$ für GFP, von $543 \mathrm{~nm}$ für mCherry und von $633 \mathrm{~nm}$ für den Cy5Antikörper gegen $\alpha$-Synuclein-HA (Anti-HA-Tag-C29F4 und Anti-rabbit-IgG-Cy5) angeregt. Die detektierte Fluoreszenz in den genannten Kanälen bestätigt eine erfolgreiche Transfektion sowohl von TOM70-GFP und/oder SNAP25-GFP, von mCherry- $\alpha$-Synuclein als auch von $\alpha$-Synuclein-HA. Die Proteine TOM70-GFP und SNAP25-GFP emittierten die gleiche Fluoreszenz, konnten jedoch aufgrund der unterschiedlichen Lokalisation (s. Abbildung 19, weiße Pfeile) innerhalb der Zelle (TOM70-GFP in den Mitochondrien und SNAP25-GFP in der Plasmamembran) voneinander differenziert werden. In Teil B sind die einzeln gemessenen Signale in übereinander gelagerter Form dargestellt. Es konnten die Signale aller Kanäle in einer Zelle detektiert werden.

A

B
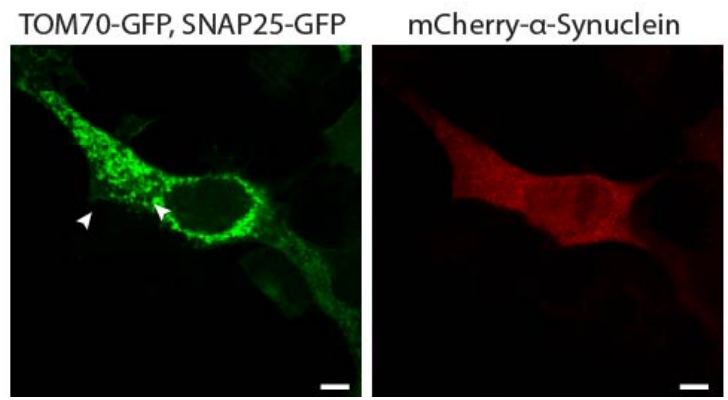

a-Synuclein-HA

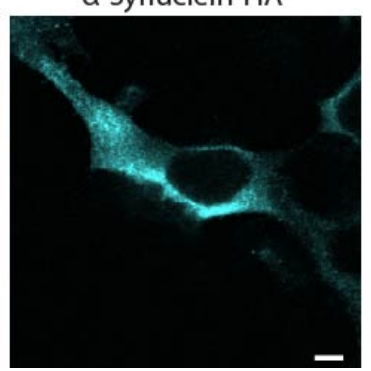

Überlagerung

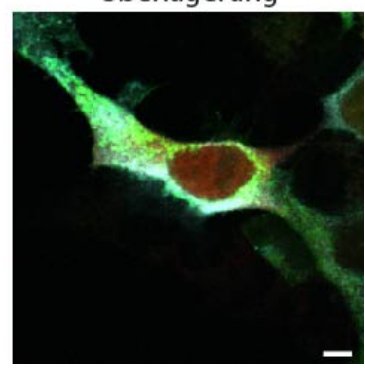

Abbildung 19: Vier-Transfekt-Zelle. HEK-293-Zellen wurden mit GFP-TOM70, GFPSNAP25, mCherry- $\boldsymbol{\alpha}$-Synuclein und $\boldsymbol{\alpha}$-Synuclein-HA in einem Schritt transfiziert. (A) Nach einer spezifischen Anregung bei 488-, 543- und $633 \mathrm{~nm}$ konnten fluoreszierende Signale in allen Kanälen detektiert werden. TOM70-GFP und SNAP25-GFP konnten anhand ihrer unterschiedlichen Lokalisation innerhalb einer Zelle voneinander differenziert werden (s. weiße Pfeile). (B) Die dargestellte Überlagerung der gemessenen Signale innerhalb einer HEK-293Zelle bestätigt eine erfolgreich durchgeführte Vier-Plasmid-Transfektion. Die Balkenbreite beträgt $5 \mu \mathrm{m}$. 


\subsection{Multiplexe Epitop-Analyse}

In den nächsten Schritten sollte die Eignung der Epitop-Analyse als ein multiplexes Verfahren überprüft werden. Multiplex bedeutete, dass mithilfe der Epitop-Analyse mehrere in eine Zelle transfizierte Proteinkonstrukte detektiert werden sollten. Auf Basis einer multiplen Transfektion der Proteinkonstrukte in HEK-293-Zellen wurden Umstände geschaffen, die den Beginn einer Testung der Epitop-Analyse als multiplexes Verfahren ermöglichten. Unter Anwendung zweier unterschiedlicher Immunfärbungsmethoden (s. Kapitel 2.7) wurden die Tests aufeinander aufbauend durchgeführt (Zwei-, Drei-, Vier-Transfekt-Experimente).

\subsubsection{Anwendung der multiplexen Epitop-Analyse nach einer direkten \\ Immunfärbung der Zwei- bis Vier-Transfekt-Experimente}

Das Verfahren der multiplen Epitop-Analyse wurde anhand von drei aufeinander aufbauenden Experimenten überprüft. Bei den in Abbildung 20 dargestellten Experimenten handelte es sich um Transfektion von zwei, drei oder vier Proteinkonstrukte in HEK-293-Zellen. In dem Zwei-Transfekt-Experiment zählten zu den ausgewählten Konstrukten TOM70_mCherry und GalNact_GFP_syn87. In dem Drei-Transfekt-Experiment wurden TOM70_mCherry, GalNact_GFP_syn87 und NLS_mCherry_GFP_syn2 und in dem Vier-Transfekt-Experiment TOM70_mCherry, GalNact_GFP_syn87, NLS_mCherry_GFP_syn2 und Lifeact_mCherry_ syn2 transfiziert. Nach erfolgter Transfektion (s. Kapitel 2.5) wurde in allen drei Experimenten eine direkte Immunfärbung (s. Kapitel 2.7.3) mit den jeweiligen Epitop-spezifischen Nanobodies durchgeführt. Zu den in den Experimenten verwendeten Nanobodies gehörten der NbGFP, der LaM-2, der NbSyn87 und der NbSyn2. Die spezifische Anregung der einzelnen Kanäle erfolgte mittels des AXIO LSM710 (s. Kapitel 2.7.4). In Abbildung 20 Teil A sind die in den Zellen der Zwei-, Drei- und Vier-Transfekt-Experimenten detektierten Signale der eingesetzten Nanobodies einzeln dargestellt. Die weißen Kästchen stellen unspezifische Signale dar bzw. versinnbildlichen einen nicht eingesetzten Nanobody. In Teil B werden die gemessenen Signale in überlagernder Weise visualisiert.

Bei dem Zwei-Transfekt-Experiment wurden der NbGFP, der LaM-2 und der NbSyn87 eingesetzt. Die Detektion der in Teil A einzeln dargestellten Signale der an die Nanobodies gekoppelten Fluorophore erfolgte nach einer spezifischen Anregung (488-, 543-, 405 nm). Die Fluoreszenz des NbGFPs (in Rot) steht stellvertretend für ein GFP-Epitop, der LaM-2 zeigt spezifische Wechselwirkungen mit dem mCherry-Epitop (in Blau) und der NbSyn87 mit einem syn87-Epitop (in Grau). Der NbSyn2 wurde nicht verwendet (weißes Kästchen). Teil B illustriert vorhandene Kolokalisationen der detektierten Signale der jeweiligen Epitope. Die 
dargestellte Kolokalisation der Signale des GFP- und des syn87-Epitopes (in Pink) entschlüsselt einen Epitop-Satz bestehend aus GFP und syn87. Dieser Epitop-Satz identifiziert GalNact_GFP_syn87 als das dazugehörige Konstrukt. Das Signal des mCherry-Epitops zeigt keine Überlagerung mit anderen Signalen und ermöglicht daher die Identifizierung von TOM70_mCherry als zweites transfiziertes Konstrukt. Da das GFP- und syn87-Epitop nicht mit dem mCherry-Epitop überlagern, kann KDEL_GFP_mCherry_syn87 als transfiziertes Konstrukt ausgeschlossen werden, obwohl Signale der drei auch in diesem Konstrukt vertretenen Epitope theoretisch detektiert worden sind. Das gleiche Ausschlussverfahren konnte aufgrund der fehlenden Überlagerung der Signale des mCherry- sowie des GFP-Epitops für SNAP25_mCherry_GFP angewendet werden.

In dem Drei-Transfekt-Experiment wurde neben TOM70_mCherry und GalNact_GFP_syn87 auch NLS_mCherry_GFP_syn2 transfiziert. Angesichts des im NLS_mCherry_GFP_syn2 vorhandenen syn2-Epitops wurde der NbSyn2 als vierter Nanobody eingesetzt. Teil A des Drei-Transfekt-Experiments zeigt einzeln die gemessenen fluoreszierenden Signale der verwendeten vier Nanobodies nach einer spezifischen Anregung (488-, 543-, 405-, 633 nm) mittels des AXIO LSM710. Der NbGFP bindet an zwei in ihrer Lokalisation voneinander abweichenden GFP-Epitope (in Rot). Der LaM-2 zeigt Wechselwirkungen mit zwei mCherry-Epitopen (in Blau) an divergierenden Orten innerhalb der Zelle an. Das Bindungsverhalten des NbSyn87 bleibt identisch mit dem vorherigen Ergebnis des ZweiTransfekt-Experimentes, da lediglich ein Signal infolge der Interaktion des NbSyn87 mit einem syn87-Epitop detektiert werden konnte (in Grau). Das fluoreszierende Signal des eingesetzten NbSyn2 konnte an einer Position lokalisiert werden und korrespondiert nur mit dem syn2-Epitop eines transfizierten Genkonstrukts. Anhand der detektierten Nanobody-Sätze konnte anschließend unter Anwendung der Epitop-Analyse auf die Epitop-Sätze der transfizierten Konstrukte geschlossen werden. Da jedes Proteinkonstrukt durch einen individuellen Epitop-Satz markiert ist, konnte auf das transfizierte Konstrukt geschlossen werden. Die in Teil B dargestellte Signalüberlagerung der GFP-Epitops und des syn87-Epitops ermöglicht die Identifizierung von GalNact_GFP_syn87 (in Pink). Die Kolokalisation des zweiten dargestellten GFP-Epitops mit den Signalen eines mCherry- und eines syn2-Epitopes identifiziert NLS_mCherry_GFP_syn2 (in Weiß-Gelb) als weiteres transfiziertes Konstrukt. Das zweite fluoreszierende Signal des LaM-2 zeigt weiterhin keine Überlagerung mit anderen Signalen, wodurch TOM70_mCherry (in Rot) als drittes Konstrukt bestimmt werden kann.

In dem Vier-Transfekt-Experiment wurden neben den drei in den vorherigen Experimenten bereits verwendeten Konstrukten zusätzlich Lifeact_mCherry_syn2 transfiziert. Des Weiteren wurden alle Nanobodies zur Durchführung der Epitop-Analyse eingesetzt. In Teil A zeigt der 
NbGFP zwei innerhalb der Zelle verschieden lokalisierte fluoreszierende Signale (in Rot). Die Signale des LaM-2 können an drei Orten detektiert werden (in Blau). Der NbSyn87 zeigt ein fluoreszierendes mit einem GFP-Epitop überlagerndes Signal (in Grau), während dem NbSyn2 zwei Signale zugeordnet werden können (in Grün). Mithilfe des Einsatzes der auf dem Bindungsverhalten der Nanobodies basierenden Epitop-Analyse sowie der in Teil B ermittelten Kolokalisation des GFP- mit dem syn87-Epitops kann GalNact_GFP_syn87 als transfiziertes Konstrukt bestätigt werden. Die Überlagerung eines GFP-, eines mCherry- und eines syn2-Epitops ermöglicht die Identifizierung von NLS_GFP_mCherry_syn2 (in GelbGrün). Angesichts der Kongruenz des mCherry-Epitops mit dem syn2-Epitops kann Lifeact_mCherry_syn2 (in Grün-Blau) als viertes transfiziertes Konstrukt bestimmt werden.

Die in Abbildung 20 veranschaulichte auf Nanobodies basierende Epitop-Analyse der transfizierten Genkonstrukte, ermöglicht einen kombinatorischen Vergleich der ermittelten Epitope (GFP, mCherry, syn87, syn2) im Zusammenhang mit ihrer Lokalisation innerhalb der Zelle. Wenn die Signale der dargestellten Epitope überlagern, müssen die Epitope innerhalb desselben Konstrukts vertreten sein. Liegen Abweichungen zwischen den detektierten Signalen der Epitope vor, handelt es sich um Epitope, die Teil von unterschiedlichen Proteinkonstrukten sind. Dieses Ausschlussverfahren anhand der detektierten Nanobody-Signale erlaubt eine Entschlüsselung der entsprechenden Epitop-Sätze. Dieses ermöglicht wiederum die Identifizierung der transfizierten Konstrukte. 
A

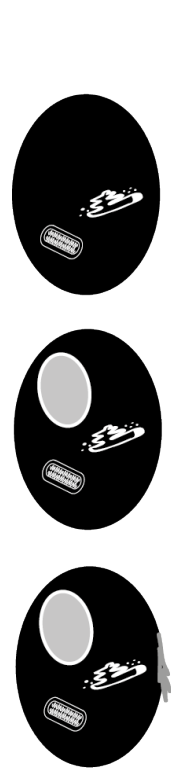

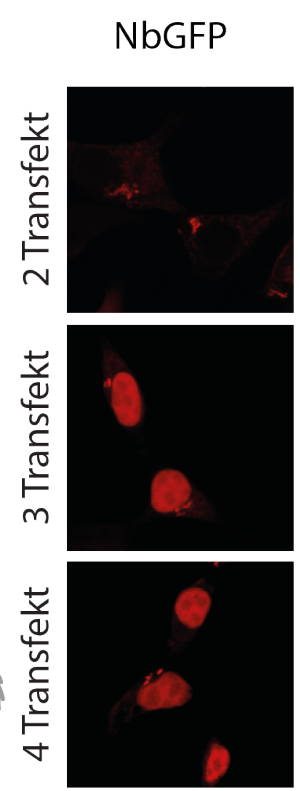
LaM-2

NbSyn87
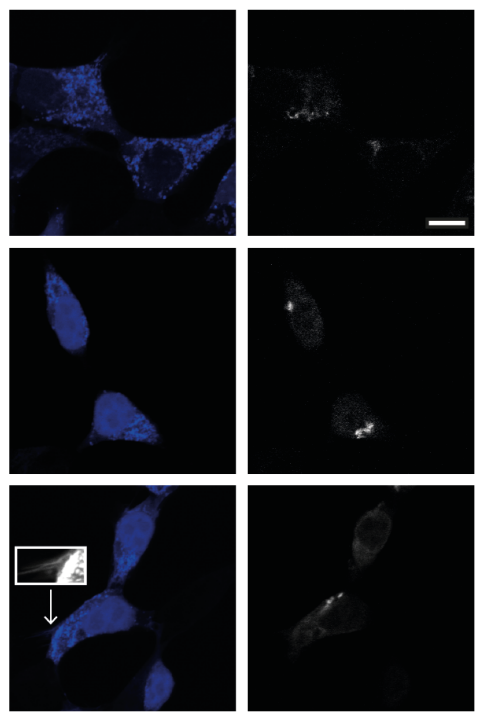
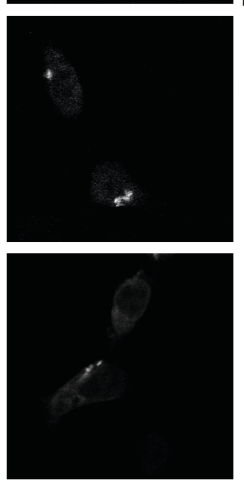

B

Überlagerung
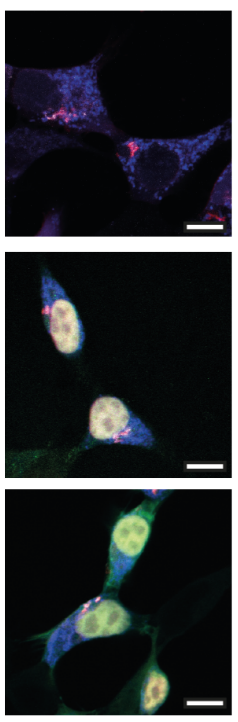

Abbildung 20: Multiplexe Epitop-Analyse nach direkter Immunfärbung. HEK-293Zellen wurden mit GalNact_GFP_syn87, TOM70_mCherry (Zwei-Transfekt), - NLS_ mCherry_GFP_syn2 (Drei-Transfekt) und - Lifeact_mCherry_syn2 (Vier-Transfekt) transfiziert. Es wurde eine direkte Immunfärbung mit dem NbGFP, LaM-2, NbSyn87 und NbSyn2 durchgeführt. (A) Nach einer spezifischen Anregung (488-, 543-, 405-, $633 \mathrm{~nm}$ ) wurden die gemessenen Signale der Nanobodies einzeln dargestellt. Die Signale des NbGFP stellen GFPEpitope (in Rot), die des LaM-2 mCherry-Epitope (in Blau), die des NbSyn87 syn89-Epitope (in Grau) dar und die Signale des NbSyn2 repräsentieren die syn2-Epitope (in Grün). (B) Zu sehen sind zum Teil kolokalisierende Signale der in (A) einzeln dargestellten Epitope. Aufgrund der Signalüberlagerung einiger Epitope und mithilfe der multiplexen Epitop-Analyse konnten die transfizierten Konstrukte identifiziert werden. Die Balkenbreite beträgt $10 \mu \mathrm{m}$.

\subsubsection{Anwendung der multiplexen Epitop-Analyse bei einer sequenziellen direkten Immunfärbung eines Live-Imaging-Experiments}

Nach der erfolgreichen Bestätigung der Funktionalität der Epitop-Analyse zur multiplexen Identifizierung von Proteinen nach einer direkten Immunfärbung, wurde ebenso ihre Eignung zur Proteindetektion während eines Live-Imaging-Experimentes getestet.

Als Vorbereitung für das Live-Imaging-Experiment wurde eine Vier-Plasmid-Transfektion in HEK-293-Zellen durchgeführt. Zu den transfizierten Proteinkonstrukten gehörten TOM70_mCherry, GalNact_GFP_syn87, NLS_mCherry_GFP_syn2 und Lifeact_mCherry_syn2.

Anschließend wurde eine direkte sequenzielle Immunfärbung (s. Kapitel 2.7.3.2) mit den vier Epitop-spezifischen Nanobodies innerhalb einer Live-Imaging-Kammer durchgeführt. Die Voraussetzung für die Methode der sequenziellen Färbung war, dass vor jeder NanobodyFärbung bereits vorhandene Fluoreszenz weggebleicht werden mussten, sodass nur die Fluo- 
reszenz des verwendeten Nanobodies gemessen werden konnte. Das hieß, dass zu Beginn es Versuchs die bereits durch Transfektion vorhandene Fluoreszenz des mCherry- und des GFPEpitops gebleicht werden mussten. Dazu wurden bestimmte Zellen in einem Bereich ausgewählt und diese während des gesamten Live-Imaging-Experimentes als zu visualisierende Objekte beibehalten. Zur Visualisierung der nacheinander verwendeten fluorophorgekoppelten Nanobodies erfolgte eine spezifische Anregung der jeweiligen Kanäle (488- oder $546 \mathrm{~nm}$ ) durch Anwendung eines AXIO LSM710 (s. Kapitel 2.7.4). Zunächst wurden die Signale des syn87-Epitops mithilfe des NbSyn87 detektiert, dann die des syn2-Epitops durch Färbung mit dem NbSyn2 und anschließend die Signale des GFP-Epitops mithilfe des NbGFPs. Zuletzt wurde der LaM-2-546 zur Visualisierung der vorhandenen mCherry-Epitope innerhalb der ausgewählten HEK-293-Zellen verwendet. Zwischen den einzelnen Färbungsschritten wurde die erzielte Fluoreszenz immer wieder gebleicht.

Abbildung 21 stellt die während des Live-Imaging-Experiments detektierten Signale der verwendeten Nanobodies dar. Teil A zeigt zwei Vier-Transfekt-HEK-293-Zellen (innerhalb des weißen Kästchens) vor dem Beginn der sequenziellen Immunfärbung in einer Live-ImagingKammer. Die Aufnahmen wurden vor (oberes Bild) und nach (unteres Bild) der Bleichung der in den Konstrukten vorhandenen mCherry- und GFP-Epitope aufgenommen.

In Teil B sind die Signale der fluoreszierenden Nanobodies dargestellt, die jeweils einzeln während des Ablaufs der sequenziellen Immunfärbung gemessen wurden. Mithilfe des NbGFPs, des LaM-2s und des NbSyn2s konnten in den Zellen jeweils zwei in ihrer Lokalisation voneinander divergierende Signale detektiert werden, während mit dem NbSyn87 nur ein einzelnes Signal gemessen werden konnte. Das zu dem NbSyn87 gehörige Signal des syn87-Epitops kolokalisiert dabei nur mit einem Signal des NbGFPs, wodurch GalNact_GFP_syn87 als eines der transfizierten Genkonstrukte identifiziert werden konnte. Das mit keinem anderen Signal überlagernde LaM-2-Signal im Bereich der Mitochondrien stimmt mit dem mCherry-Epitop von TOM70_mCherry überein. Sowohl mit dem NbGFP als auch mit dem LaM-2 und dem NbSyn2 konnten jeweils kongruierende Signale innerhalb der Kern-Region detektiert werden, infolge dessen die Identifizierung von NLS-mCherry_GFP_syn2 ermöglicht wurde. Mithilfe der kolokalisierenden Signale des LaM-2s und des NbSyn2s innerhalb der Membran konnte Lifeact_mCherry_syn2 als viertes transfiziertes Genkonstrukt identifiziert werden. 
A

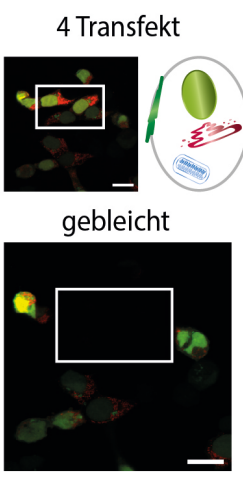

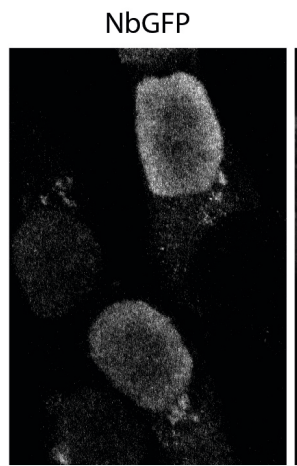

LaM-2

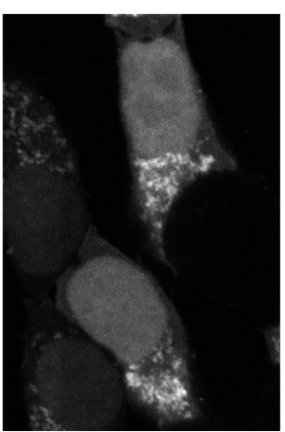

NbSyn87

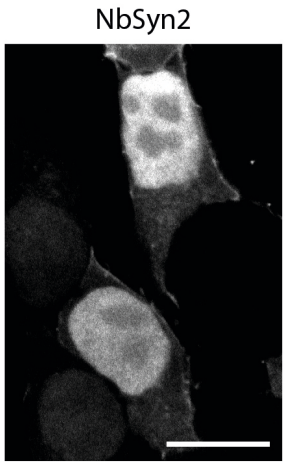

Abbildung 21: Multiplexe Epitop-Analyse während eines Live-Imaging-Experiments. (A) HEK-293-Zellen wurden mit vier verschiedenen Proteinkonstrukten transfiziert. Durch eine spezifische Anregung bei $488 \mathrm{~nm}$ und $543 \mathrm{~nm}$ mithilfe des AXIO LSM710 wurden fluoreszierende Signale der GFP- und mCherry-Epitope der transfizierten Proteinkonstrukte gemessen (Vier-Transfekt). Anschließend wurden die detektierten Signale zweier ausgewählter HEK-293-Zellen (s. weißes Kästchen) mittels einer Laserbestrahlung gebleicht. (B) Die dargestellten Signale der bei einer sequenziellen Immunfärbung nacheinander verwendeten fluoreszierenden Nanobodies dienen zur Visualisierung der jeweiligen Epitope der transfizierten Proteinkonstrukte. Durch die abgebildete Kolokalisation des GFP-Epitops mit dem syn87Epitop, sowie der Kolokalisation mit den LaM-2 und dem syn2-Epitop können GalNact_GFP_syn87 und NLS_mCherry_GFP_syn2 als zwei der vier transfizierten Genkonstrukte identifiziert werden. Das inkongruente Signale des LaM-2s signalisiert das mCherryEpitop von TOM70_mCherry und die vorhandene Kolokalisation eines LaM-2-Signal mit einem syn2-Signal bestätigt die Transfektion von Lifeact_mCherry_syn2 als viertes Genkonstrukt. Es wurden also die Konstrukte TOM70_mCherry, GalNact_GFP_syn87, NLS_mCherry_GFP_syn2 und Lifeact_mCherry_syn2 identifiziert. Die Balkenbreite beträgt $20 \mu \mathrm{m}$.

Die multiplexe Epitop-Analyse hat sich als geeignetes Verfahren zur Identifizierung von Proteinen während eines Live-Imaging-Experiments repräsentiert. Der Vorteil dieser Methode ist, dass keine Differenzierung mehr zwischen mehreren Fluorophoren notwendig ist. Das Risiko einer Überlagerung der Wellenlängen kann ausgeschlossen werden. 


\section{Diskussion}

Da die zellulären Funktionen auf der Zusammenarbeit einer Vielzahl von Proteinen beruhen, ist die Fähigkeit der multiplexen Proteinbestimmung und -bildgebung für die medizinische und biologische Forschung von immenser Bedeutung. Die aktuellen Technologien sind derzeit nur begrenzt zur multiplexen Identifizierung von Proteinen anwendbar. Die wesentlichen Schwierigkeiten von multiplexen Verfahren bestehen darin, dass die meisten ihre Basis auf Antikörpern begründen, da diese Antigene mit hoher Spezifität an der antigenen Determinante binden können (Fagraeus 1948). Zu diesen Verfahren gehören zum Beispiel die MikrospotTechnik (Feinberg und Wheeler 1963) oder auch ELISA (Engvall und Perlmann 1971). Dabei wird für jedes zu identifizierende Protein jedoch auch ein entsprechender Antikörper benötigt, sodass die Zahl der gleichzeitig zu identifizierenden Proteine sehr begrenzt ist. Aus diesem Grund befasst sich die vorliegende Arbeit mit der Entwicklung einer auf Nanobodies basierenden Epitop-Analyse zur Identifizierung von Proteinen. Dieser neue Ansatz stellt eine Alternative zu den heutigen Verfahren der multiplexen Bildgebung dar und soll die multiple Entschlüsselung von Proteinen ermöglichen. Die Verifizierung der Epitop-Analyse erfolgte anhand der Identifizierung von 15 Protein-Epitop-Konstrukten auf Basis des Bindungsverhaltens von vier Nanobodies.

Die Grundidee der Epitop-Analyse beruht darauf, dass durch die einzigartige Protein-EpitopKombination der Konstrukte ebenfalls einzigartige Nanobody-Bindungssätze pro Konstrukt detektiert werden können. Die jeweils detektierbaren Nanobody-Bindungssätze sind analog zu den pro Protein vertretenen Epitop-Sätzen. Auf deren Basis erfolgt anschließend die Identifizierung der jeweiligen Konstrukte. Dieser Leitgedanke des Projekts wurde in Form von Experimenten zu dem Epitop-spezifischen Bindungsverhalten von vier als Sonden fungierenden Nanobodies bestätigt. Die Verifizierung der Epitop-Analyse erfolgte dabei mittels der Entschlüsselung von 15 künstlich designten Proteinkonstrukten, die in HEK-293-Zellen transfiziert worden sind. Die eingesetzten Nanobodies besitzen keine spezifische Affinität für ein einzelnes Protein, sondern nur für bestimmte Epitope. Diese Epitope waren Teil der Proteinkonstrukte. Es hat sich gezeigt, dass die Nanobodies in der Lage sind diejenigen Konstrukte zu binden, die innerhalb ihrer Aminosäuresequenz das entsprechende spezifische Epitop vertreten hatten, sodass jedem Epitop das Signal eines bestimmten Nanobodies zugeordnet werden konnte. Je nach Zusammenstellung der Epitope, konnte an jedes exprimierte Proteinkonstrukt nur eine bestimmte Kombination von Nanobodies binden (s. Abbildung 6). Anhand 
der jeweils spezifisch gebundenen Sätze an Nanobodies ermöglichte die Epitop-Analyse die Identifizierung jedes einzelnen Konstrukts. In dieser Arbeit konnte die Eignung der EpitopAnalyse sowohl als singleplexes als auch als multiplexes Verfahren bestätigt werden.

\subsection{Gewinnung und Funktionalität der Nanobodies}

In diesem Projekt zur Entwicklung der Epitop-Analyse stellen Nanobodies die Grundlage der Epitop-Analyse dar. Im Folgenden werden die bei der Gewinnung und bei der Funktionalität entstandenen Herausforderungen und Lösungsansätze diskutiert.

Die für die Arbeit benötigten Nanobodies wurden zum Teil gekauft (s. Tabelle 2), zum Teil nach Anleitung aus etablierten Protokollen selbst gereinigt (Guilliams et al. 2013). Zu den eigenständig nach dem Protokoll der His-tag-Isolation (s. Kapitel 2.4) gereinigten Nanobodies gehörte der NbSyn87. Bei der Kontrolle der Reinigung mithilfe der SDS-Page (s. Kapitel 3.2) wurden neben dem erwarteten Band bei $41 \mathrm{kDa}$ Kontaminationen bei $37 \mathrm{kDa}$ festgestellt.

Diese Kontaminationen spiegeln die typischen Herausforderungen wider, die bei der Verwendung von Polyhistidin-Affinitätsmarkierungen auftreten können. Obwohl die Aminosäure Histidin in der Aminosäuresequenz von Proteinen nur selten vertreten ist, enthalten einige zelluläre Proteine mehrere hintereinander folgende Histidinreste (Schmitt et al. 1993). Diese Proteine besitzen ebenfalls eine Affinität für die IMAC-Matrix und eine Ko-Elution mit dem eigentlich gewünschten Protein würde anschließend zu einer Kontamination des Endprodukts führen. Eine weitere Ursache für die Verunreinigungen der Probe könnten ebenfalls Disulfidbindungen oder verschiedene hydrophobe Wechselwirkungen sein, die zwischen dem gewünschten Protein und anderen Proteinen auftreten können. Damit diese Auslöser vermieden werden können, sollten in nachfolgenden Projekten einige Veränderungen am durchgeführten Protokoll vorgenommen werden. Durch Zugabe des nichtionischen Detergens Triton X-100 können zum Beispiel Wechselwirkungen in den Puffern reduziert werden, ohne dass die Bindung des markierten Proteins mit der $\mathrm{Ni}^{2+}$-Matrix wesentlich beeinflusst wird. Bei kontaminierenden Proteinen sollte zudem die Waschzeit verlängert sowie die NaCl-Konzentration (bis $500 \mathrm{mM}$ ) erhöht werden, da die Entfernung unspezifisch gebundener Komponenten durch eine erhöhte Ionenstärke erfolgt. Eine weitere Methode zur Kontaminationsvermeidung beruht auf der Steigerung der Imidazol-Konzentration des Waschpuffers, wodurch die Stringenz der Waschung erhöht und unspezifische Proteine wirksamer eluiert werden können (Bornhorst und Falke 2000).

Wie in Abbildung 11 gezeigt, stellt sich die ermittelte Kontamination als Band bei einem Molekulargewicht $(37 \mathrm{kDa})$ dar, welches kleiner ist als das des eigentlichen Proteins $(41 \mathrm{kDa})$. In 
diesem Fall handelt es sich wahrscheinlich um unvollständig exprimierte Nanobodies, die zum Beispiel durch einen frühzeitigen Translationsabbruch entstanden sind. Da sich der ausge-

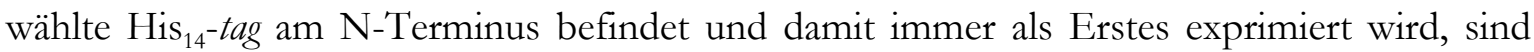
unvollständig exprimierte Proteine trotzdem in der Lage sich an die Ni-NTA-Matrix zu binden. Damit dieser Effekt vermieden werden kann, sollte für nachfolgende Aufreinigungen schon bei der Kultivierung ein Expressionsvektor gewählt werden, bei dem der His ${ }_{14}$-tag am C-Terminus des Proteins angefügt ist und somit erst als Letztes translatiert wird. Dadurch sind nur vollständig translatierte Proteine fähig sich an die Ni-NTA-Matrix zu heften.

Eine Alternative zur Protein-Markierung mit einem His-tag könnte die Aufreinigung nach der Twin-Strep-tag-Technik darstellen, die für ihre Bereitstellung rekombinanter Proteine mit einem hohen Reinheitsgrad und Funktionalität nach Anwendung eines Ein-Schritt-Protokolls bekannt ist (Schmidt et al. 2013). Des Weiteren wurde von Dmitry G. Vassylyevs Gruppe eine ultrahohe Affinitätschromatographie entwickelt, die auf der hohen Dissoziationskonstante $\left(\mathrm{K}_{\mathrm{D}}\right)$ zwischen Colichin-DNAasen (CE) und Immunity Proteinen (Im) beruht. Aufgrund der hohen CL7/Im7-Affinität können Inkubation und Waschung unter sehr stringenten Bedingungen (mehr als $1 \mathrm{M} \mathrm{NaCl}$ ) erfolgen, wodurch die Kontaminationswahrscheinlichkeit des Endprodukts stark reduziert werden kann (Vassylyeva et al. 2017). In den nächsten Projekten auf Nanobody-Basis sollten also entsprechende Protokolle zur Gewinnung und Reinigung der Nanobodies angewendet werden, damit Kontaminationen vermieden und der Reinheitsgrad verbessert werden kann.

Die festgestellten Verunreinigungen könnten eine Ursache des unspezifischeren Bindungsverhaltens des NbSyn87 im Vergleich zu dem LaM-2 und dem GFP-Nb darstellen. Dieses ist in dem Funktionstest der Nanobodies beobachtet worden (s. Kapitel 3.3). Da die Nanobodies die Basis dieser Arbeit darstellen, ist ihre spezifische Reaktion mit den entsprechenden Epitopen als eine Voraussetzung zur Umsetzung der Epitop-Analyse anzusehen. Das Bindungsverhalten der Nanobodies wurde während eines Funktionstests überprüft. Die beiden Nanobodies NbSyn2 und NbSyn87 interagieren mit bestimmten Epitopen des Proteins $\alpha$-Synuclein. Die Länge dieser Epitope umfasst nur wenige Aminosäuren (Aminosäuren 118-131 bzw. Aminosäuren 137 - 140) (Guilliams et al. 2013). Dagegen betrug die Länge des im Proteinkonstrukt vertretenen mCherry-Epitops 236 Aminosäuren und die des GFP-Epitops 239 Aminosäuren. Bei der Auswertung des Funktionstests der Nanobodies konnte im Vergleich zu den Nanobodies LaM-2 und NbGFP bei dem NbSyn2 und dem NbSyn87 ein größeres Hintergrundsignal festgestellt werden (s. Kapitel 3.3). Dieses könnte mit den unterschiedlich hohen Affinitäten $\left(K_{D}\right)$ der Nanobodies in Bezug auf ihre Epitope begründet werden. Während 
der NbGFP (NanoTag Biotechnologies) einen $K_{D}$-Wert im picomolaren Bereich und der LaM2 bei 0,49 nM (Fridy et al. 2014) aufweist, liegt der $K_{\mathrm{D}}$-Wert des NbSyn87 bei 61,7 nM und der des NbSyn2 bei 190 nM (Guilliams et al. 2013). Fridy et al. stellen fest, dass eine starke Korrelation zwischen einem niedrigem $\mathrm{K}_{\mathrm{D}}$ und einem hohen Hintergrundsignal besteht. Des Weiteren gehen steigende $K_{D}$-Werte (auch schon bei $10 \mathrm{nM}$ ) mit einer reduzierten Affinitätsleistung der jeweiligen Nanobodies einher. In nachfolgenden Experimenten sollte daher ein großer Wert auf die Verfügbarkeit von ultrahoch-affinen Liganden $\left(K_{D}\right.$ kleiner als $\sim 30 \mathrm{pM}$ ) zur Detektion von Proteinen gelegt werden. Ein erhöhtes Hintergrundsignal könnte ebenfalls mit der Größe der antigenen Determinante, das heißt der Größe des jeweiligen Epitops gegen das die Nanobodies gerichtet sind, begründet werden. Eine geringe EpitopGröße könnte die niedrigere Affinität und Spezifität der NbSyn2 und NbSyn87 im Vergleich zu den anderen Nanobodies begründen, da dadurch die Wahrscheinlichkeit einer unspezifischen Bindung potenziert wird (Guilliams et al. 2013). Je kleiner das Epitop ist, desto größer ist die Wahrscheinlichkeit, dass die jeweilige Aminosäuresequenz auch zufällig in anderen Proteinen als nur im $\alpha$-Synuclein vertreten ist. Um eine gewisse Affinität zu gewährleisten, ist es ratsam, dass die Epitop-Größe eine bestimmte Aminosäure-Anzahl nicht unterschreitet.

\subsection{Fluorophorgekoppelte Nanobodies}

Zur Funktionsüberprüfung der Nanobodies wurden diese an Fluorophore gekoppelt. Nach einer spezifischen Anregung der jeweils gekoppelten Fluorphore, konnten in jeder Zelle die Signale der Nanobodies detektiert und voneinander differenziert werden. Im Folgenden werden sowohl die Herausforderungen und Ergebnisse im Bereich der Kopplung als auch hinsichtlich der Auswertung und Differenzierung der Signale dargestellt.

Das durchgeführte Protokoll beruhte auf dem Verfahren der Maleimid-Markierung (s. Kapitel 2.7). $\mathrm{Zu}$ den verwendeten Fluorophoren gehörten unter anderem Alexa 488, CF 633, Alexa 546, Dylight 405 und CF 350 (s. Tabelle 6). Während der Kopplungsversuche sowie den Untersuchungen zu den gekoppelten Nanobodies konnten unterschiedliche Erfolge bzw. Schwierigkeiten in Bezug auf die gewählten Fluorophore festgestellt werden. Die größte Herausforderung hinsichtlich der Kopplung entstand bei den blauen Fluorophore Dylight 405 und CF 350. Diese konnten während der Durchführung des Protokolls in der Sephadex-Säule aufgrund ihrer Farblosigkeit nur schwer aufgefangen werden. Um diese Schwierigkeiten hinsichtlich der manuellen Durchführung der Kopplungs-Protokolle zu vermeiden, könnte als eine Vereinfachung die Kopplung mithilfe von Geräten, wie zum Beispiel dem Äkta-Prime FPLC system (GE Healthcare, Schweden), erfolgen. Mit der Anwendung der Superdex 200 10/300 GL-Säule 
(GE Healthcare, Schweden) im Äkta-Prime wäre unter diesen Umständen die Kopplung ein maschinell programmierbarer Prozess, bei dem Komplikationen, die auf einer manuellen Durchführung beruhen, verhindert werden können.

Eine weitere Schwierigkeit stellte sich bei der Erstellung von Aufnahmen zur Analyse des Bindungsverhaltens der Nanobodies ein. Bei der Anregung der Fluorophore mit verschiedenen Mikroskopen wurde eine Bleichung der blauen Fluorophore festgestellt, sodass eine Wiederholung der Aufnahme zum Teil nicht möglich war. Ähnliche Probleme traten ebenfalls bei anderen Studien auf, die eine Bleichung von Fluorophoren als einen lichtinduzierten Prozess der irreversiblen Zerstörung der Fluorophore ansehen. In Fluoreszenz-FluktationsExperimenten wurden verschiedene Strategien getestet, die dazu dienten, eine Bleichung von Fluorophoren zu umgehen (Satsoura et al. 2007). Damit der Bleichungsgrad minimiert werden konnte, wurden in dieser Arbeit bei Serienaufnahmen aller verwendeten Fluorophore als Erstes die blauen Fluorophore angeregt und abgebildet. Dadurch konnte verhindert werden, dass eine Bleichung der blauen Fluorophore durch die Belichtung der Fluorophore längerer Wellenlänge stattfindet, bevor die eigentliche Detektion der blauen Fluorophore erfolgen konnte. Bei der Anregung der blauen Fluorophore Dylight 405 und CF 350 mit kurzwelligem Licht wurde ebenfalls eine verstärkte Autofluoreszenz aller benachbarten Zellen festgestellt. Durch die Autofluoreszenz besteht die Gefahr, die autofluoreszierenden Signale als positive Ergebnisse der zu untersuchenden Zielobjekte zu interpretieren. Außerdem verringern diese ungewollten Signale die Fähigkeit, die Signale der eigentlichen Objekte korrekt zu identifizieren (Levenson und Mansfield 2006). Damit die Autofluoreszenz reduziert werden konnte, wurden die Laserleistung und die Belichtungsdauer möglichst gering gehalten.

Bei der Auswertung bezüglich der Nanobody-Signale wurde festgestellt, dass durch eine definierte, nicht veränderliche Laserstärke einige Fluorophore überbelichtet wurden, während andere kaum zu sehen waren, da diese im Vergleich eine höhere Laserstärke benötigt hätten. In Abhängigkeit von den unterschiedlichen Fluorophoren musste deswegen die Laserleistung mehrmals separat eingestellt werden. Dies war vor allem kritisch, wenn mehrere Nanobodies, die an unterschiedliche Fluorophore gekoppelt waren, gleichzeitig verwendet wurden. Diese Umstände stellten sich vor allem bei der gleichzeitigen Anwendung von Alexa 488 mit CF 633 oder Dylight 405 ein. Die möglichen Gründe für eine notwendige separate Lasereinstellung sind in vielen unterschiedlichen Bereichen zu suchen. Zum einen könnten die variierend starken Signale ausschließlich darauf zurückzuführen sein, dass die Fluorophore unterschiedliche Laserleistungen zur Anregung ihrer Elektronen benötigen. Zum anderen könnte ein Grund in der Transfektions- bzw. Expressionseffizienz der verschiedenen Proteinkonstrukte innerhalb der Zelle liegen. Je höher die Expressionsrate ist, desto mehr Nanobodies sind in der Lage an 
ihre exprimierten Epitope zu binden und desto größer ist anschließend das zu detektierende Signal. Ähnliche Ergebnisse wurden bei der Testung der multiplexen Epitop-Analyse in Bezug auf den Nanobody LAM-2 während des Drei-Transfekt-Experiments (s. Kapitel 3.6.1) festgestellt. Bei der Auswertung dieses Experiments konnte bei gleicher Belichtungszeit ein stärkeres Signal des LAM-2 bei Bindung an das mCherry_TOM70-Konstrukt als an das Lifeact_mCherry_syn2-Konstrukts festgestellt werden, obwohl äquivalente Mengen an Plasmiden in die Zellen transfiziert worden waren. Um Signaldifferenzen aufgrund unterschiedlicher Expressionsraten zu vermeiden, sollten die Transfektions- und Expressionsgrade aller transfizierten Plasmide/Konstrukte auf ein gleiches Level gebracht werden. Nach T. Wimmer lässt sich die Transfektionseffizienz des verwendeten, auf kationische Lipide beruhenden Verfahren der Lipofektion (s. Kapitel 2.5) erheblich steigern, wenn die DNA-Lipid-Komplexe auf zuvor mit Trypsin/EDTA gelöste und anschließend resuspendierte und wieder ausplattierte Zellen getropft werden. Durch diesen Schritt soll die Effizienz der Transfektion auf über $80 \%$ gesteigert werden können (Laborjournal 2010). Neben dem unterschiedlich hohen Expressionsgrad von Proteinen könnte ebenso die Lokalisation bzw. die Struktur der Proteine in der Zelle ausschlaggebend für den Bindungserfolg der Nanobodies sein. Lifeact, ein von der Hefe Abp140p abgeleitetes 17 Aminosäuren langes Peptid (Riedl et al. 2008), konnte in diesem Projekt im Vergleich zu TOM70, welches Teil der Mitochondrien ist, schlechter dargestellt werden bzw. benötigte für die gleiche Darstellungsintensität eine größere Laserleistung und längere Belichtungszeit. Einen weiteren Grund für die unterschiedlich gute und starke Signalgebung der Nanobodies könnte ein falsch dosiertes Fluorophor:Nanobody-Verhältnis während der Kopplungsverfahren (s. Kapitel 2.7.1) liefern. Um zu garantieren, dass jeder Nanobody an ein Fluorophor gekoppelt wird, wurde das Verhältnis so gewählt, dass ein Fluorophor-Überschuss von 1000:1 vorlag. Bei einem Missverhältnis von Fluorophor und Nanobody ist es möglich, dass die Kopplungsreaktion einen Teil der Nanobodies inaktiviert oder ein abweichendes Bindungsverhalten zu der eigentlichen antigenen Determinante hervorruft (Vira et al. 2010).

Eine weitere Herausforderung für eine für alle Experimente universell eingestellte Laserleistung liegt darin, dass mit der Transfektion der Proteinkonstrukte bereits ohne Färbung fluoreszierende Produkte durch die Zelle exprimiert werden, wie zum Beispiel durch die in den Konstrukten vertretenen mCherry- und GFP-Epitope. Diese bereits durch die Proteinexpression vorhandene Fluoreszenz ist in ihrer Signalstärke nur schwierig mit den durch fluoreszierende Nanobodies detektierten Signalen zu vergleichen. Letztere wurden in allen Experimenten als schwächer festgestellt, bzw. benötigten für die gleiche Signalstärke eine höhere Laserleistung und Belichtungszeit. Es bestand die Gefahr, dass die stärker fluoreszierenden Signale 
der bereits exprimierten Proteine die Fähigkeit zur Signaldetektion der eigentlich zu identifizierenden Objekte verringern.

Eine weitere optimierte Vorgehensweise in Bezug auf die Signalstärke der Fluorophore könnte sein, dass nur noch mit den ,gut funktionierenden“ Fluorophoren (v. a. Alexa 488 und Alexa 546) gearbeitet wird. Dadurch wird jedoch die mögliche Farbauswahl stark eingegrenzt, sodass ebenfalls die Zahl der gleichzeitig verwendbaren Nanobodies dezimiert werden müsste. Da die designten Genkonstrukte zum Teil aus vier Epitopen bestanden, mussten jedoch in diesen Fällen auch vier Nanobodies zur Detektion der Epitope eingesetzt werden. Da die EpitopAnalyse in dieser Arbeit auf visueller Basis stattfinden sollte, wurde deshalb trotzdem zunächst auf eine breitere Farbauswahl gesetzt. Vier an unterschiedliche Fluorophore gekoppelte Nanobodies waren die Voraussetzung zur Durchführung der Epitop-Analyse nach einer simultanen Färbung (s. Kapitel 3.4 und 3.6.1). Die Farben wurden jedoch dahingehend ausgewählt, dass zum Beispiel bei den blauen Fluorophoren verschiedene Varianten getestet und anschlieBend das erfolgversprechendste Fluorophor (Dylight 405) mit dem schmalsten Emissionsspektrum und der geringsten Bleichung ausgesucht wurde.

Eine Problematik in Bezug auf die simultane Anwendung mehrerer Fluorophore besteht in der spektralen Überlappung der emittierten und zu messenden Fluoreszenz. Diese Farbbarriere limitiert in vielen Experimenten die Zahl der darzustellenden Objekte (Strack 2016). Ähnliche Limitationen sind in diesem Projekt bei der Überprüfung der kombinatorischen EpitopAnalyse als multiplexes Verfahren nach der simultanen Färbung aufgetreten. Da die EpitopAnalyse nach einer simultanen Färbung auf visueller Basis praktiziert worden waren, sollte eine Ergebnisverzerrung aufgrund einer unbemerkten spektralen Überlagerung der verwendeten Fluorophore ausgeschlossen werden. Aus diesem Grund wurde die Epitop-Analyse ebenso nach einer sequenziellen Färbung getestet. Der Vorteil der sequenziellen Färbungsmethode beruht darin, dass spektrale Überlagerungen der an Nanobodies gekoppelten Fluorophore vermieden werden können. Des Weiteren konnte dadurch die benötigte Farbauswahl der Fluorophore auf die grünen und roten Fluorophore (Alexa 488 und Alexa 546) reduziert werden, da bei der sequenziellen Färbung alle Nanobodies nacheinander verwendet werden und jeder fluorophorgekoppelter Nanobody auf einen durch Bleichung erzielten fluorophorfreien (Zell)Bereich aufgetragen wird. Dadurch kann die Fluorophoranzahl und -auswahl auf ein einziges und gleichzeitig erfolgversprechendste Fluorophor begrenzt werden, womit einhergehend etwaige spektrale Überlagerungen ausgeschlossen werden können. Mit der Praktik der sequenziellen Methode kann so theoretisch eine unbegrenzte Anzahl an Nanobodies hintereinander verwendet werden. Bei der Anwendung der sequenziellen Färbung muss jedoch das KostenNutzen-Verhältnis abgewägt werden, da der Zeitaufwand ca. das Vierfache der simultanen 
Färbungsmethode beträgt. In diesem Zusammenhang könnten in weiterführenden Experimenten statt den bisher verwendeten Fluorophoren fluoreszierende Quantendots dienlich sein, eine neue Entwicklung aus der Nanotechnologie. Diese weisen einzigartige optische Eigenschaften auf, wie zum Beispiel enge und auf die Größe abstimmbare Emissionsspektren (4651 - $2300 \mathrm{~nm}$ ), große Stokes-Shifts sowie eine wesentlich höhere Fluoreszenzintensität und -dauer (Zrarhevskiy und Gao 2013). Dadurch könnte zum einen trotz simultaner Färbungsmethode die Gefahr einer spektralen Überlagerung reduziert werden. Zum anderen ist es durch die lange Fluoreszenzlebensdauer der Quantendots möglich, die zu messende Fluoreszenz von anderen, kurzlebigeren Signalen, die zum Beispiel durch Autofluoreszenz hervorgerufen worden sind, zu unterschieden (Michalet et al. 2005). So könnte weiterhin der zeitsparende Weg der simultanen Immunfärbung durchgeführt werden, ohne die durch die herkömmlichen Fluorophore potenzierten Wahrscheinlichkeit der spektralen Überlagerung zu riskieren.

Bei der Durchführung der Epitop-Analyse kann eine spektrale Überlagerung ebenfalls durch Anwendung verschiedener optischer Geräte umgangen werden, ohne dass ein immenser Zeitaufwand notwendig ist. Mithilfe eines STORMs (stochastic optical reconstruction microscopy) ist es möglich, die Fluorophore trotz spektraler Überlappung voneinander zu differenzieren, sodass die Zahl der gleichzeitig zu identifizierenden Ziele erhöht werden kann (Zhang et al. 2015). Diese Fähigkeit beruht auf der sequenziellen Lokalisierung an- und ausschaltbarer Fluorophore, die durch selektive Aktivierungen zu unterschiedlichen Zeiten während der Bildgebung emittieren. Einen weiteren Ansatz, eine multiplexe Bildgebung ohne spektrale Überlagerung zu ermöglichen, stellen Serienaufnahmen von aufeinander folgenden Abschnitten dar (Stack 2014). Als eine Alternative zur rein visuellen Überprüfung der Ergebnisse der Epitop-Analyse könnten ebenfalls verschiedene Softwareprogramme genutzt werden, die die Analyse von multiplexen Bildern ermöglichen. Damit dabei alle Ziele identifiziert und quantifiziert werden können, muss eine Umwandlung der Signale in die entsprechende optische Intensität und anschließend eine lineare Zerlegung basierend auf charakteristische Absorptionsspektren stattfinden (Teverovskiy et al. 2008). Die Farbdetektionskapazität der verwendeten Kamera bestimmt dabei die Farbquantität, die für die Analyse mittels Bildgebungssoftware bereitgestellt wird. Da die in dieser Arbeit verwendete Kamera die monochromatische Bildung in vier verschiedenen Kanälen ermöglicht, wäre die multiplexe Analysefähigkeit der Software auf die vier Farben beschränkt und es gäbe keine Möglichkeit dazwischenliegenden Emissionsüberlappungen der Fluorophore zu extrahieren. Um Einschränkungen in der Auswertung zu vermeiden, sollte stattdessen eine Multispektralkamera verwendet werden, die diskrete Spektralintervalle des gesamten sichtbaren Spektrums erfassen kann, sodass die Emissionsspektren aller 
Fluorophore ermittelt und gegeneinander analysiert werden können (Levenson und Mansfield 2006).

\subsection{Die Immunfärbung}

Das während dieser Arbeit verwendete Protokoll zur Immunfärbung schreibt zunächst eine Fixierung der Zellen mit PFA vor. Aus vielen anderen Studien geht hervor, das PFA eine Ursache für verschiedene experimentelle Probleme darstellt. Dazu gehören zum Beispiel morphologische Veränderungen der Probe, verschwundene Epitope oder fehlgeleitete Zielproteine (Melan 1994). Die festgestellten Differenzen, bezogen auf das Bindungsverhalten der Nanobodies, könnten also ebenso auf das bereits bei der Fixierung der Zellen verwendete PFA zurückzuführen sein.

Richter et al. (2018) stellten heraus, dass das Dialdehyd Glyoxal aufgrund seiner vielfältigen Eigenschaften im Vergleich zu PFA die geeignetere Variante zur Fixierung von Zellen ist. Durch die Anwendung von Glyoxal werden die Zellen schneller fixiert, sodass die Wahrscheinlichkeit von morphologischen Veränderungen reduziert werden kann. Des Weiteren lieferte eine Glyoxal-Fixierung, im Vergleich zu einer Fixierung mit Formaldehyd, nach einer anschließend durchgeführten Immunfärbung stärkere Fluoreszenzsignale. Durch die Änderung der Fixierungsdurchführung besteht die Perspektive in Folgeprojekten vermeidbare Herausforderungen, wie erhöhte Hintergrundintensitäten bzw. unspezifische Signale aufgrund morphologischer Veränderungen oder anderer Ursachen, zu vermeiden.

Ein wichtiger Vorteil in Bezug auf den Zeitaufwand sind die unterschiedlich aufwendigen Schritte zur Durchführung einer direkten Nanobody-Färbung bzw. einer indirekten Antikörper-Färbung. Nach Protokoll (s. Kapitel 2.7) sind für die Antikörper-Färbung pro Färbung ca. 60 min mehr einzuplanen, da hier die Färbungsmethode nach einem auf zwei Schritten beruhenden Antikörper-Antikörper-Prinzip stattfindet. Im Gegensatz dazu ist die Durchführung des Protokolls für die direkte Immunfärbung einfacher und fehlerfreier, da bei dieser einSchritt-Methode nur in einem Part die Nanobodies verwendet werden.

Ein wesentlicher Vorteil der Nanobody-Färbung im Vergleich zu der Antikörper-Färbung besteht in dem Zeitgewinn, der höheren Schärfe der Bilder und des ausgeprägten Affinitätsgrads der Nanobodies. Aufgrund der Durchführungsweise der Antikörper-Färbung nach dem Antikörper-Antikörper-Prinzip können Lokalisierungsfehler auftreten, weil zwischen dem eigentlichem Zielprotein und dem messbaren Fluorophor Abstände von ca. $30 \mathrm{~nm}$ bestehen. Mit steigender Größe der eingesetzten Sonden und bei bivalenter Affinität sinken sowohl die Markierungseffektivität als auch der Auflösungsgrad der Detektion (Opazo et al. 2012). Infol- 
ge ihrer strukturellen Beschaffenheit kann durch den Einsatz von Nanobodies eine präzisiere Bildgebung erfolgen, weil durch die geringe Größe von $15 \mathrm{kDa}$ der Objekt-FluorophorAbstand dezimiert wird. Diese Präzisionsunterschiede sind vor allem bei der Auswertung der singleplexen Epitop-Analyse (s. Kapitel 3.4) zu vermerken, wenn die Nanobody- und Antikörper-Färbungen miteinander verglichen werden. Bei der Nanobody-Färbung ist es möglich eine genauere Lokalisation des betrachteten Proteins in der Zelle zu detektieren, während bei der Antikörper-Färbung ein größeres und flächigeres Areal markiert wird. Diese Beobachtungen unterstützen anderen Publikationen, die festgestellt haben, dass eine erhöhte Molekülgröße außerdem zu einer begrenzten Zieldurchdringungswirksamkeit (Hughes 2010) und einem hohen Hintergrundgehalt bei der Bildgebung führt (Hildebrant und Gambhir 2004).

\subsection{Die singleplexe Epitop-Analyse}

Mit der Testreihe der singleplexen Epitop-Analyse sollte die Eignung des neuen Prinzips zur Identifizierung und Bildgebung von Proteinen überprüft werden. Das Ergebnis dieser Testreihe ist, dass mithilfe der kombinatorischen Epitop-Analyse auf Basis des Bindungsverhaltens der Nanobodies an ihre Epitope, die Darstellung aller transfizierten Proteinkonstrukte möglich ist. Der Vorteil dieser Methode beruht in erste Linie darauf, dass für die Identifizierung von 15 Proteinkonstrukten lediglich vier Nanobodies benötigt werden. Für die Darstellung der gleichen Anzahl von Proteinen mithilfe von proteinspezifischen Antikörpern werden dagegen 15 bzw. 30 Antikörper (auf Basis des Antikörper-Antikörper-Prinzips) benötigt. Für das gleiche Ergebnis sind daher weniger Nanobodies notwendig als mit Antikörpern, wodurch der Zeit- und Geldaufwand sowie der Komplikationsgrad der angewendeten Protokolle verringert werden kann. Außerdem liegt ein signifikanter Vorteil für die Anwendung von Nanobodies darin, dass die Nanobody-Gewinnung weit weniger aufwendig ist als die der Antiköper. Nanobodies können im Gegensatz zu Antikörpern in E. coli vermehrt werden (ArbabiGhahroudi et al. 1997).

Kritisch hinterfragt werden müssen die Instrumente, anhand derer die kombinatorischen Epitop-Analyse verifiziert worden ist. Die Bestätigung des neuen Prinzips stützte sich auf künstlich designte Proteinkonstrukte, bestehend aus einem Protein und einer daran gekoppelten spezifischen Auswahl an Epitopen, die als antigene Determinante der eingesetzten Nanobodies fungierten. Die ausgewählten Proteine wurden dabei in Bezug auf ihre Lokalisation innerhalb der Zelle bestimmt. Es wurde eine Selektion dahingehend getroffen, dass die Wahrscheinlichkeit einer Akkumulation der Proteine innerhalb der Zelle gering gehalten werden sollte. Deswegen wurden zum Beispiel in diesem Projekt unter anderem NLS (Nukleus), Gal- 
Nact (Golgi-Apperat), TOM70 (Mitochondrien), SNAP25 (Zellmembran) usw. ausgesucht. Diese Vorkehrung wurde getroffen, weil die Analyse des Bindungsverhaltens zunächst nur auf visueller Basis durchgeführt wurde und eine Überlagerung der Proteinkonstrukte die Differenzierung jener mittels der Epitop-Analyse erschweren würde. Wie bereits erwähnt, sollte in weiteren Projekten die Auswertung der Epitop-Analyse mithilfe von Fluoreszenz-messenden Softwareprogrammen (Teverovskiy et al. 2008) oder anderen systemunterstützten Geräten präzisiert werden, sodass diese Vorauswahl der zu analysierenden Objekten überflüssig wird und die Epitop-Analyse als universell einsetzbare Technologie zur Identifizierung von Proteinen verwendet werden kann.

\subsection{Die Kreierung einer Multitransfekt-Zelle}

Um die Eignung der kombinatorischen Epitop-Analyse als multiplexes Verfahren zu überprüfen, mussten Umstände kreiert werden, die eine multiplexe Testung gestatten.

Der erste Weg zur Erschaffung einer multitransfekten Zelle beruhte auf dem Prinzip der Fusion zwischen Zellen mittels eines HVJe-Virus (Lamb und Kolakofsky 1996). Die Herausforderung der angewendeten Suspensions-Methode der Fusion beruhte auf einem von vielen unterschiedlich zu interpretierenden Variablen basierenden Protokoll (s. Kapitel 2.6). Dieses machte ein genaues und akkurates Befolgen des Protokolls schwierig. Des Weiteren entsprachen die mit diesem Protokoll erzielten Ergebnisse oftmals keinem der beschriebenen Ziele. Eine Komplikation bestand darin, dass eine große Zahl an Zellen während der Versuche gestorben ist. Außerdem konnte in vielen Fällen keine richtige Fusion, sondern eher eine Verklumpung von Zellen beobachtet werden. Bei der Durchführung des in diesem Projekt angewendeten Verfahrens der Suspensions-Methode, wurden die beiden zu klonierenden Zellenlinien zunächst gesammelt und anschließend in Falcons durch Zugabe des Virus kloniert. Erst im Anschluss daran wurden die Zellen wieder ausgesät. Im Gegensatz zu diesem Protokoll existiert ein alternatives Verfahren nach dem Protokoll der Plating-Methode. Bei dieser Methode wird nur eine der zu klonierenden Zell-Kolonien eingesammelt, mit dem Virus gemischt und anschließend auf eine adhärente Zellpopulation gegeben. Da eine der Zellpopulationen während der Fusion adhärent mit der Glasoberfläche verbleibt, kann so die Wahrscheinlichkeit der Verklumpung der Zellen minimiert werden. Des Weiteren wird ebenfalls das Stresslevel der adhärent verbleibenden Zellpopulation verringert, sodass die Sterberate der Zellen reduziert werden kann. In nachfolgenden Studien empfiehlt es sich daher durch ein Vergleichsexperiment beider Verfahren, den geeigneteren und erfolgreicheren Ansatz zu identifizieren und weiterhin anzuwenden. 
Das zweite Experiment zur Kreierung einer Multitransfekt-Zelle fand auf Basis des Gibson Assembly statt. Während der Anwendung des Protokolls wurden sowohl bei der Durchführung der PCR als auch beim Gibson Assembly Komplikationen festgestellt. Bei der PCR bestand das Problem in der Größe der zu amplifizierenden Konstrukte. Mit zunehmender GröBe steigt die Wahrscheinlichkeit ungewollter Kontaminationen, da mit steigender Länge eine erhöhte Tendenz zu einem verfrühten Translationsabbruch durch Dissoziation des verwendeten $\mathrm{Q}_{5}$-Enzyms besteht. Ein weiteres Problem stellten die GC-reichen Sequenzen der Genkonstrukte sowie der verwendeten Primer dar (s. Tabelle 13 und Tabelle 14). Die GC-reichen Sequenzen können die Durchführung einer PCR erschweren, da diese hairpins und andere Sekundärstrukturen bilden. Diese Strukturen führen zu einer vorzeitigen Beendigung der PCR, wodurch unvollständige und unspezifische Produkte entstehen (Sahdev et al. 2007). Des Weiteren potenzieren die GC-reichen Überhänge der letztendlich amplifizierten Konstrukte aufgrund der niedrigen isothermen Bedingungen im Gibson Assembly die Entstehungen von Fehlpaarungen, die vor allem durch eine Selbst-Ligation der Vektoren auftreten (Li et al. 2018). Eine Herausforderung stellte ebenfalls die Auswahl der annealing-Temperatur der Primer dar. Da das Gibson Assmbly bei ca $48{ }^{\circ} \mathrm{C}$ stattfindet (s. Kapitel 2.10), musste die Tm der Schwänze der ausgewählten Primer ebenfalls $48{ }^{\circ} \mathrm{C}$ sein, während der Kopfteil eine Tm von ca. $60{ }^{\circ} \mathrm{C}$ aufweisen sollte. Diese Fakten stellen eine Voraussetzung für eine ungehinderte Durchführung einer PCR dar. Da die Bedingungen durch den Aufbau der Genkonstrukte nur schwierig zu realisieren waren, wurde das Gibson Assmbly als Methode zunächst umgangen. Dieses war möglich, da die dritte Methode zur Kreierung einer Multitransfekt-Zelle sehr gute Ergebnisse lieferte.

Der dritte Versuchsansatz war die gleichzeitige Transfektion von vier Plasmiden in eine Zelle. $\mathrm{Ab}$ der Transfektion von fünf Plasmiden nahm die Vier-Transfekt-Wahrscheinlichkeit der Zellen wieder ab. Insgesamt konnten die Ein- bzw. Zwei-Transfekt-Zellen die höchste Entstehungswahrscheinlichkeit aufweisen. Die erzielten Erkenntnisse können zum einen in Zusammenhang mit der gewählten Zellpopulation stehen (s. Kapitel 2.1), zum anderen mit den jeweils transifizierten Plasmiden/Proteinkonstrukte (s. Kapitel 3.4). Da jedoch die EpitopAnalyse in Zukunft an Proben von In-vivo-Zellen zur multiplexen Identifizierung von Proteinen angewendet werden soll, wurde der Fokus dieser Arbeit nicht auf die Analyse des Transfektionsgrades künstlich erstellter Plasmide gelegt. 


\subsection{Die multiplexe Epitop-Analyse}

Da die meisten biologischen Prozesse in unserem Körper vielfältigen Protein-ProteinInteraktionen unterliegen (Petta et al. 2015), sind Kenntnisse über das menschliche Proteom eine Voraussetzung, um einen Einblick über physiologische und pathologische Zustände bzw. Veränderungen im Organismus im Zusammenhang mit Proteinkonzentration zu verstehen (Legrain et al. 2011). Die zellulären Funktionen beruhen dabei auf der Zusammenarbeit und der Organisation von mehreren tausend Proteinen. Für die Fähigkeit einer korrekten und aussagekräftigen Proteinbestimmung und -messung ist es unabdingbar, dass der Weg einer multiplexen Entschlüsselung von Proteinen geebnet wird. Mit diesem Ziel wurde die kombinatorische Epitop-Analyse als multiplexes Verfahren getestet. Ihre Eignung konnte sowohl nach einer simultanen, als auch nach einer sequenziellen Färbungsmethode (s. Kapitel 2.7.3.2) an Zwei- bis Vier-Transfekt-Experimenten (s. Kapitel 3.6) nachgewiesen werden. Damit der multiplexe Ansatz ohne Einschränkungen und ohne Gefahr spektraler Überlagerungen, jedoch auch mit möglichst geringem Zeitaufwand gesteigert werden kann, sollte das Ziel nachfolgender Experimente sein, die Auswertung der Epitop-Analyse mithilfe von Softwareprogrammen zu erleichtern und zu präzisieren. So kann die multiplexe Identifizierung von Proteinen schnell und sicher durchgeführt werden.

Im Vergleich zu anderen multiplexen Verfahren liegt die Einzigartigkeit der Epitop-Analyse darin, dass nicht für jedes zu bestimmende Protein ein spezifischer Antikörper/Nanobody benötigt wird. Mit dem Prinzip, Proteine anhand von Nanobody-Sätzen entsprechend den jeweils erhaltenen Epitopen zu unterscheiden, wurde ein ganz neuer Ansatz zur Identifizierung von Proteinen vorgestellt. Da jedes Protein durch eine individuelle Kombination an enthaltenden Epitopen mit einem einzigartigen Epitop-Satz markiert ist, kann dieser mithilfe spezifischer Nanobodies unter Anwendung der Epitop-Analyse entschlüsselt werden. Für jedes zu identifizierende Protein steht also ein ganz spezifischer, analog zum Epitop-Satz passender Satz an gebundenen Nanobodies. Durch die Anwendung der Epitop-Analyse können so

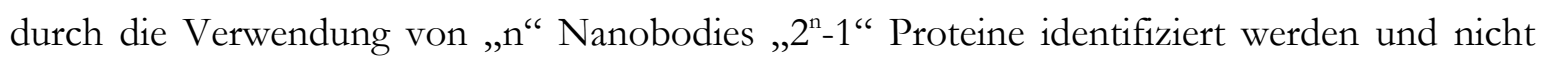
wie bei anderen Verfahren nur „,n“ Proteine. Mithilfe dieser neuen Technologie ist es möglich, die vielen in der multiplexen Bildgebung bestehenden Probleme zu umgehen (s. Kapitel 1.2) und eine neue Basis zu bilden, von der aus weitere Proteomik-Forschungen mit neuem Potenzial hervorgehen können. 


\section{$5 \quad$ Zusammenfassung}

Die Fähigkeit, Proteine zu bestimmen und zu messen, ist für die biologische und medizinische Forschung von großer Bedeutung, um einen Einblick in die subzellulären Organisationen und Funktionen zu erhalten, die auf der Zusammenarbeit und der Organisation von mehreren tausend Proteinen beruhen. Damit physiologische oder pathologische Veränderungen im Organismus im Zusammenhang mit den verschiedenen Proteinkonzentrationen gebracht werden können, sind Verfahren zur multiplexen Bildgebung unumgänglich. Die derzeitigen Technologien ähneln sich dahingehend, dass für jedes zu bestimmende Protein ein/zwei spezifische Antikörper für die Detektion benötigt wird/werden. Durch diesen Umstand wird die Gesamtzahl der gleichzeitig zu identifizierenden Antigene auf drei bis vier Antigene pro Immunfärbung begrenzt, weil nur eine entsprechende Anzahl von Antikörpern simultan eingesetzt werden kann. Aus diesem Grund befasste sich die vorliegende Arbeit mit der Entwicklung einer auf Nanobodies basierenden Epitop-Analyse von Proteinen, die ein einfaches, unkompliziertes und schnelles Verfahren für die multiplexe Bildgebung darstellt. Der Ansatz dieser Arbeit beruht auf der Idee, dass jedes Protein aufgrund eines in seiner Aminosäuresequenz enthaltenden einzigartigen Epitop-Satzes markiert ist, der sich je nach Protein in Art, Anzahl und Kombination unterscheidet. Infolge des individuellen Epitop-Satzes können die Proteine mittels des spezifischen Bindungsverhaltens von Nanobodies in Bezug auf die enthaltenden Epitope identifiziert werden. Für jedes zu identifizierende Protein wird ein dem Epitop-Satz entsprechender, spezifisch gebundener Satz an Nanobodies ermittelt. Anhand des NanobodySatzes kann wiederum mithilfe der Epitop-Analyse ein Rückschluss auf den jeweiligen EpitopSatz vollzogen werden, aufgrund dessen Einzigartigkeit jedes Protein identifiziert werden kann. In dieser Arbeit erfolgte die Verifizierung der Epitop-Analyse anhand der Identifizierung und der hochauflösenden Bildgebung von 15 künstlich designten Proteinkonstrukten mithilfe von vier Nanobodies.

Die in diesem Projekt eingesetzten vier Nanobodies besitzen also keine spezifische Affinität für ein einzelnes Protein, sondern nur für bestimmte Epitope, die Teil künstlich designter Proteinkonstrukte sind. Die 15 Proteinkonstrukte sind so aufgebaut, dass an jedes der 15 Proteine jeweils eine bestimmte Kombination der vier für die Nanobodies spezifischen Epitope gekoppelt wurde. So ist jede Epitop-Kombination nur einmalig in dem Verbund mit einem Protein vertreten. Die Nanobodies sind daher in der Lage, diejenigen Konstrukte zu binden, die innerhalb ihrer Aminosäuresequenz das entsprechende spezifische Epitop vertreten. 
Zur Überprüfung der Eignung der Epitop-Analyse wurden die Proteinkonstrukte in Zellen transfiziert, koexprimiert und anschließend wurden die verschiedenen Epitope unter Verwendung der kombinatorischen Epitop-Analyse detektiert. Die Detektion erfolgte durch die Messung der Signale der fluorophorgekoppelten Nanobodies. Die Fluorophor-Kopplung beruhte auf dem Verfahren der Maleimid-Markierung. Anhand der spezifischen Sätze an detektierten Nanobody-Signalen konnte jedes transfizierte Konstrukt identifiziert und in der Zelle lokalisiert werden. Die Eignung der Epitop-Analyse wurde zunächst als singleplexes und anschlieBend auch als multiplexes Verfahren überprüft. Für die Erschaffung einer multiplextransifizierten Zelle wurden die Wege der Fusion, der multiplen Transfektion und des Gibson Assemblys getestet. Die multiple Transfektion von Zellen hat sich als erfolgversprechendste Methode erwiesen. Damit eine spektrale Überlagerung der fluorophorgekoppelten Nanobodies während der Auswertung der Epitop-Analyse vermieden werden konnte, wurde neben dem Verfahren der simultanen Immunfärbung auch eine sequenzielle Immunfärbung der Proteinkonstrukte durchgeführt.

Das Ziel dieser Arbeit ist die Entwicklung der auf Nanobodies basierenden Epitop-Analyse zur Bestimmung von Proteinen. In den Untersuchungen zur Anwendung der Epitop-Analyse hat sich gezeigt, dass durch die Verwendung von „n“ Nanobodies während der EpitopAnalyse „2n $2^{\text {“ }}$ Proteine identifiziert werden können. Damit können die auf Antikörpern-basierenden Verfahren der Proteinbestimmung nach dem Eins-zu-eins-Prinzip umgangen werden. Die auf Nanobodies-basierende Epitop-Analyse stellt somit eine wertvolle Alternative zu derzeit existierenden Nachweisverfahren dar und könnte zukünftig für die Analyse multipler zellbiologischer Fragestellungen eingesetzt werden. Zur Präzisierung und Simplifikation der Epitop-Analyse sollten in weiteren Forschungen fluoreszenzmessende Softwareprogramme unterstützend zur Auswertung hinzugezogen werden. 


\section{$6 \quad$ Literaturverzeichnis}

Arbabi-Ghahroudi M, Desmyter A, Wyns L, Hamers R, Muyldermans S (1997): Selection and identification of single domain antibody fragments from camel heavy-chain antibodies. FEBS Lett $414,521-526$

Avrameas S (1969): Indirect immunoenzyme techniques for the intracellular detection of antigens. Immunochemistry $\underline{6}, 825-831$

Boja ES, Jortani SA, Ritchie J, Hoofnagle AN, Tezak Z, Mansfield E, Keller P, Rivers R, Rahbar A, Anderson N (2011): The journey to regulation of protein-based multiplex quantitative assays. Clin Chem 57, 560-567

Bornhorst J, Falke J (2000): Purification of Proteins Using Polyhistidine Affinity Tags. Methods Enzymol 326, 245-254

Conrath KE, Lauwereys M, Galleni M, André M, Frère J-M, Kinne J, Wyns L, Mulydermans S (2001): $\beta$-Lactamase Inhibitors Derived from Single-Domain Antibody Fragments Elicited in the Camelidae. Antimicrob Agents Chemother 45, 2807-2812

Conrath KE, Wernery U, Muyldermans S, Nguyen VK (2003): Emergence and evolution of functional heavy-chain antibodies in Camelidae. Dev Comp Immunol 27, 87-103

Coppieters K, Dreier T, Silence K, de Haard H, Lauwereys M, Casteels P, Beirnaert E, Jonckheere H, van de Wiele C, Staelens L (2006): Formatted anti-tumor necrosis factor alpha VHH proteins derived from camelids show superior potency and targeting to inflamed joints in a murine model of collagen-induced arthritis. Arthritis Rheumatol 54, 1856-1866

Davies J, Riechmann L (1995): Antibody VH domains as small recognition units. Biotechnology (NY) $13,475-479$

Davies J, Riechmann L (1996): Single antibody domains as small recognition units: design and in vitro antigen selection of camelized, human VH domains with improved protein stability. Protein Eng 9 , 531-537

de Genst E, Silence K, Decanniere K, Conrath K, Loris R, Kinne J, Muyldermans S, Wyns L (2006): Molecular basis for the preferential cleft recognition by dromedary heavy-chain antibodies. Proc Natl Acad Sci USA $\underline{103}, 4586-4591$

de Genst E, Guilliams T, Wellens J, O’Day E, Waudby C, Meehan S, Dumoulin M, Hsu S, Cremades N, Verschueren K (2010): Structure and Properties of a Complex of $\alpha$-Synuclein and a Single-Domain Camelid Antibody. J Mol Biol 402, 326-343 
de Jager W, Rijkers GT (2006): Solid-phase and bead-based cytokine immunoassay: a comparison. Methods $\underline{38}, 294-303$

Dickinson ME, Bearman G, Tille S, Lansford R, Fraser SE (2001): Multi-spectral imaging and linear unmixing add a whole new dimension to laser scanning fluorescence microscopy. Biotechniques $31,1272,1274-1276,1278$

Dumoulin M, Conrath K, van Meirhaeghe A, Meersman F, Here-mans K, Frenken LGJ, Muyldermans S, Wyns L, Matagne A (2002): Single-domain antibody fragments with high conformationalstability. Protein Sci 11, 500-515

Ekins RP (1989): Multi-analyte immunoassay. J Pharm Biomed Anal ㄱ, 155-168

Engvall E, Perlmann P (1971): Enzyme-linked immunosorbent assay (ELISA) quantitative assay of immunoglobulin. Immunochemistry $\underline{8}, 871-874$

Fagraeus A (1948): The plasma cellular reaction and its relation to the formation of antibodies in vitro. J Immunol 58, 1-13

Feinberg JG (1961): A 'microspot' test for antigens and antibodies. Nature 9 , 985-986

Feinberg JG, Wheeler AW (1963): Detection of auto-immune antibody and tissue antigens by the 'microspot' technique. J Clin Pathol 16, 282-284

Frenken LG, van der Linden RH, Hermans PW, Bos JW, Ruuls RC, de Geus B, Verrips CT (2000): Isolation of antigen specific llama VHH antibody fragments and their high level secretion by Saccharomyces cerevisiae. J Biotechnol 78, 11-21

Fridy P, Li Y, Keegan S, Thompson M, Nudelman I, Scheid J, Oeffinger M, Nussenzweig M, Fenyö D, Chait B (2014): A robust pipeline for rapid production of versatile Nanobody repertoires. Nat Methods $\underline{11}, 1253-1260$

Glockshuber R, Malia M, Pfitzinger I, Pluckthun A (1990): A comparison of strategies to stabilize immunoglobulin Fv-fragments. Biochemistry 29, 1362-1367

Gomez-Cabrero D, Abugessaisa I, Maier D, Teschendorff A, Merkenschlager M, Gisel A, Ballestar E, Bongcam-Rudloff E, Conesa A, Tegnér J (2014): Data integration in the era of omics: current and future challenges. BMC Syst Biol 8 Suppl 2, I1

Guilliams T, El-Turk F, Buell AK, O'Day EM, Aprile FA, Esbjörner EK, Vendruscolo M, Cremades N, Pardon E, Wyns L (2013): Nanobodies Raised against Monomeric $\alpha$-Synuclein Distinguish between Fibrils at Different Maturation Stages. J Mol Biol 425, 2397-2411

Hamers-Casterman C, Atarhouch T, Muyldermans S, Robinson G, Hamers C, Songa EB, Bendahman N, Hamers R (1993): Naturally occurring antibodies devoid of light chains. Nature $\underline{363}, 446-48$ 
Harmsen MM, de Haard HJ (2007): Properties, production, and applications of camelid singledomain antibody fragments. Appl Microbiol Biotechnol 77, 13-22

Harmsen MM, Ruuls RC, Nijman IJ, Niewold TA, Frenken LG, de Geus B (2000): Llama heavychain $\mathrm{V}$ regions consist of at least four distinct subfamilies revealing novel sequence features. Mol Immunol 37, 579-90

Holliger P, Hudson PJ (2005): Engineered antibody fragments and the rise of single domains. Nat Biotechnol 23, 1126-1136

Horan PK, Wheeless LL (1977): Quantitative single cell analysis and sorting. Science 198, 149-157 Hughes B (2010): Antibody-drug conjugates for cancer: poised to deliver? Nat Rev Drug Discov 9 (9), 665-667

Kabat EA, Wu TT, Bilofsky H (1977): Unusual distributions of amino acids in complementarity determining (hypervariable) segments of heavy and light chains of immunoglobulins and their possible roles in specificity of antibody-combining sites. J Biol Chem 252, 6609-6616

Kingsmore SF, Patel DD (2003): Multiplexed protein profiling on antibody-based microarrays by rolling circle amplification. Curr Opin Biotechnol 14, 74-81

Kricka LJ (1992): Multianalyte Testing. Clin Chem $\underline{38}$ (3), 327-328

Kumar A, Baycin-Hizal D, Shiloach J, Betenbaugh MA, Betenbaugh MJ (2015): Coupling enrichment methods with proteomics for understanding and treating disease. Proteomics Clin Appl 9, $33-47$

Lamb RA, Kolakofsky D: Paramyxoviridae: The viruses and their replication. In: Fields BN, Knipe DM, Howley PM (Hrsg.): Fields Virology. 3. Auflage; Lippincott-Raven Press, Philadelphia $1996,689-724$

Lauwereys M, Arbabi Ghahroudi M, Desmyter A, Kinne J, Holzer W, de Genst E, Wyns L, Muyldermans S (1998): Potent enzyme inhibitors derived from dromedary heavy-chain antibodies. EMBO J 17, 3512-3520

Legrain P, Aebersold R, Archakov A, Bairoch A, Bala K, Beretta L, Bergeron J, Borchers CH, Corthals GL, Costello CE (2011): The human proteome project: current state and future direction. Mol Cell Proteomics 10, M111.009993

Levenson RM, Mansfield JR (2006): Multispectral Imaging in Biology and Medicine: Slices of Life. Cytometry $69,748-758$

Li L, Jiang W, Lu Y (2018): A modified Gibson Assembly Method for Cloning Large DNA Fragments with High GC Contents. Methods Mol Biol 1671, 203-209 
Litvak-Greenfeld D, Benhar I (2012): Risks and untoward toxicities of antibody-based immunoconjugates. Adv Drug Deliv Rev 64, 1782-1799

Luo Y, Chen M, Wen Q, Zhao M, Zhang B, Li X, Wang F, Huang Q, Yao C, Jiang T (2006): Rapid and simultaneous quantification of 4 urinary proteins by piezoelectric quartz crystal microbalance immunosensor array. Clin Chem $\underline{5}, 2273-2280$

Lv LL, Liu BC (2007): High-throughput antibody microarrays for quantitative proteomic analysis. Expert Rev Proteomics 4, 505-513

Melan MA (1994): Overview of cell fixation and permabilization. Methods Mol Biol 34, 55-66

Michalet X, Pinaud F, Bentolila L, Tsay J, Doose S, Li J, Sundaresan G, Wu A, Gambhir S, Weiss S (2005): Quantum dots for live cells, in vivo imaging, and diagnostics. Science 307, 538-544

Muyldermans S (2013): Nanobodies: Natural Single-Domain Antibodies. Annu Rev Biochem $\underline{82}$, 775-797

Muyldermans S, Atarhouch T, Saldanha J, Barbosa J, Hamers R (1994): Sequence and structure of V-H domain from naturally-occurring camel heavy-chain immunoglobulins lacking lightchains. Protein Eng $\underline{7}, 1129-1135$

Natsume A, Niwa R, Satoh M (2009): Improving effector functions of antibodies for cancer treatment: Enhancing ADCC and CDC. Drug Des Devel Ther $\underline{3}, 7-16$

Nguyen VK, Hamers R, Wyns L, Muyldermans S (2000): Camel heavy-chain antibodies: diverse germline VHH and specific mechanisms enlarge the antigen-binding repertoire. EMBO J 19 , 921-930

Nguyen VK, Desmyter A, Muyldermans S (2001): Functional heavy-chain antibodies in Camelidae. Adv Immunol $\underline{79}, 261-96$

Nguyen VK, Su C, Muyldermans S, van der Loo W (2002): Heavy-chain antibodies in Camelidae; a case of evolutionary innovation. Immunogenetics $\underline{54}, 39-47$

Opazo F, Levy M, Byrom M, Schäfer C, Geisler C, Groemer T.W, Ellington AD, Rizzoli SO (2012): Aptamers as potential tools for super-resolution microscopy. Nat Methods $\underline{9}$, 938-939

Padlan EA (1994): Anatomy of the antibody molecule. Mol Immunol 31, 169-217

Perez JM, Renisio JG, Prompers JJ, van der Platerink CJ, Cambillau C, Darbon H, Frenken LG (2001): Thermal unfolding of a llama antibody fragment: a two-state reversible process. Biochemistry $\underline{40}, 74-83$

Petta I, Lievens S, Libert C, Tavernier J, de Bosscher K (2015): Modulation of Protein-Protein Interactions for the Development of Novel Therapeutics. Mol Ther 24, 707-718 
Potts SJ, Johnson TD, Voelker FA, Lange H, Young GD (2011): Multiplexed measurement of proteins in tissue in a clinical environment. Appl Immunohistochem Mol Morphol 19, 494-498

Richter K, Revelo N, Seitz K, Helm M, Sarakr D, Saleeb R, D’Este E, Eberle J, Wagner E, Vogl C (2018): Glyoxal as an alternative fixative to formaldehyde in immunostaining and superresolution microscopy. EMBO J $\underline{37}, 139-159$

Riedl J, Crevenna A, Kessenbrock K, Yu J, Neukirchen D, Bista M, Bradke F, Jenne D, A Holak T, Werb Z, Sixt M, Wedlich-Soldner R (2008): Lifeact: an versatile marker to visualize F-actin. Nat Methods $\underline{5}, 605$

Ries J, Kaplan C, Platonova E, Eghlidi H, Ewers H (2012): A simple, versatile method for GFPbased super resolution microscopy via nanobodies. Nat Methods 9 , 582-584

Roopenian D, Akiles S (2007): FcRn: the neonatal Fc receptor comes of age. Nat Rev Immunol $\underline{7}$, 715-725

Safarnejad RM, Jouzani GS, Tabatabaie M, Twyman RM, Schillberg S (2011): Antibody-mediated resistance against plant pathogens. Biotechnol Adv 29, 961-971

Sahdev S, Saini S, Tiwari P, Saxena S, Singh Saini K (2007): Amplification of GC-rich genes by following a combination strategy of primer design, enhancers and modified PCR cycle conditions. Mol Cell Probes 21, 303-307

Saiki RK, Scharf S, Faloona F, Mullis KB, Horn GT, Erlich HA, Arnheim N (1985): Enzymatic amplification of beta-globulin genomic sequences and restriction site of analysis for diagnosis of sickle cell anemia. Science 230, 1350-1354

Satsoura D, Leber B, Andrews D, Fradin C (2007): Circumvention of Fluorophore Photobleaching in Fluorescence Fluctuation Experiments: a Beam Scanning Approach. Chemphyschem $\underline{8}$, 843-848

Schmidt TG, Batz L, Bonet L, Carl U, Holzapfel G, Kiem K, Matulewicz K, Niermeier D, Schuchardt I, Stanar K (2013): Development of the Twin-Strep-tag ${ }^{\circledR}$ and its application for purification of recombinant proteins from cell culture supernatants. Protein Expr Purif 92, 54-61

Schmitt J, Hess H, Stunnenberg HG (1993): Affinity purification of histidine-tagged proteins. Mol Biol Rep $\underline{18}, 223-230$

Schroeder H, Cavacini L (2010): Structure and Function of Immunoglobulins. J Allergy Clin Immunol $\underline{125}, 41-52$

Shah K, Maghsoudlou P (2016): Enzyme-linked immunosorbent assay (ELISA): the basics. Br J Hosp Med (Lond) 77, 98-101 
Shastry BS (1995): Overexpression of genes in health and sickness. A bird's eye view. Comp Biochem Physiol B Biochem Mol Biol 112, 1-13

Skoog L, Tani E (2011): Immunocytochemistry: an indispensable technique in routine cytology. Cytopathology 22, 215-229

Stack E, Wang C, Roman K, Hoyt C (2014): Multiplexed immunohistochemistry, imaging, and quantition: A review, with an assessment of Tyramide signal amplification, multispectral imaging and multiplex analysis. Methods $\underline{70}, 46-58$

Tang YC, Amon A (2013): Gene copy-number alterations: a cost-benefit analysis. Cell 152, 394405

Teverovskiy M, Vengrenyul Y, Tabesh A, Sapir M, Fogarasi S, Pang HY, Khan FM, Hamann S, Capodeici P, Clayton M, Kim R, Fernandez G, Mesa-Tejada R, Donovan MJ: Automated localization and quantification of protein multiplexes via multispectral fluorescence imaging. 5th IEEE Int Symp Biomed Imaging: From Nano to Macro. Paris 2008, 300-303

Tighe P, Negm O, Todd I, Fairclough L (2013): Utility, reliability and reproducibility of immunoassay multiplex kits. Methods $\underline{61}, 23-29$

Tighe P, Ryder R, Todd I, Fairclough L (2015): ELISA in the multiplex era: Potentials and pitfalls. Proteomics Clin Appl $\underline{9}, 406-422$

van der Linden RH, Frenken LG, de Geus B, Harmsen MM, Ruuls RC, Stok W, de Ron L, Wilson S, Davis P, Verrips CT (1999): Comparison of physical chemical properties of llama VHH antibody fragments and mouse monoclonal antibodies. Biochim Biophys Acta 1431, 37-46

van der Loos C (2013): Chromogens in Multiple Immunohistochemical Staining Used for Visual Assessment and Spectral Imaging: The Colorful Future. J Histotechnol 33, 31-40

Varma M, Inerowicz HD, Regnier FE, Nolte DD (2004): High-speed label-free detection by spinning-disk micro-interferometry. Biosens Bioelectron 19, 1371-1376

Vassylyeva M, Klyuyev S, Vassylyev A, Wesson H, Zhang Z, Renfrow H, Higgins N, Chow L, Vassylyev D (2017): Efficient, ultra-high-affinity chromatography in a one-step purification of complex proteins. Proc Natl Acad Sci U S A 114, 5138-5147

Vega CG, Bok M, Vlasova AN, Chattha KS, Gómez-Sebastián S, Nuñez C, Alvarado C, Lasa R, Escribano JM, Garaicoechea LL (2013): Recombinant monovalent llama-derived antibody fragments (VHH) to rotavirus VP6 protect neonatal gnotobiotic piglets against human rotavirus-induced diarrhea. PLoS Pathog $\underline{9,}$ e 1003334

Vira S, Mekhedov, Humphrey G, Blank P (2010): Fluorescent labeled antibodies- balancing functionality and degree of labeling. Anal Biochem $\underline{402}, 146-150$ 
Vu KB, Ghahroudi MA, Wyns L, Muyldermans S (1997): Comparison of llama V-H sequences from conventional and heavy chain antibodies. Mol Immunol 34, 1121-1131

Whitlow M, Bell BA, Feng SL, Filpula D, Hardman KD, Hubert SL, Rollence ML, Wood JF, Schott ME, Milenic DE (1993): An improved linker for single-chain Fv with reduced aggregation. Protein Eng $\underline{6}, 989-995$

Williams AF, Barclay AN (1988): The immunglobulin superfamily- domains for cell surface recognition. Annu Rev Immunol $\underline{6}$, 381-405

Xing Y, Chaudry Q, Shen C, Kong KY, Zhau HE, Chung LW, Petros JA, O’Regan M, Yezhelyev MV, Simons JW (2007): Bioconjugated quantum dots for multiplexed and quantitative immunohistochemistry. Nat Protoc $2,1152-1165$

Zhang Z, Kenney SJ, Hauser M, Li W, Xu K (2015): Ultrahigh-throughput single-molecule spectroscopy and spectrally resolved super-resolution microscopy. Nat Methods $\underline{12}, 935-938$

Zrarhevskiy P, Gao X (2013): Quantum dot imaging platform for single-cell molecular profiling. Nat Commun $\underline{4}, 1619$ 


\section{Danksagung}

Die vorliegende Arbeit entstand während meiner Forschung als Doktorandin im Institut für Neuro- und Sinnesphysiologie in Göttingen. An dieser Stelle möchte ich meinen besonderen Dank nachstehenden Personen aussprechen ohne deren Mithilfe die Anfertigung dieser Doktorarbeit nicht zustande gekommen wäre.

Herrn Prof. Dr. Silvio O. Rizzoli, dem Leiter des Institutes für Neuro- und Sinnesphysiologie, gilt mein besonderer Dank für die vertrauensvolle und wohlwollende Unterstützung sowie seinen fachlichen Rat zu der vorliegenden Arbeit.

Frau Prof. Dr. Blanche Schwappach-Pignataro danke ich für die Übernahme des KoReferats.

Danken möchte ich außerdem Frau Dr. Danielle de Jong-Bolm für die herzliche und kooperative Zusammenarbeit und Unterstützung während und nach der Zeit meiner Forschungstätigkeit.

Zum Gelingen dieser Arbeit trugen ebenso wertvolle Diskussionen mit den Mitgliedern des Institutes der Neuro- und Sinnesphysiologie bei, für deren Anregungen ich mich bedanken möchte. 